\title{
Adult stem cell-derived complete lung organoid models emulate lung disease in COVID-19
}

\begin{abstract}
Courtney Tindle ${ }^{1,2 \dagger}$, MacKenzie Fuller ${ }^{1,2 \dagger}$, Ayden Fonseca, ${ }^{1,2 \dagger}$, Sahar Taheri ${ }^{3 \dagger}$, Stella-Rita Ibeawuchi ${ }^{4}$, Nathan Beutler ${ }^{5}$, Gajanan Dattatray Katkar ${ }^{1}$, Amanraj Claire ${ }^{1,2}$, Vanessa Castillo ${ }^{1}$, Moises Hernandez ${ }^{6}$, Hana Russo ${ }^{4}$, Jason Duran 7 , Laura E Crotty Alexander ${ }^{8,9}$, Ann Tipps ${ }^{4},{ }^{6}$ Grace Lin ${ }^{4}$, Patricia A Thistlethwaite ${ }^{6}$, Ranajoy Chattopadhyay ${ }^{1,2,10 *}$, Thomas F Rogers ${ }^{5,11,12 *}$, Debashis Sahoo ${ }^{3,13 *}$, Pradipta Ghosh ${ }^{1,2,14 * \dagger}$, Soumita Das ${ }^{2,4 * \dagger}$
\end{abstract}

1Department of Cellular and Molecular Medicine, University of California San Diego, San Diego, United States; ${ }^{2}$ HUMANOID CoRE, University of California San Diego, San Diego, United States; ${ }^{3}$ Department of Computer Science and Engineering, Jacobs School of Engineering, University of California San Diego, San Diego, United States; ${ }^{4}$ Department of Pathology, University of California San Diego, San Diego, United States; ${ }^{5}$ Department of Immunology and Microbiology, The Scripps Research Institute, La Jolla, United States; ${ }^{6}$ Division of Cardiothoracic Surgery, University of California San Diego, San Diego, United States; ${ }^{7}$ Division of Cardiology, Department of Internal Medicine, UC San Diego Medical Center, San Diego, United States; ${ }^{8}$ Pulmonary Critical Care Section, Veterans Affairs (VA) San Diego Healthcare System, La Jolla, United States; ${ }^{9}$ Division of Pulmonary and Critical Care, Department of

*For correspondence: rachatto72@gmail.com (RC); trogers@health.ucsd.edu (TFR); dsahoo@ucsd.edu (DS); prghosh@ucsd.edu (PG); sodas@ucsd.edu (SD)

'These authors contributed equally to this work

Competing interest: The authors declare that no competing interests exist.

Funding: See page 37

Received: 10 January 2021

Accepted: 11 August 2021

Published: 13 August 2021

Reviewing Editor: Milica Radisic, University of Toronto, Canada

(c) Copyright Tindle et al. This article is distributed under the terms of the Creative Commons Attribution License, which permits unrestricted use and redistribution provided that the original author and source are credited. Medicine, University of California, San Diego, La Jolla, CA, United States; ${ }^{10}$ Cell Applications Inc., La Jolla, CA, United States; ${ }^{11}$ Division of Infectious Diseases, Department of Medicine, University of California, San Diego, La Jolla, United States; ${ }^{12}$ Department of Immunology and Microbiology, The Scripps Research Institute, La Jolla, United States; ${ }^{13}$ Department of Pediatrics, University of California, San Diego, La Jolla, CA, United States; ${ }^{14}$ Department of Medicine, University of California, San Diego, La Jolla, CA, United States

\section{Abstract}

Background: SARS-CoV-2, the virus responsible for COVID-19, causes widespread damage in the lungs in the setting of an overzealous immune response whose origin remains unclear.

Methods: We present a scalable, propagable, personalized, cost-effective adult stem cell-derived human lung organoid model that is complete with both proximal and distal airway epithelia. Monolayers derived from adult lung organoids (ALOs), primary airway cells, or hiPSC-derived alveolar type II (AT2) pneumocytes were infected with SARS-CoV-2 to create in vitro lung models of COVID-19.

Results: Infected ALO monolayers best recapitulated the transcriptomic signatures in diverse cohorts of COVID-19 patient-derived respiratory samples. The airway (proximal) cells were critical for sustained viral infection, whereas distal alveolar differentiation (AT2 $\rightarrow$ AT1) was critical for mounting the overzealous host immune response in fatal disease; ALO monolayers with well-mixed proximodistal airway components recapitulated both.

Conclusions: Findings validate a human lung model of COVID-19, which can be immediately utilized to investigate COVID-19 pathogenesis and vet new therapies and vaccines. 
Funding: This work was supported by the National Institutes for Health $(\mathrm{NIH})$ grants 1R01DK107585-01A1, 3R01DK107585-05S1 (to SD); R01-Al141630, CA100768 and CA160911 (to PG) and R01-Al 155696 (to PG, DS and SD); R00-CA151673 and R01-GM138385 (to DS), R01HL32225 (to PT), UCOP-R00RG2642 (to SD and PG), UCOP-R01RG3780 (to P.G. and D.S) and a pilot award from the Sanford Stem Cell Clinical Center at UC San Diego Health (P.G, S.D, D.S). GDK was supported through The American Association of Immunologists Intersect Fellowship Program for Computational Scientists and Immunologists. L.C.A's salary was supported in part by the VA San Diego Healthcare System. This manuscript includes data generated at the UC San Diego Institute of Genomic Medicine (IGC) using an Illumina NovaSeq 6000 that was purchased with funding from a National Institutes of Health SIG grant (\#S10 OD026929).

\section{Introduction}

SARS-CoV-2, the virus responsible for COVID-19, causes widespread inflammation and injury in the lungs, giving rise to diffuse alveolar damage (DAD) (Andrea Valeria Arrossi and Farver, 2020; Damiani et al., 2021; Borczuk et al., 2020; Li et al., 2021; Roden, 2020), featuring marked infection and viral burden leading to apoptosis of alveolar pneumocytes (Hussman, 2020), along with pulmonary edema (Bratic and Larsson, 2013; Carsana et al., 2020). DAD leads to poor gas exchange and, ultimately, respiratory failure; the latter appears to be the final common mechanism of death in most patients with severe COVID-19 infection. How the virus causes so much damage remains unclear. A particular challenge is to understand the out-of-control immune reaction to the SARS-CoV-2 infection known as a cytokine storm, which has been implicated in many of the deaths from COVID-19. Although rapidly developed preclinical animal models have recapitulated some of the pathognomonic aspects of infection, for example, induction of disease, and transmission, and even viral shedding in the upper and lower respiratory tract, many failed to develop severe clinical symptoms (Lakdawala and Menachery, 2020). Thus, the need for preclinical models remains both urgent and unmet.

To address this need, several groups have attempted to develop human preclinical COVID-19 lung models, all within the last few months (Duan et alı, 2020; Mulay et al., 2020; Salahudeen et al., 2020). While a head-to-head comparison of the key characteristics of each model can be found in Table 1, what is particularly noteworthy is that most of the models do not recapitulate the heterogeneous epithelial cellularity of both proximal and distal airways, that is, airway epithelia, basal cells, secretory club cells, and alveolar pneumocytes. Although induced pluripotent stem cells (iPSC)derived AT2 cells be differentiated into proximal and distal cell types, including AT1, ciliated, and club cells (Kawakita et al., 2020; Dye et al., 2015; Huang et al., 2020), these iPSC-derived models lack propagability and cannot be reproducibly generated for biobanking; nor can they be scaled up in cost-effective ways for use in drug screens. More specifically, adult lung organoid models that can be grown in a sustainable mode and are complete with proximo-distal epithelia are yet to emerge. Besides the approaches described so far, there are a few more approaches used for modeling COVID19: (i) 3D organoids from bronchospheres and tracheospheres have been established before (Hild and Jaffe, 2016; Rock et al., 2009; Tadokoro et al., 2016) and are now used in apical-out cultures for infection with SARS-COV-2 (Suzuki, 2020); (ii) the most common model used for drug screening is the air-liquid interphase (ALI model) in which pseudo-stratified primary bronchial or small airway epithelial cells are used to recreate the multilayered mucociliary epithelium (Mou et al., 2016; Randell et al., 2011); (iii) several groups have also generated 3D airway models from iPSCs or tissue-resident stem cells (Dye et al., 2015; Wong et al., 2012; Ghaedi et al., 2013; Konishi et al., 2016; McCauley et al., 2017; Miller et al., 2019); (iv) others have generated AT2 cells from iPSCs using closely overlapping protocols of sequential differentiation starting with definitive endoderm, anterior foregut endoderm, and distal alveolar expression (Gotoh et alı, 2014; Jacob et alı, 2017; Jacob et al., 2019; Yamamoto et al., 2017; Chen et al., 2017; Huang et al., 2014); and (v) finally, long-term in vitro culture conditions for pseudo-stratified airway epithelium organoids, derived from healthy and diseased adult humans suitable to assess virus infectivity (Sachs et al., 2019; van der Vaart and Clevers, 2021; Zhou et al., 2018), have been pioneered; unfortunately, these airway organoids expressed virtually no lung mesenchyme or alveolar signature. What remains unclear is if any of these models accurately recapitulate the immunopathological phenotype that is seen in the lungs in COVID-19. 


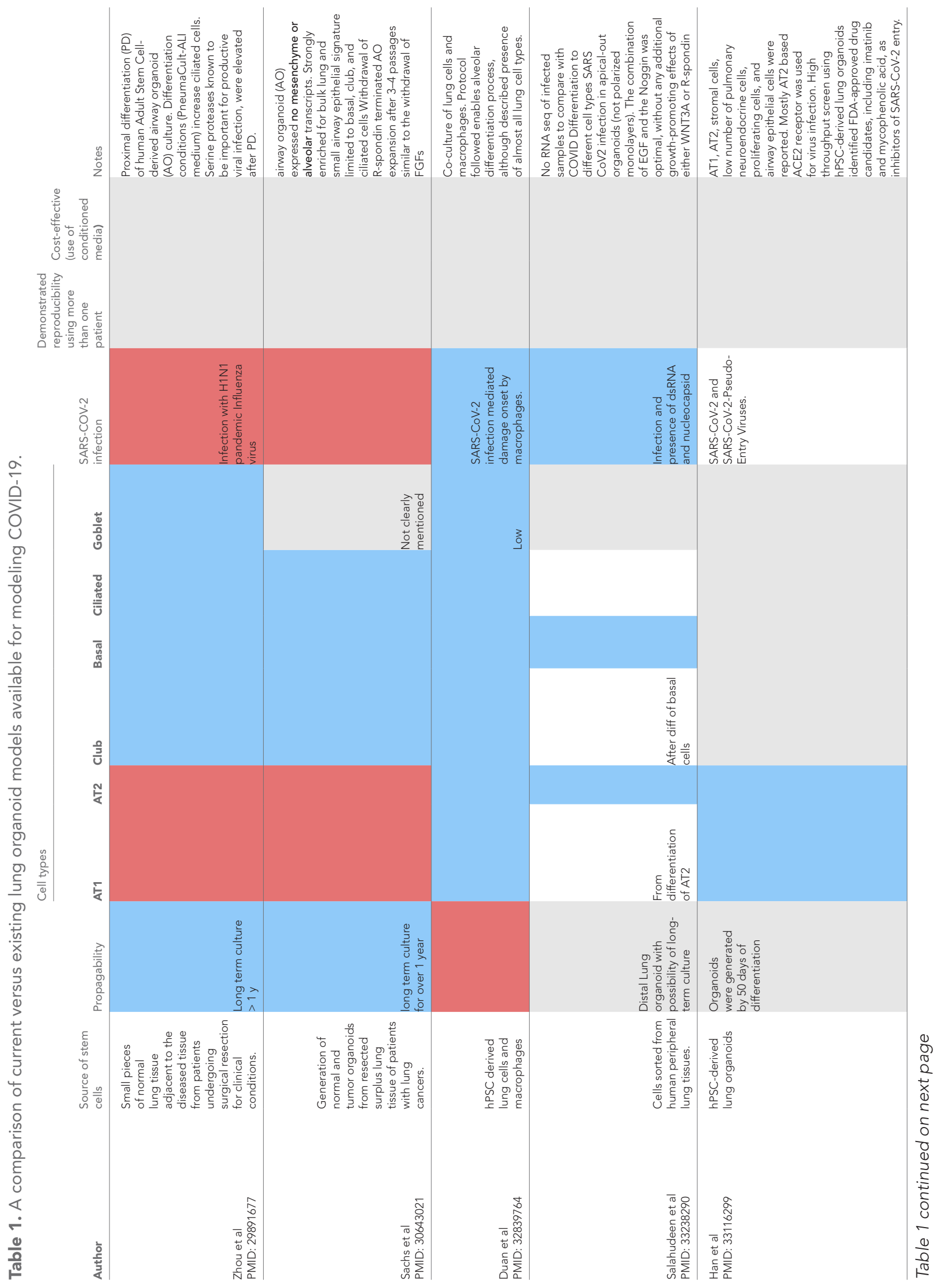




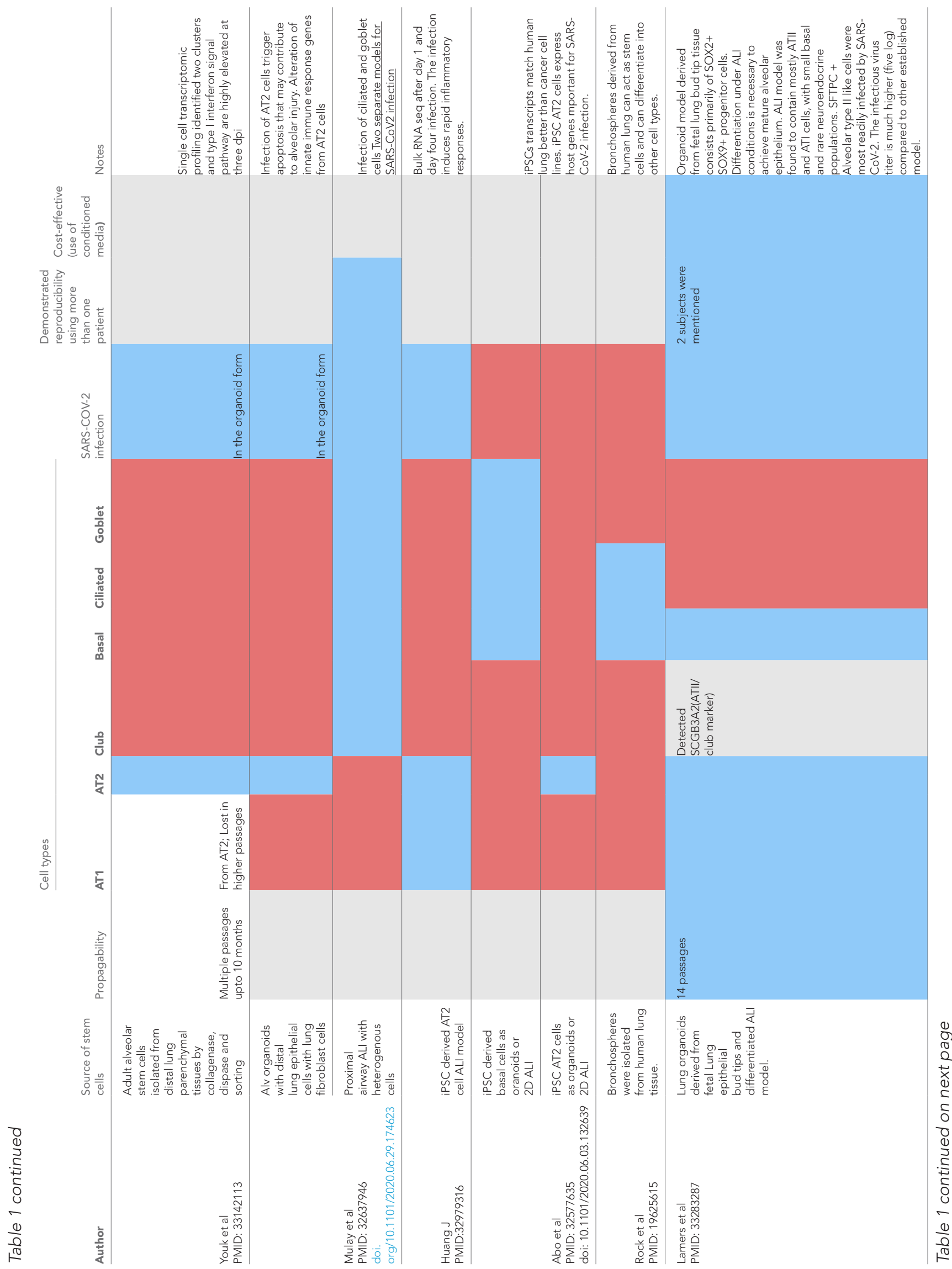




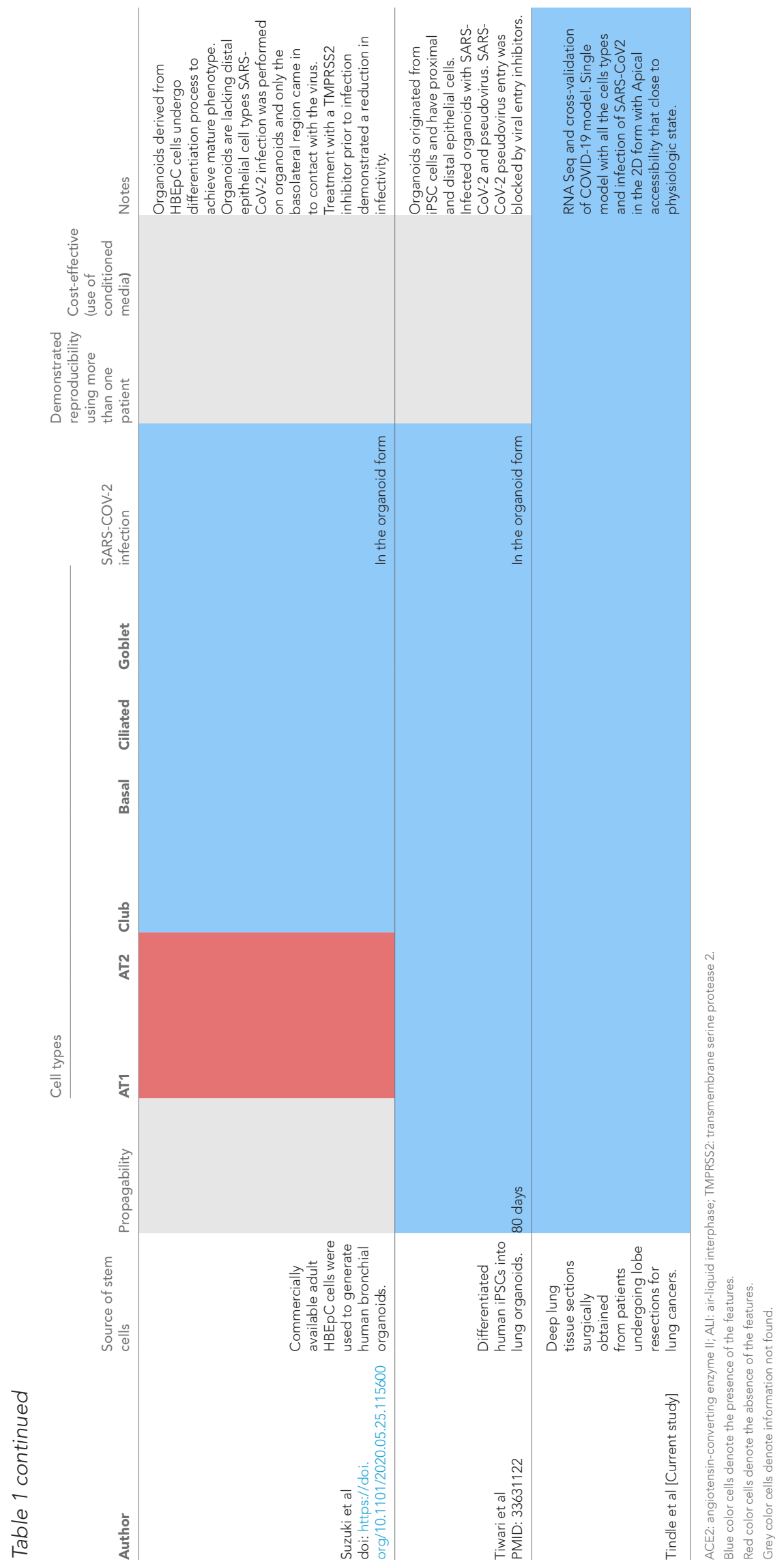


Table 2. Markers used to identify various cell types in the lung.

\begin{tabular}{|c|c|}
\hline Cell type & Markers \\
\hline AT1 & 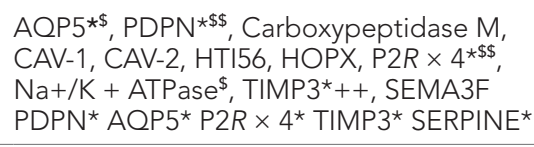 \\
\hline AT2 & $\begin{array}{l}\text { ABCA3*\$\$, CC10 (SCGB1A1*)+, CD44v6, } \\
\text { C×32, gp600++, ICAM-1++, KL-6, } \\
\text { LAMP3*\$\$, MUC1, SFTPA } 1 * \$ \$, S F T P{ }^{*}, \\
\text { SFTPC*+, SFTPD*, SERPINE1 }\end{array}$ \\
\hline Club & 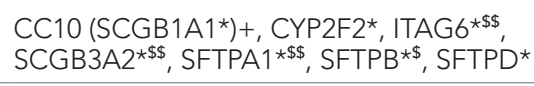 \\
\hline Goblet & $\begin{array}{l}\text { CDX-2*, MUC5AC*, MUC5B*, TFF3*, } \\
\text { UEA1+ }\end{array}$ \\
\hline Ciliated & 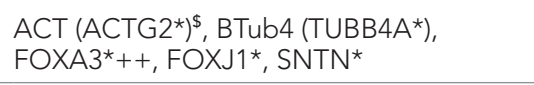 \\
\hline Basal & $\begin{array}{l}\text { CD44v6 (CD44*), ITGA6*\$\$ } \text { KRT5*\$ }^{\star \$} \\
\text { KRT13*, KRT14* }{ }^{*} \text { p63 (CKAP4*), p75 } \\
\left(\text { NGFR*) }^{\$ \$}\right.\end{array}$ \\
\hline $\begin{array}{l}\text { Generic } \\
\text { Lung } \\
\text { Lineage }\end{array}$ & $\begin{array}{l}\text { Cx43 (GJA1*), TTF-1 (TTF1*; Greatest in } \\
\text { AT2 \& Club), EpCAM (EPCAM*) }\end{array}$ \\
\hline
\end{tabular}

*Markers used for single-cell gating (Figure 1A).

$\$$ denotes markers used in this work for

Immunofluorescence (IF).

$\$$ denotes markers used in this work for qPCR.

+ denotes markers used in both IF and GPCR.

++ denotes obscure markers (Not a lot of research relative to lung). the highest expression of both receptors (Figure 1A, Figure 1-figure supplement 1A). These observations are consistent with published studies demonstrating that ACE2 is indeed expressed highest in AT2 and ciliated cells (Mulay et al., 2020; Zhao et al., 2020; Jia et al., 2005). In a cohort of deceased COVID-19 patients, we observed by H\&E (Figure 1-figure supplement 1B) that gas-exchanging flattened AT1 pneumocytes are virtually replaced by cuboidal cells that were subsequently confirmed to be AT2-like cells via immunofluorescent staining with the AT2-specific marker, surfactant protein C (SFTPC; Figure 1B, upper panel, Figure 1-figure supplement 1C, top). We also confirmed that club cells express ACE2 (Figure 1-figure supplement 1C, bottom), underscoring the importance of preserving these cells in any ideal lung model of COVID-19. When we analyzed the lungs of deceased COVID-19 patients, the presence of SARS-COV-2 in alveolar pneumocytes was also confirmed, as determined by the colocalization of viral nucleocapsid protein with SFTPC (Figure 1B, lower panel, Figure 1-figure supplement 1D). Immunohistochemistry studies further showed the presence of SARS-COV-2 virus in alveolar pneumocytes and in alveolar immune cells (Figure 1-figure supplement 1E). These findings are consistent with the gathering consensus that alveolar pneumocytes support the interaction between the epithelial cells and inflammatory cells recruited to the lung; via mechanisms that remain unclear, they are generally believed to contribute to the development of acute lung injury and acute respiratory distress syndrome (ARDS), the severe hypoxemic respiratory failure during COVID-19 (Hou et al., 2020; Spagnolo et alı, 2020). Because prior work has demonstrated that SARS-CoV-2 infectivity in patient-derived airway cells is highest in the proximal airway epithelium compared to the distal alveolar pneumocytes (AT1 and AT2) (Hou et al., 2020), and yet, it is the AT2 pneumocytes that harbor the virus, and the AT1 pneumocytes that are ultimately destroyed during DAD, we hypothesized that both proximal airway and distal (alveolar pneumocyte) components might 


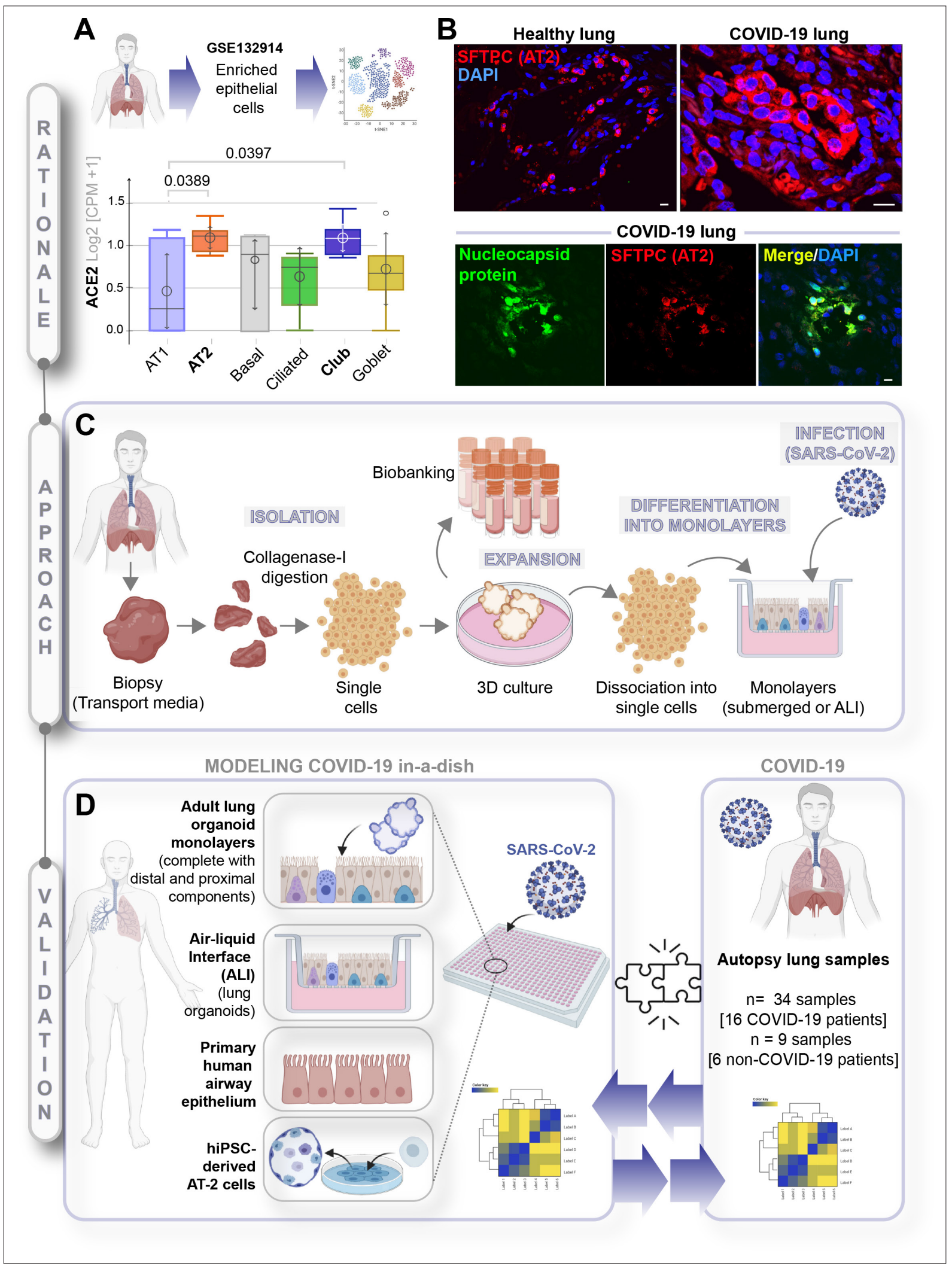

Figure 1. A rationalized approach to building and validating human preclinical models of COVID-19. A) Whisker plots display relative levels of angiotensin-converting enzyme II (ACE2) expression in various cell types in the normal human lung. The cell types were annotated within a publicly available single-cell sequencing dataset (GSE132914) using genes listed in Table 1. p-values were analyzed by one-way ANOVA and Tukey's post hoc test. (B) Formalin-fixed paraffin-embedded sections of the human lung from normal and deceased COVID-19 patients were stained for SFTPC, alone Figure 1 continued on next page 
Figure 1 continued

or in combination with nucleocapsid protein and analyzed by confocal immunofluorescence. Representative images are shown. Scale bar $=20 \mu m$. (C) Schematic showing key steps generating an adult stem cell-derived, propagable, lung organoid model, complete with proximal and distal airway components for modeling COVID-19-in-a-dish. See Materials and methods for details regarding culture conditions. (D) A transcriptome-based approach is used for cross-validation of in vitro lung models of SARS-CoV-2 infection (left) versus the human disease, COVID-19 (right), looking for a match in gene expression signatures.

The online version of this article includes the following figure supplement(s) for figure 1:

Figure supplement 1. Alveolar type II pneumocyte hyperplasia is a pathognomonic feature of lung injury in COVID-19.

play distinct roles in the respiratory system to mount the so-called viral infectivity and host immune response phases of the clinical symptoms observed in COVID-19 (Chen and Li, 2020).

Because no existing lung model provides such proximodistal cellular representation (Table 1), and hence, may not recapitulate with accuracy the clinical phases of COVID-19, we first sought to develop a lung model that is complete with both proximal and distal airway epithelia using adult stem cells that were isolated from deep lung biopsies (i.e., sufficient to reach the bronchial tree). Lung organoids were generated using the work flow outlined in Figure $1 \mathrm{C}$ and a detailed protocol that had key modifications from previously published (Sachs et al., 2019; Zhou et al., 2018) methodologies (see Materials and methods). Organoids grown in 3D cultures were subsequently dissociated into single cells to create 2D monolayers (either maintained submerged in media or used in ALI model) for SARS-CoV-2 infection, followed by RNA seq analysis. Primary airway epithelial cells and hiPSC-derived alveolar type II (AT2) pneumocytes were used as additional models (Figure 1D, left panel). Each of these transcriptomic datasets was subsequently used to cross-validate our ex vivo lung models of SARS-CoV-2 infection with the human COVID-19 autopsy lung specimens (Figure 1D, right panel) to objectively vet each model for their ability to accurately recapitulate the gene expression signatures in the patient-derived lungs.

\section{Creation of a lung organoid model, complete with both proximal and distal airway epithelia}

Three lung organoid lines were developed from deep lung biopsies obtained from the normal regions of lung lobes surgically resected for lung cancer; both genders, smokers and non-smokers, were represented (Figure 2-figure supplement 1A; Table 3). Three different types of media were compared (Figure 2-figure supplement 1B); the composition of these media was inspired either by their ability to support adult-stem cell-derived mixed epithelial cellularity in other organs (like the gastrointestinal [GI] tract [Miyoshi and Stappenbeck, 2013; Sato et al., 2009; Sayed et al., 2020c]) or rationalized based on published growth conditions for proximal and distal airway components (Gotoh et al., 2014; Sachs et al., 2019; van der Vaart and Clevers, 2021). A growth condition that included conditioned media from L-WRN cells that express Wnt3, R-spondin, and Noggin, supplemented with recombinant growth factors, which we named as 'lung organoid expansion media,' emerged as superior compared to alveolosphere media-I and II (Jacob et al., 2019; Yamamoto et al., 2017) (details in Materials and methods), based on its ability to consistently and reproducibly support the best morphology and growth characteristics across multiple attempts to isolate organoids from lung tissue samples. Three adult lung organoid lines (ALO1-3) were developed using the expansion media, monitored for their growth characteristics by brightfield microscopy and cultured with similar phenotypes until P10 and

Table 3. Characteristics of patients enrolled into this study for obtaining lung tissues to serve as source of stem cells to generate lung organoids.

\begin{tabular}{|c|c|c|c|c|c|c|}
\hline Name & Date of surgery & Age & Sex & Smoking history & Reason for surgery & Histology \\
\hline & & & & $\begin{array}{l}\text { Current, chronic sr } \\
\text { Packs/day: } 0.50 \\
\text { Years: } 53\end{array}$ & & \\
\hline ALO1 & $4 / 17 / 2020$ & 64 & Male & Pack years: 26.5 & Lung carcinoma & Invasive squamous cell carcinoma, non-keratinizing \\
\hline ALO2 & $4 / 17 / 2020$ & 59 & Male & Non-smoker & Lung carcinoma & Invasive adenocarcinoma \\
\hline $\mathrm{ALO} 3$ & 7/7/2020 & 46 & Female & Non-smoker & Left lower lobe nodule & Invasive adenocarcinoma \\
\hline
\end{tabular}


beyond (Figure 2-figure supplement 1C and D). The 3D morphology of the lung organoid was also assessed by H\&E staining of slices cut from formalin-fixed paraffin-embedded (FFPE) cell blocks of HistoGel-emb`edded ALO1-3 (Figure 2-figure supplement 1E).

To determine if all the six major lung epithelial cells (illustrated in Figure 2A) are present in the organoids, we analyzed various cell-type markers by qRT-PCR (Figure 2B-H and Figure 2-figure supplement 2A-H). All three ALO lines had a comparable level of AT2 cell surfactant markers (compared against hiPSC-derived AT2 cells as positive control) and a significant amount of AT1, as determined using the marker AQP5. ALOs also contained basal cells (as determined by the marker ITGA6, p75/NGFR, TP63), ciliated cells (as determined by the marker FOXJ1), and club cells (as determined by the marker SCGB1A1). As expected, the primary normal human bronchial epithelial cells (NHBE) had significantly higher expression of basal cell markers than the ALO lines (hence, served as a positive control), but they lacked stemness and club cells (hence, served as a negative control).

The presence of all cell types was also confirmed by assessing protein expression of various cell types within organoids grown in 3D cultures. Two different approaches were used-(i) slices cut from FFPE cell blocks of HistoGel-embedded ALO lines (Figure 2I and J) or (ii) ALO lines grown in 8-well chamber slides were fixed in Matrigel (Figure 2K), stained, and assessed by confocal microscopy. Such staining not only confirmed the presence of more than one cell type (i.e., mixed cellularity) of proximal (basal-KRT5) and distal (AT1/AT2 markers) within the same ALO line, but also, in some instances, demonstrated the presence of mixed cellularity within the same 3D structure. For example, AT2 and basal cells, marked by SFTPB and KRT5, respectively, were found in the same 3D structure (Figure 2J, interrupted curved lines). Similarly, ciliated cells and goblet cells stained by Ac-Tub and Muc5AC, respectively, were found to coexist within the same structure (Figure $2 \mathrm{~J}$, interrupted box; Figure 2K, arrow). Intriguingly, we also detected 3D structures that co-stained for CC10 and SFTPC (Figure 2J, bottom panel) indicative of mixed populations of club and AT2 cells. Besides the organoids with heterogeneous makeup, each ALO line also showed homotypic organoid structures that were relatively enriched in one cell type (Figure 2J, arrowheads pointing to two adjacent structures that are either KRT5- or SFTPB-positive). Regardless of their homotypic or heterotypic cellular organization into $3 \mathrm{D}$ structures, the presence of mixed cellularity was documented in all three ALO lines (see multiple additional examples in Figure 2-figure supplement 2I). It is noteworthy that the coexistence of proximal and distal epithelial cells in lung organoids has been achieved in one another instance prior; Lamers et al. showed such mixed cellular composition in fetal lung bud tip-derived organoids Lamers et al., 2021. However, their model lacked ciliated and goblet cells (Lamers et al., 2021), something that we could readily detect in our 3D organoids.

Finally, using qRT-PCR of various cell-type markers as a measure, we confirmed that the ALO models overall recapitulated the cell-type composition in the adult lung tissues from which they were derived (Figure 2-figure supplement 3) and retained such composition in later passages without significant notable changes in any particular cell type (Figure 2-figure supplement 4). The mixed proximal and distal cellular composition of the ALO models and their degree of stability during in vitro culture was also confirmed by flow cytometry (Figure 2-figure supplement 5).

\section{Organoid cellularity resembles tissue sources in 3D cultures but differentiates in 2D cultures}

To model respiratory infections such as COVID-19, it is necessary for pathogens to be able to access the apical surface. It is possible to microinject into the lumens of 3D organoids, as done previously with pathogens in the case of gut organoids (Engevik et al., 2015; Forbester et al., 2015; Leslie et al., 2015; Williamson et al., 2018), or FITC-dextran in the case of lung organoids (Porotto et al., 2019), or carry out infection in apical-out 3D lung organoids with basal cells (Salahudeen et al., 2020). However, the majority of the researchers have gained apical access by dissociating 3D organoids into single cells and plating them as 2D-monolayers (Duan et alo, 2020; Mulay et alo, 2020; Huang et alı, 2020; Sachs et al., 2019; Zhou et alı, 2018; Han et al., 2020a; Han et alı, 2020b. As in any epithelium, the differentiation of airway epithelial cells relies upon dimensionality (apicobasal polarity); because the loss of dimensionality can have a major impact on cellular proportions and impact disease-modeling in unpredictable ways, we assessed the impact of the 3D-to-2D conversion on cellularity by RNA seq analyses. Two commonly encountered methods of growth in 2D monolayers were tested: (i) monolayers polarized on trans-well inserts but submerged in growth media (Figure 3A 


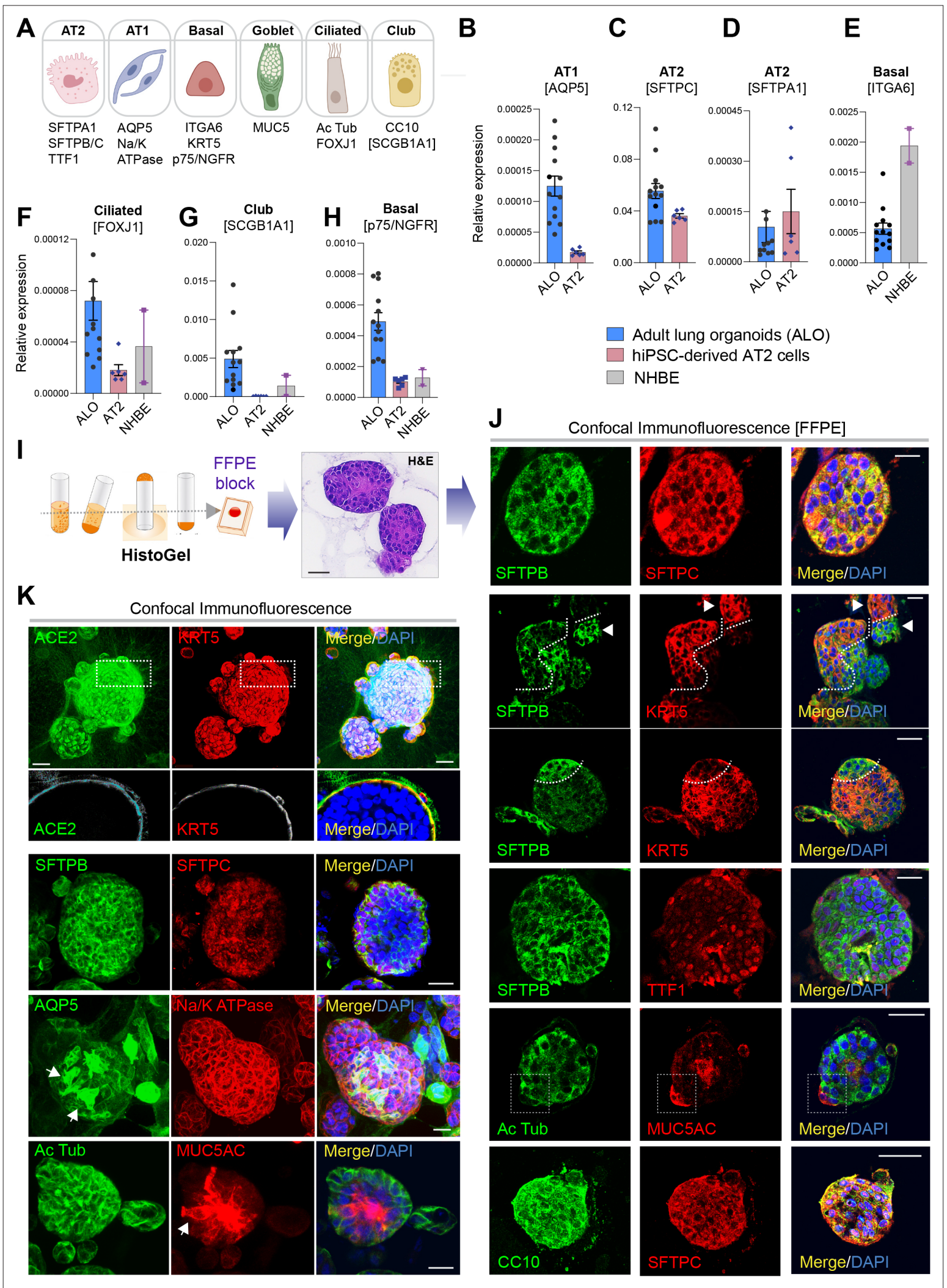

Figure 2. Adult stem cell-derived lung organoids are propagatable models with both proximal and distal airway components. (A) Schematic lists the various markers used here for $\mathrm{QPCR}$ and immunofluorescence to confirm the presence of all cell types in the 3D lung organoids here and in $2 \mathrm{D}$ monolayers later (in Figure 3). (B-H) Bar graphs display the relative abundance of various cell-type markers (normalized to 18S) in adult lung organoids (ALO), compared to the airway ( normal human bronchial epithelial cell [NHBE]) and/or alveolar (AT2) control cells, as appropriate. p-values were

Figure 2 continued on next page 
Figure 2 continued

analyzed by one-way ANOVA. Error bars denote SEM; $n=3-6$ datasets from three independent ALOs and representing early and late passages. See also Figure 2-figure supplement 2 for individual ALOs. (I, J). H\&E-stained cell blocks were prepared using HistoGel (I). Slides were stained for the indicated markers and visualized by confocal immunofluorescence microscopy. Representative images are shown in (J). Scale bar $=50 \mu m$. (K) 3D organoids grown in 8-well chamber slides were fixed, immunostained, and visualized by confocal microscopy as in (J). Scale bar $=50 \mu \mathrm{m}$. See also Figure 2-figure supplement 2. Top row (ACE2/KRT5-stained organoids) displays the single and merged panels as max projections of z-stacks (top) and a single optical section (bottom) of a selected area. For the remaining rows, the single (red/green) channel images are max projections of z-stacks; however, merged panels are optical sections to visualize the centers of the organoids. All immunofluorescence images showcased in this figure were obtained from ALO lines within passage \#3-6. See also Figure 2-figure supplements 3-5 for additional evidence of mixed cellularity of ALO models, their similarity to lung tissue of origin, and stability of cellular composition during early (\#1-8) and late (\#8-15) passages, as determined by qPCR and flow cytometry.

The online version of this article includes the following figure supplement(s) for figure 2:

Figure supplement 1. Lung organoids are reproducibly established from three different donors and propagated in each case over 10 passages.

Figure supplement 2. Adult stem cell-derived lung organoids are propagatable models with both proximal and distal airway components.

Figure supplement 3. Adult stem cell-derived lung organoids (ALO) generally recapitulate cell-type-specific gene expression patterns observed in the adult lung tissue (ALT) from which they originate.

Figure supplement 4. Adult stem cell-derived lung organoids (ALO) generally maintain their cellular composition from early (E) to late ( $L$ ) passages, as determined by cell-type-specific gene expression by qPCR.

Figure supplement 5. Adult stem cell-derived lung organoids (ALO) comprised both proximal and distal airway epithelial population and generally maintain such diversity from early $(\mathrm{E})$ to late $(\mathrm{L})$ passages, as determined by FACS.

and Figure 3-figure supplement 1A-D) and (ii) monolayers were grown at the air-liquid interface (popularly known as the 'ALI model'; Prytherch et al., 2011; Dvorak et al., 2011) for 21 days to differentiate into the mucociliary epithelium (Figure 3A and Figure 3-figure supplement 1E-G). The submerged 2D monolayers had several regions of organized vacuolated-appearing spots (Figure 3figure supplement 1D, arrow), presumably due to morphogenesis and cellular organization even in 2D. Consistent with this morphological appearance, the epithelial barrier formed in the submerged condition was leakier, as determined by relatively lower transepithelial electrical resistance (TEER; Figure 3-figure supplement 1B) and the flux of FITC-dextran from apical to basolateral chambers (Figure 3-figure supplement 1C), and corroborated by morphological assessment by confocal immunofluorescence of localization of occludin, a bona fide TJ marker. We chose occludin because it is a shared and constant marker throughout the airway that stabilizes claudins and regulates their turnover McGowan, 2014 and plays an important role in maintaining the integrity of the lung epithelial barrier Liu et alı, 2014. Junction-localized occludin was patchy in the monolayer, despite the fact that the monolayer was otherwise intact, as determined by phalloidin staining (Figure 3-figure supplement $1 \mathrm{H}$ and I). Our finding that ALO 3D organoids differentiating into monolayers in submerged cultures (where alveolar differentiation and cell flattening happens dynamically as progenitor cells give rise to AT1/2 cells) are leaky is in keeping with prior work demonstrating that the TJs are rapidly remodeled as alveolar cells mature Schlingmann et al., 2015; Yang et al., 2016. By contrast, and as expected Rayner et al., 2019, the ALI monolayers formed a more effective epithelial barrier, as determined by TEER (Figure 3-figure supplement 1F), and appeared to be progressively hazier with time after air-lift, likely due to the accumulation of secreted mucin (Figure 3-figure supplement 1G).

RNA seq datasets were analyzed using the same set of cell markers, as we used in Figure 1A (listed in Table 2). Consistent with our morphological, gene expression, and FACS-based studies showcased earlier (Figure 2 and Figure 2-figure supplements 2-5), cell-type deconvolution of our transcriptomic dataset using CIBERSORTx (https://cibersortx.stanford.edu/runcibersortx.php) confirmed that cellular composition in the human lung tissues was reflected in the 3D ALO models and that such composition was also relatively well-preserved over several passages (Figure 3B, left); both showed a mixed population of simulated alveolar, basal, club, ciliated, and goblet cells. When 3D organoids were dissociated and plated as 2D monolayers on transwells, the AT2 signatures were virtually abolished with a concomitant and prominent emergence of AT1 signatures, suggesting that growth in 2D monolayers favors differentiation of AT2 cells into AT1 cells Shami and Evans, 2015 (Figure 3B, middle). A compensatory reduction in proportion was also observed for the club, goblet, and ciliated cells. The same organoids, when grown in long-term 2D culture conditions in the ALI model, showed a strikingly opposite pattern; alveolar signatures were almost entirely replaced by a concomitant increase 


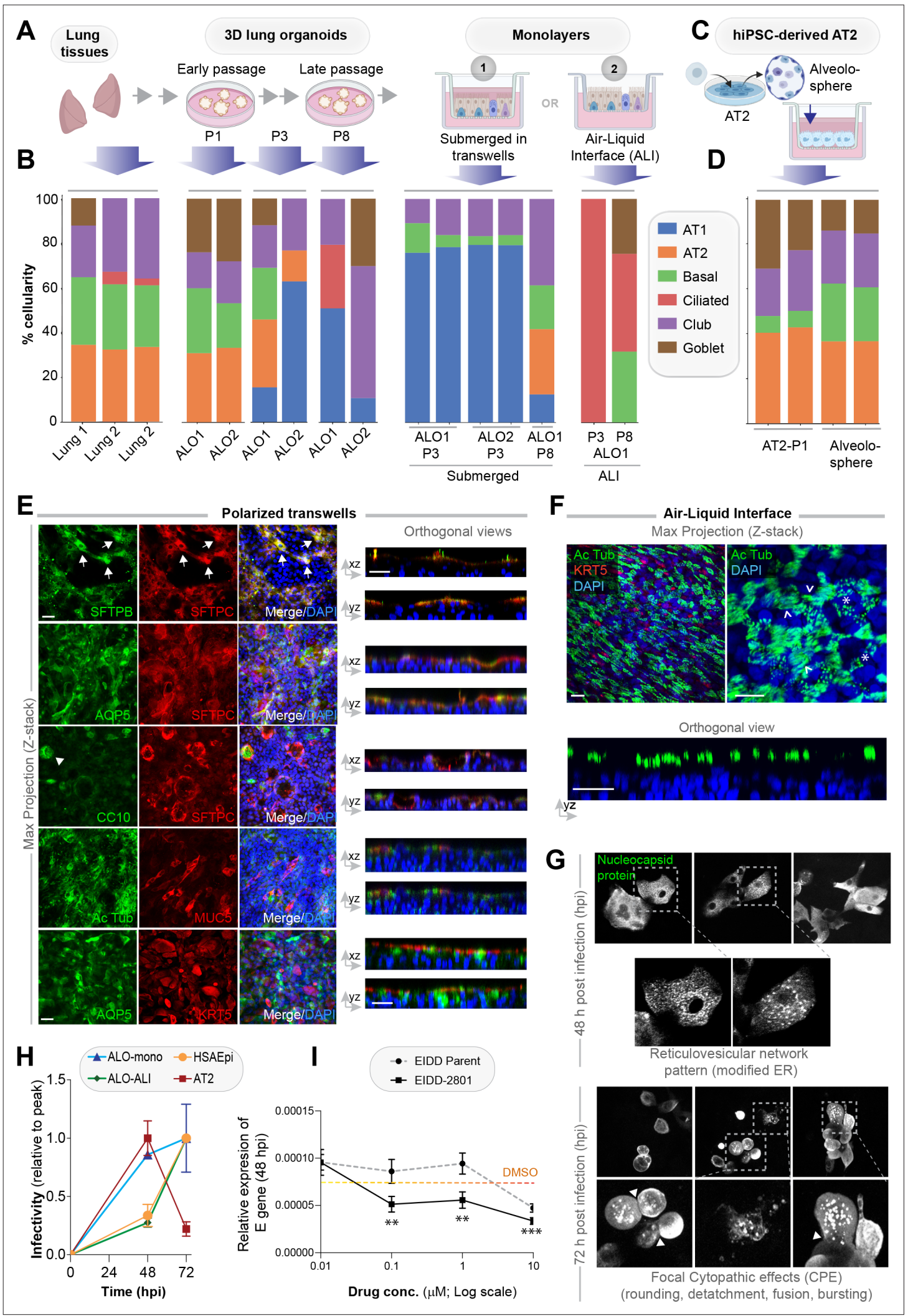

Figure 3. Monolayers derived from lung organoids differentiate into proximal and distal airway components. (A, B) Samples collected at various steps of lung organoid isolation and expansion in culture, and from the two types of monolayers prepared using the lung organoids were analyzed by bulk RNA seq and the datasets were compared for \% cellular composition using the deconvolution method, CYBERSORTx. Schematic in (A) shows the workflow steps, and bar plots in (B) show the relative proportion of various lung cell types. (C, D) hiPSC-derived AT2 cells and alveolospheres (C) were Figure 3 continued on next page 
Figure 3 continued

plated as monolayers and analyzed by RNA seq. Bar plots in (D) show \% cellular composition. (E, F) Submerged adult lung organoids (ALO) monolayers in transwells $(\mathbf{E})$ or monolayers were grown as air-liquid interphase (ALI) models (F) were fixed and stained for the indicated markers and visualized by confocal immunofluorescence microscopy. The representative max projected z-stack images (left) and the corresponding orthogonal images (right) are displayed. Arrows in (E) indicate AT2 cells; arrowheads in (E) indicate club cells; asterisk in (F) indicates bundles of cilia standing perpendicular to the plane of the ALI monolayers; arrowheads in (F) indicate bundles of cilia running parallel to the plane of the ALI monolayers. Scale bar $=20 \mu \mathrm{m}$. (G) Monolayers of ALO1-3 were challenged with SARS-CoV-2 for indicated time points prior to fixation and staining for KRT5, SARS-COV2 viral nucleocapsid protein and DAPI and visualized by confocal microscopy. A montage of representative images are shown, displaying reticulovesicular network patterns and various cytopathic effects. Scale bar $=15 \mu \mathrm{m}$. (H) Monolayers of ALO, hiPSC-derived AT2 cells, and other alternative models (see Figure 3-figure supplements 1-2) were infected or not with SARS-CoV-2 and analyzed for infectivity by qPCR (targeted amplification of viral envelope, E gene). See also Figure 3-figure supplement 3B, C for comparison of the degree of peak viral amplification across various models. (I) ALO monolayers pretreated for $4 \mathrm{hr}$ with either vehicle (DMSO) control or EIDD-parent (NHC) or its metabolite EIDD-2801/MK-4482 were infected with SARS-CoV-2 and assessed at 48 hpi for infectivity as in (H). Line graphs display the relative expression of E gene. Error bars display SEM. $\mathrm{p}$ value ${ }^{\star \star}<0.01 ;{ }^{\star \star \star}<0.001$.

The online version of this article includes the following figure supplement(s) for figure 3 :

Figure supplement 1. Monolayers derived from adult lung organoids (ALO) can form an epithelial barrier.

Figure supplement 2. Alternative models of lung epithelial cells used in this work for modeling SARS-CoV-2 infection and/or as a control for gene expression studies.

Figure supplement 3. Proof of SARS-CoV-2 infectivity.

in ciliated and goblet cells (Figure 3B, right). These findings are consistent with the well-established notion that ALI conditions favor growth as pseudo-stratified mucociliary epithelium Prytherch et al., 2011; Dvorak et al., 2011. As an alternative model for use as monolayers for viral infection, we developed hiPSC-derived AT2 cells and alveolospheres (Figure 3C), using established protocols Huang et al., 2020. Because they were grown in the presence of CHIR99021 (an aminopyrimidine derivate that is a selective and potent Wnt agonist) Jacob et al., 2019; Yamamoto et al., 2017; Abdelwahab et al., 2019, which probably inhibits the AT2 $\rightarrow$ AT1 differentiation, these monolayers were enriched for AT2 and devoid of AT1 cells (Figure 3D).

The multicellularity of lung organoid monolayers was also confirmed by immunofluorescence staining and confocal microscopy of the submerged and ALI monolayers, followed by the visualization of cell markers in either max-projected z-stacks (Figure 3E, left) or orthogonal views of the same (Figure 3E, right). As expected, markers for the same cell type (i.e., SFTPB and SFTPC, both AT2 markers) colocalize, but markers for different cell types do not. Submerged monolayers showed the prominent presence of both AT1 (AQP5-positive) and AT2 cells. Compared to the 3D organoids, the 2D organoid cultures, especially the ALI model, showed a significant increase in ciliated structures, as determined by acetylated tubulin (compare Ac Tub-stained panels in Figure $2 \mathrm{~J}$ and $\mathrm{K}$ with Figure 3E and F). The observed progressive prominence of ciliary structures from 3D to 2D models is in keeping with the fact that 3D ALOs that are yet to form lumen represent the least differentiated state, whereas 2D submerged monolayers are intermediate and the 2D ALI monolayers are maximally differentiated; differentiation is known to establish apicobasal polarity, which is essential for the emergence of mature cilia on the apical surface. This increase in ciliated epithelium was associated with a concomitant decrease in KRT5-stained basal cells (Figure 3F). Such loss of the basal cell marker KRT5 between submerged monolayers and the ALI model can be attributed to and the expected conversion of basal cells to other cell types (i.e., ciliated cells) Gras et al., 2017; Khelloufi et al., 2018. The presence of AT2 cells, scattered amidst the ciliated cells in these ALI monolayers, was confirmed by co-staining them for SFTPC and Ac-Tub (Figure 3-figure supplement 1J).

Finally, we sought to confirm that the epithelial barrier that is formed by the submerged monolayers derived from ALO is responsive to infections. To this end, we simulated infection by challenging ALO monolayers with LPS. Compared to unchallenged controls, the integrity of the barrier was impaired by LPS, as indicated by a significant drop in the TEER (Figure 3-figure supplement $1 \mathrm{~K}$ and L), which is in keeping with the known disruptive role of LPS on the respiratory epithelium Kalsi et al., 2020.

Taken together, the immunofluorescence images are in agreement with the RNA seq dataset; both demonstrate that the short-term submerged monolayer favors distal differentiation (AT2 $\rightarrow$ AT1), whereas the 21 -day ALI model favors proximal mucociliary differentiation. It is noteworthy that these distinct differentiation phenotypes originated from the same 3D organoids despite the seeding of cells in the same basic media composition (i.e., PneumaCult) prior to switching over to an ALI maintenance 
media for the prolonged growth at ALI; the latter is a well-described methodology that promotes differentiation into ciliated and goblet cells Rayner et al., 2019.

\section{Differentiated 2D monolayers show that SARS-CoV-2 infectivity is higher in proximal than distal epithelia}

Because the lung organoids with complete proximodistal cellularity could be differentiated into either distal-predominant monolayers in submerged short-term cultures or proximal-predominant monolayers in long-term ALI cultures, this provided us with an opportunity to model the respiratory tract and assess the impact of the virus along the entire proximal-to-distal gradient. We first asked if ALO monolayers are permissive to SARS-CoV-2 entry and replication and support sustained viral infection. Confocal imaging of infected ALO monolayers with anti-SARS-COV-2 nucleocapsid protein antibody showed that submerged ALO monolayers did indeed show progressive changes during the 48-72 hr window after infection (Figure 3G): by $48 \mathrm{hpi}$, we observed the formation of 'reticulovesicular patterns' that are indicative of viral replication within modified host endoplasmic reticulum (Knoops et al., 2008; Figure 3G, left), and by 72 hpi we observed focal cytopathic effect (CPE) (Kaye, 2006) such as cell-rounding, detachment, and bursting of virions (Figure 3G, right, Figure 3-figure supplement 3A).

We next asked how viral infectivity varies in the various lung models. Because multiple groups have shown the importance of the ciliated airway cells for infectivity (i.e., viral entry, replication, and apical release [Hou et al., 2020; Milewska et al., 2020; Zhu et al., 2020; Hui et al., 2020]), as positive controls, we infected monolayers of human airway epithelia (see the legend, Figure 3-figure supplement 2A-D. AT2 cells, which express high levels of viral entry receptors ACE2 and TMPRSS2 (Figure 1A, Figure 1-figure supplement 1A), have been shown to be proficient in the viral entry but are least amenable to sustained viral release and infectivity (Hou et al., 2020; Hui et al., 2020). To this end, we infected monolayers of hiPSC-derived homogeneous cultures of AT2 cells as secondary controls (see the legend, Figure 3-figure supplement 2E-G). Infection was carried out using the Washington strain of SARS-CoV-2, USA-WA1/2020 (BEl Resources NR-52281 Rogers et al., 2020). As expected, the 2D lung monolayers we generated, both the submerged and the ALI models, were readily infected with SARS-CoV-2 (Figure 3-figure supplement 3B), as determined by the presence of the viral envelope gene (E gene; Figure $3 \mathrm{H}$ ); however, the kinetics of viral amplification differed. When expressed as levels of $\mathrm{E}$ gene normalized to the peak values in each model (Figure $3 \mathrm{H}$ ), the kinetics of the ALI monolayer model mirrored that of the primary airway epithelial monolayers; both showed slow beginning (0-48 hpi) followed by an exponential increase in E gene levels from 48 to 72 hpi. The submerged monolayer model showed sustained viral infection during the 48-72 hpi window (Figure 3-figure supplement 3B, left). In the case of AT2 cells, the 48-72 hpi window was notably missing in monolayers of hiPSC-derived AT2 cells (Figure $3 \mathrm{H}$ and Figure 3-figure supplement 3B, right). When we specifically analyzed the kinetics of viral $\mathrm{E}$ gene expression during the late phase (48-72 hpi window), we found that proximal airway models (human bronchial airway epi [HBEpC]) showed high levels of sustained infectivity than distal models (human small airway epi [HSAEpC] and AT2) to viral replication (Figure 3-figure supplement 3C); the ALO monolayers showed intermediate sustained infectivity (albeit with variability). All models showed extensive cell death and detachment by $96 \mathrm{hr}$ and, hence, were not analyzed. Finally, using the E gene as a readout, we asked if ALO models could be used as platforms for preclinical drug screens. As a proof of concept, we tested the efficacy of nucleoside analog $\mathrm{N}^{4}$-hydroxycytidine (NHC; EIDD-parent) and its derivative pro-drug, EIDD-2801; both have been shown to inhibit viral replication, in vitro and in SARS-CoV2-challenged ferrets (Cox et al., 2021; Sheahan et al., 2020). ALO monolayers plated in 384-wells were pretreated for $4 \mathrm{hr}$ with the compounds or DMSO (control) prior to infection and assessed at $48 \mathrm{hpi}$ for the abundance of $\mathrm{E}$ gene in the monolayers. Both compounds effectively reduced the viral titer in a dose-dependent manner (Figure 3I), and the pro-drug derivative showed a better efficacy, as shown previously.

Taken together, these findings show that sustained viral infectivity is best simulated in monolayers that resemble the proximal mucociliary epithelium, that is, 2D monolayers of lung organoids grown as $\mathrm{ALI}$ models and the primary airway epithelia. Because prior studies conducted in patient-derived airway cells (Hou et al., 2020) mirror what we see in our monolayers, we conclude that proximal airway cells within our mixed-cellular model appear to be sufficient to model viral infectivity in COVID-19. 
Findings also validate optimized protocols for the adaptation of ALO monolayers in miniaturized 384well formats for use in high-throughput drug screens.

\section{Differentiated 2D monolayers show that host immune response is higher in distal than proximal epithelia}

Next, we asked if the newly generated lung models accurately recapitulate the host immune response in COVID-19. To this end, we analyzed the infected ALO monolayers (both the submerged and ALI variants) as well as the airway epithelial (HSAEpC) and AT2 monolayers by RNA seq and compared them all against the transcriptome profile of lungs from deceased COVID-19 patients. We did this analysis in two steps of reciprocal comparisons: (i) The actual human disease-derived gene signature was assessed for its ability to distinguish infected from uninfected disease models (in Figure 4). (ii) The ALO model-derived gene signature was assessed for its ability to distinguish healthy from diseased patient samples (in Figure 5). A publicly available dataset (GSE151764) Nienhold et al., 2020, comprising lung transcriptomes from victims deceased either due to noninfectious causes (controls) or due to COVID-19, was first analyzed for differentially expressed genes (DEGs; Figure 4A and B). This cohort was chosen as a test cohort over others because it was the largest one available at the time of this study with appropriate postmortem control samples. DEGs showed an immunophenotype that was consistent with what is expected in viral infections (Figure 4C, Table 4, and Figure 4-figure supplement 1) and showed overrepresentation of pathways such as interferon, immune, and cytokine signaling (Figure 4D, Table 5, and Figure 4-figure supplement 2). DEG signatures and reactome pathways that were enriched in the test cohort were fairly representative of the host immune response observed in patient-derived respiratory samples in multiple other validation cohorts; the signature derived from the test cohort could consistently classify control (normal) samples from COVID-19-samples (receiver operating characteristics area under the curve [ROC AUC] 0.89-1.00 across the board; Figure 4E). The most notable finding is that the patient-derived signature was able to perfectly classify the EpCAM-sorted epithelial fractions from the bronchoalveolar lavage fluids of infected and healthy subjects (ROC AUC 1.00; GSE145926-Epithelium Liao et al., 2020), suggesting that the respiratory epithelium is a major site where the host immune response is detected in COVID-19. When compared to existing organoid models of COVID-19, we found that the patientderived COVID-19-lung signature was able to perfectly classify infected vs. uninfected late passages (>50) of hiPSC-derived AT1/2 monolayers (GSE155241) Han et al., 2020a and infected vs. uninfected liver and pancreatic organoids (Figure 4F). The COVID-19-lung signatures failed to classify commonly used respiratory models, for example, A549 cells and bronchial organoids, as well as intestinal organoids (Figure 4F). A similar analysis on our own lung models revealed that the COVID-19-lung signature was induced in submerged monolayers with distal-predominant AT2 $\rightarrow$ AT1 differentiation, but not in the proximal-predominant ALI model (ROC AUC 1.00 and 0.50, respectively; Figure 4G). The ALI model and the small airway epithelia, both models that mimic the airway epithelia (and lack alveolar pneumocytes; see Figure 3B), failed to mount the patient-derived immune signatures (Figure 4H, left). These findings suggested that the presence of alveolar pneumocytes is critical for emulating host response. To our surprise, induction of the COVID-19-lung signature also failed in hiPSC-derived AT2 monolayers (Figure 4H, right), indicating that AT2 cells are unlikely to be the source of such host response. These findings indicate that both proximal airway and AT2 cells, when alone, are insufficient to induce the host immune response that is encountered in the lungs of COVID-19 patient.

Next, we analyzed the datasets from our ALO monolayers for DEGs when challenged with SARSCOV-2 (Figure 5A,B). Genes and pathways upregulated in the infected lung organoid-derived monolayer models (Figure 5-figure supplements 1-2) overlapped significantly with those that were upregulated in the COVID-19 lung signature (compare Figure $4 C, D$ with Figure 5C,D, Table 6, Table 7, Table 8). We observed only a partial overlap (ranging from $\sim 22-55 \%$ across various human datasets; Figure 5-figure supplement 3) in upregulated genes and no overlaps among downregulated genes between model and disease (COVID-19; Figure 5E). Because the degree of overlap was even lesser (ranging from 10 to $25 \%$ across various human datasets; Figure 5-figure supplement 3 ) in the case of another publicly released model (GSE160435) (Mulay et al., 2020), these discrepancies between the model and the actual disease likely reflect the missing stromal and immune components in our organoid monolayers. Regardless of these missing components, the model-derived DEG signature was sufficient to consistently and accurately classify diverse cohorts of patient-derived respiratory 


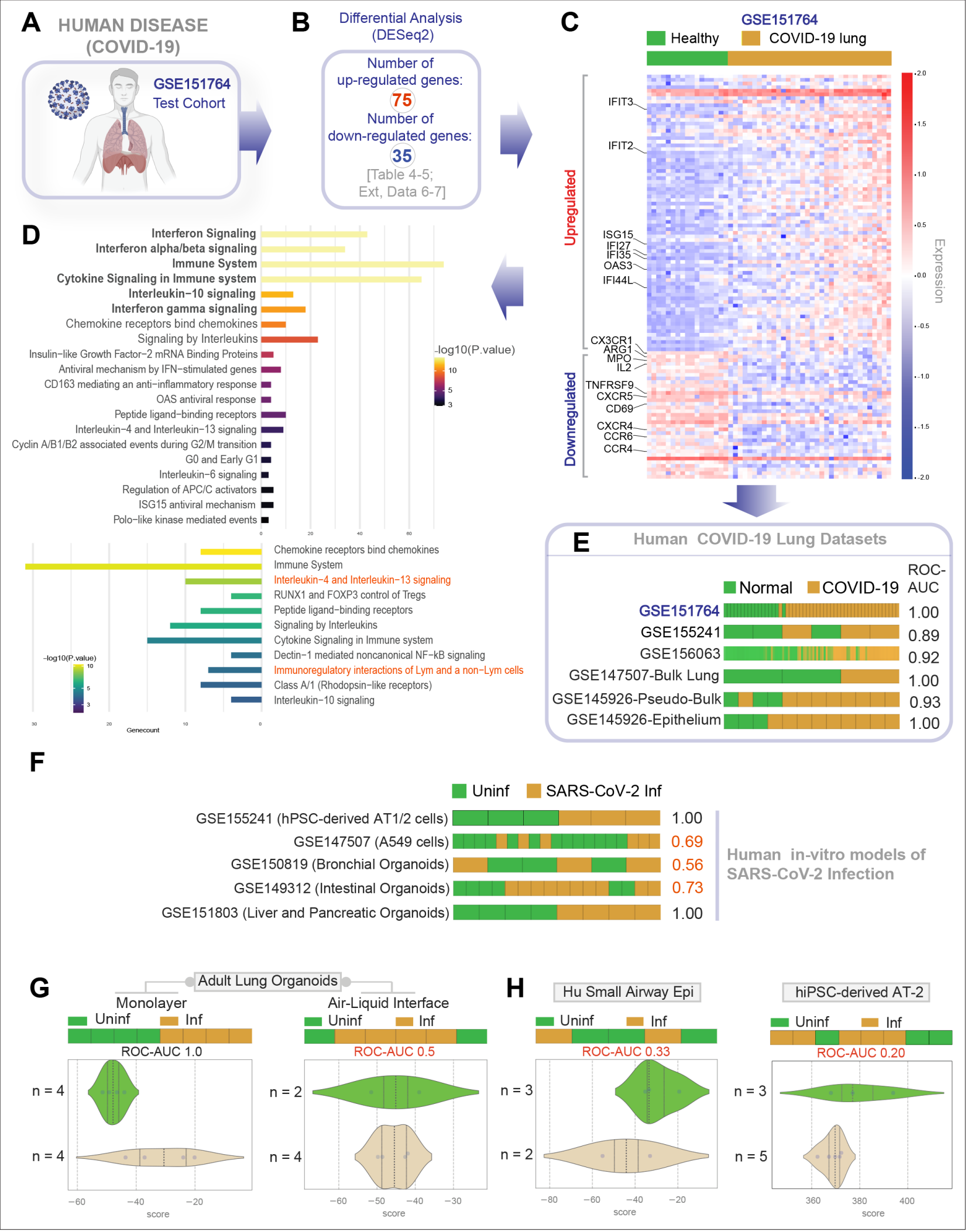

Figure 4. Gene expression patterns in the lungs of patients with COVID-19 (actual disease) are recapitulated in lung organoid monolayers infected with SARS-CoV-2 (disease model). (A-C) Publicly available RNA seq datasets (GSE151764) of lung autopsies from patients who were deceased due to COVID-19 or noninfectious causes (healthy normal control) were analyzed for differential expression of genes (B). The differentially expressed genes (DEGs) are displayed as a heatmap labeled with selected genes in (C). See also Figure 4-figure supplement 1 for the same heatmap with all genes Figure 4 continued on next page 
Figure 4 continued

labeled. (D) Reactome-pathway analysis shows the major pathways up- or downregulated in the COVID-19-afflicted lungs. See also Figure 4-figure supplement 2 for visualization as hierarchical ReacFoam. (E) Bar plots display the ability of the DEGs in the test cohort (GSE151764) to classify human COVID-19 respiratory samples from four other independent cohorts. (F) Bar plots display the ability of the DEGs in the test cohort (GSE151764) to classify published in vitro models for SARS-CoV-2 infection where RNA seq datasets were either generated in this work or publicly available. (G, H) Bar (top) and violin (bottom) plots compare the relative accuracy of disease modeling in four in vitro models used in the current work, as determined by the induction of COVID-19 lung signatures in each model. (G) Monolayer (left) and air-liquid interphase (ALI) models (right) prepared using adult lung organoids (ALOs). (H) Primary human small airway epithelium (left) and hiPSC-derived AT2 monolayers (right). Table 6 lists details regarding the patient cohorts/tissue or cell types represented in each transcriptomic dataset.

The online version of this article includes the following figure supplement(s) for figure 4:

Figure supplement 1. Differential expression analysis of RNA seq datasets from lung autopsies (normal vs. COVID-19).

Figure supplement 2. Reactome-pathway analysis of differentially expressed genes in lung autopsies (normal vs. COVID-19).

samples (ROC AUC ranging from 0.88 to 1.00; Figure 5F); the model-derived DEG signature was significantly induced in COVID-19 samples compared to normal controls (Figure 5G,H). Most importantly, the model-derived DEG signature was significantly induced in the epithelial cells recovered from bronchoalveolar lavage (Figure 5l).

Taken together, these cross-validation studies from disease to model (Figure 4) and vice versa (Figure 5) provide an objective assessment of the match between the host response in COVID-19 lungs and our submerged ALO monolayers. Such a match was not seen in the case of the other models, for example, the proximal airway-mimic ALI model, HSAEpC monolayer, or hiPSC-derived AT2 models. Because the submerged ALO monolayers contained both proximal airway epithelia (basal cells) and promoted AT2 $\rightarrow$ AT1 differentiation, findings demonstrate that mixed cellular monolayers can mimic the host response in COVID-19. A subtractive analysis revealed that the cell type that is shared between models that showed induction of host response signatures [i.e., ALO submerged monolayers and GSE155241 (Han et al., 2020a; Figure 5F)] but is absent in models that do not show such response (hu bronchial organoids, small airway epi, ALI-model of ALO) is AT1. We conclude that distal differentiation from AT2 $\rightarrow$ AT1, a complex process that comprises distinct intermediates (Choi et al., 2020), is essential for modeling the host immune response in COVID-19. Further experimental evidence is needed to directly confirm if and which intermediate states during the differentiation of AT2 to AT1 are essential for the immune response to COVID19.

\section{Both proximal and distal airway epithelia are required to mount the overzealous host response in COVID-19}

We next asked which model best simulated the overzealous host immune response that has been widely implicated in fatal COVID-19 (Lowery et al., 2021; Lucas et al., 2020; Schultze and Aschenbrenner, 2021). To this end, we relied upon a recently described artificial intelligence (Al)-guided definition of the nature of the overzealous response in fatal COVID-19 (Sahoo et al., 2021). Using ACE2 as a seed gene, a 166-gene signature was identified and validated as an invariant immune response that was shared among all respiratory viral pandemics, including COVID-19 (Figure 6A). A subset of 20 genes within the 166-gene signature was subsequently identified as a determinant of disease severity/fatality; these 20 genes represented translational arrest, senescence, and apoptosis. These two signatures, referred to as ViP (166-gene) and severe ViP (20-gene) signatures, were used as a computational framework to first vet existing SARS-CoV-2 infection models that have been commonly used for therapeutic screens (Figure 6B-D). Surprisingly, we found that each model fell short in one way or another. For example, the Vero E6, which is a commonly used cultured cell model, showed a completely opposite response; instead of being induced, both the 166-gene and 20-gene ViP signatures were suppressed in infected Vero E6 monolayers (Figure 6B). Similarly, neither ViP signature was induced in the case of SARS-CoV-2-challenged human bronchial organoids (Suzuki, 2020) (Figure 6C). Finally, in the case of the hiPSC-derived AT1/2 organoids, which recapitulated the COVID-19-lung derived immune signatures (in Figure 4F), the 166-gene ViP signature was induced significantly (Figure 6D, top), but the 20-gene severity signature was not (Figure 6D, bottom). These findings show that none of the existing models capture the overzealous host immune response that has been implicated in a fatality. 


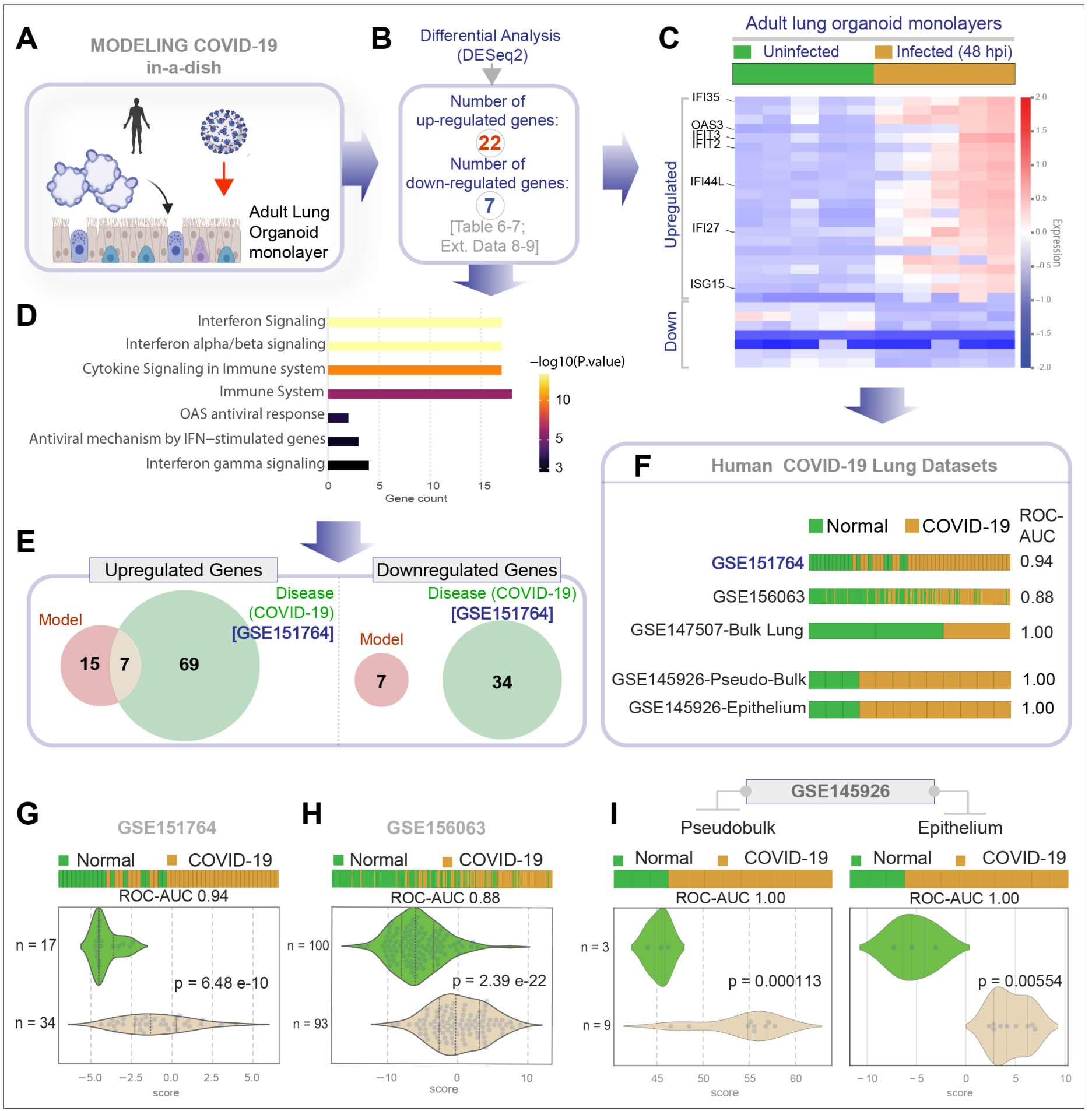

Figure 5. Genes and pathways induced in the SARS-CoV-2-infected lung organoid monolayers (disease model) are induced also in the lungs of COVID-19 patients (actual disease). (A-C) Adult lung organoid monolayers infected or not with SARS-CoV-2 were analyzed by RNA seq and differential expression analysis. Differentially expressed genes (DEGs; $\mathbf{B}$ ) are displayed as a heatmap in (C). While only selected genes are labeled in panel (C) (which represent overlapping DEGs between our organoid model and publicly available COVID-19 lung dataset, GSE151764), the same heatmap is presented in Figure 5-figure supplement 1 with all genes labeled. (D) Reactome-pathway analysis shows the major pathways upregulated in SARSCoV-2-infected lung organoid monolayers. See also Figure 5-figure supplement 2 for visualization as hierarchical ReacFoam. (E) A Venn diagram showing overlaps in DEGs between model (current work; B) and disease (COVID-19 lung dataset, GSE151764; Figure 4). (F) Bar plots display the ability of the DEGs in infected lung monolayers to classify human normal vs. COVID-19 respiratory samples from five independent cohorts. (G-I) Bar (top) and violin (bottom) plots compare the accuracy of disease modeling in three publicly available human lung datasets, as determined by the significant Figure 5 continued on next page 
Figure 5 continued

induction of the DEGs that were identified in the SARS-CoV-2-challenged monolayers. See also Table 6, which enlists details regarding the patient cohorts/tissue or cell types represented in each transcriptomic dataset.

The online version of this article includes the following figure supplement(s) for figure 5 :

Figure supplement 1. Differential expression analysis of RNA seq datasets from adult lung organoid monolayers, infected or not, with SARS-CoV-2.

Figure supplement 2. Reactome-pathway analysis of differentially expressed genes in lung organoid monolayers infected with SARS-CoV-2.

Figure supplement 3. Head-to-head comparison of our adult lung organoid (ALO)-derived model of COVID-19 versus another lung organoid model in their ability to recapitulate the differentially expressed genes (DEGs) observed in lung tissues from fatal cases of COVID-19.

Our lung models showed that both the 166- and 20-gene ViP signatures were induced significantly in the submerged ALO-derived monolayers that had distal differentiation (Figure 6E, left), but not in the proximal-mimic ALI model (Figure 6E, right). Neither signatures were induced in monolayers of small airway epithelial cells (Figure 6F) or hiPSC-derived AT2 cells (Figure 6G). Finally, we analyzed a recently published lung organoid model that supports robust SARS-CoV-2 infection; this model was generated using multipotent SOX2+ SOX9+ lung bud tip (LBT) progenitor cells that were isolated from the canalicular stage of human fetal lungs ( 16-17 weeks post-conception) (Lamers et al., 2021). Despite mixed cellularity (proximal and distal), this fetal lung organoid model failed to induce the ViP signatures (Sahoo et al., 2021) (Figure 6H). These findings indicate that despite having mixed cellular composition and the added advantage of being able to support robust viral replication (achieving $~ 5$ log-fold increase in titers), the model lacks the signature host response that is seen in all human samples of COVID-19.

Taken together with our infectivity analyses, these findings demonstrate that although the proximal airway epithelia and AT2 cells may be infected, and as described by others (Dye et al., 2015; Hou et al., 2020), may be vital for mounting a viral response and for disease transmission, these cells alone cannot mount the overzealous host immune response that is associated with the fatal disease. Similarly, even though the alveolar pneumocytes, AT1 and AT2 cells, are sufficient to mount the host immune response, in the absence of proximal airway components, they too are insufficient to recapitulate the severe ViP signature that is characterized by cellular senescence and apoptosis. However, when both proximal and distal components are present, that is, basal, ciliated, and AT1 cells, the model mimicked the overzealous host immune response in COVID-19 (Figure 6I).

\section{Discussion}

The most important discovery we report here is the creation of adult lung organoids that are complete with both proximal airway and distal alveolar epithelia; these organoids can not only be stably propagated and expanded in 3D cultures but also used as monolayers of mixed cellularity for modeling viral and host immune responses during respiratory viral pandemics. Furthermore, an objective analysis of this model and other existing SARS-CoV-2-infected lung models against patient-lung-derived transcriptomes showed that the model that most closely emulates the elements of viral infectivity, lung injury, and inflammation in COVID-19 is one that contained both proximal and distal alveolar signatures (Figure $6 \mathbf{H}$ ), whereas the presence of just one or the other fell short.

There are three important impacts of this work. First, the successful creation of adult human lung organoids that are complete with both proximal and distal signatures has not been accomplished before. Previous works show the successful use of airway basal cells for organoid creationtion, but ensuring the completeness of the model with all other lung cells has been challenging to create (Nikolić and Rawlins, 2017). The multicellularity of the lung has been a daunting challenge that many experts have tried to recreate in vitro; in fact, the demand for perfecting such a model has always remained high, not just in the current context of the COVID-19 pandemic but also with the potential of future pandemics. We have provided evidence that the organoids that were created using our methodology retain proximal and distal cellularity throughout multiple passages and even within the same organoid. Although a systematic design of experiment (DoE) approach (Bukys et al., 2020) was not involved in getting to this desirable goal, a rationalized approach was taken. For example, a Wnt/R-spondin/Noggin-containing conditioned media was used as a source of the so-called 'niche factors' for any organoid growth (Sato and Clevers, 2015). This was supplemented with recombinant 
Table 4. Upregulated genes and pathways: healthy vs COVID-19 lung (GSE151764).

Genes

\begin{tabular}{|c|c|c|c|c|}
\hline BRCA2 & XAGE1B & CDK1 & SNAI2 & CXCL11 \\
\hline CYBB & CCR5 & GBP1 & IFITM1 & IFI27 \\
\hline KRT5 & CCR2 & HLA-G & GZMB & IFI35 \\
\hline C1OB & ALOX15B & IDO1 & CD163 & TDO2 \\
\hline FCGR1A & CMKLR1 & ISG20 & CD38 & GZMA \\
\hline IL10 & MX1 & LAG3 & BST2 & OAS3 \\
\hline IL6 & TNFRSF17 & MAD2L1 & BUB1 & POU2AF1 \\
\hline CD44 & CCR1 & CXCL9 & CCL20 & CXCL13 \\
\hline CD276 & CXCR3 & MKI67 & CCNB2 & GNLY \\
\hline DMBT1 & SLAMF8 & IFIT2 & TNFSF18 & IFIT3 \\
\hline DDX58 & IL21 & IFIT1 & ISG15 & TOP2A \\
\hline TNFAIP8 & FOXM1 & CXCL10 & CDKN3 & LILRB1 \\
\hline LAMP3 & $\mathrm{IFIH} 1$ & IRF4 & C1OA & HERC6 \\
\hline KIAA0101 & $\mathrm{IFl6}$ & PSMB9 & OAS1 & TNFSF13B \\
\hline MELK & PDCD1LG2 & CCL18 & OAS2 & IFI44L \\
\hline Pathways & & & & STAT1 \\
\hline Name & $\mathrm{p}$-value & FDR & & \\
\hline Interferon signaling & $1.11 \mathrm{E}-16$ & 1.11E-14 & & \\
\hline Interferon alpha/beta signaling & $1.11 \mathrm{E}-16$ & 1.11E-14 & & \\
\hline Cytokine signaling in immune system & $1.11 \mathrm{E}-16$ & $1.11 \mathrm{E}-14$ & & \\
\hline Immune ssystem & $1.11 \mathrm{E}-16$ & $1.11 \mathrm{E}-14$ & & \\
\hline Interleukin-10 signaling & $9.85 \mathrm{E}-13$ & $7.88 \mathrm{E}-11$ & & \\
\hline Interferon gamma signaling & $9.26 \mathrm{E}-12$ & $6.11 \mathrm{E}-10$ & & \\
\hline Chemokine receptors bind chemokines & $1.08 \mathrm{E}-10$ & $6.17 \mathrm{E}-09$ & & \\
\hline Signaling by interleukins & $6.81 \mathrm{E}-09$ & $3.41 \mathrm{E}-07$ & & \\
\hline $\begin{array}{l}\text { Insulin-like growth factor-2 mRNA binding } \\
\text { proteins (IGF2BPs/IMPs/VICKZs) bind RNA }\end{array}$ & $1.27 \mathrm{E}-07$ & 0.000005581122619 & & \\
\hline $\begin{array}{l}\text { Antiviral mechanism by IFN-stimulated } \\
\text { genes }\end{array}$ & 0.000001933058349 & 0.00007732233398 & & \\
\hline $\begin{array}{l}\text { CD163 mediating an anti-inflammatory } \\
\text { response }\end{array}$ & 0.000007798676169 & 0.0002807523421 & & \\
\hline OAS antiviral response & 0.00001020870997 & 0.0003368874291 & & \\
\hline Peptide ligand-binding receptors & 0.00001714057687 & 0.0005142173062 & & \\
\hline Interleukin-4 and Interleukin-13 signaling & 0.0001014948661 & 0.002841856252 & & \\
\hline $\begin{array}{l}\text { Cyclin A/B1/B2-associated events during } \\
\text { G2/M transition }\end{array}$ & 0.0001887816465 & 0.00490832281 & & \\
\hline G0 and early G1 & 0.0003607121838 & 0.009017804596 & & \\
\hline Interleukin-6 signaling & 0.0004656678444 & 0.01071036042 & & \\
\hline ISG15 antiviral mechanism & 0.0008313991988 & 0.01745938317 & & \\
\hline $\begin{array}{l}\text { Regulation of APC/C activators between } \\
\text { G1/S and early anaphase }\end{array}$ & 0.0008313991988 & 0.01745938317 & & \\
\hline
\end{tabular}

Table 4 continued on next page 
Table 4 continued

\begin{tabular}{lll} 
Genes & & \\
\hline Polo-like kinase-mediated events & 0.001110506513 & 0.02221013026 \\
\hline $\begin{array}{lll}\text { APC/C-mediated degradation of cell cycle } \\
\text { proteins }\end{array}$ & 0.001308103581 & 0.02354586446 \\
\hline Regulation of mitotic cell cycle & 0.001308103581 & 0.02354586446 \\
\hline G2/M DNA replication checkpoint & 0.001750156332 & 0.02975265764 \\
\hline Class A/1 (rhodopsin-like receptors) & 0.002355063045 & 0.03537666782 \\
\hline Interleukin-6 family signaling & 0.002358444521 & 0.03537666782 \\
\hline TNFs bind their physiological receptors & 0.002358444521 & 0.03537666782
\end{tabular}

FGF7/10; FGF7 is known to help cell proliferation and differentiation and is required for normal branching morphogenesis (Padela et al., 2008), whereas FGF10 helps in cell maturation (Rabata et al., 2020) and in alveolar regeneration upon injury (Yuan et al., 2019). Together, they are likely to have directed the differentiation toward distal lung lineages (hence, the preservation of alveolar signatures). The presence of both distal alveolar and proximal ciliated cells was critical: proximal cells were required to recreate sustained viral infectivity, and the distal alveolar pneumocytes, in particular, the ability of AT2 cells to differentiate into AT1 pneumocytes was essential to recreate the host response. It is possible that the response is mediated by a distinct AT2-lineage population, that is, damageassociated transient progenitors (DATPs), which arise as intermediates during AT2 $\rightarrow$ AT1 differentiation upon injury-induced alveolar regeneration (Choi et al., 2020). Although somewhat unexpected, the role of AT1 pneumocytes in mounting innate immune responses has been documented before in the context of bacterial pneumonia (Yamamoto et al., 2012; Wong and Johnson, 2013). In work (Huang et al., 2020) that was published during the preparation of this article, authors used long-term ALI models of hiPSC-derived AT2 monolayers (in growth conditions that inhibit AT2 $\rightarrow$ AT1 differentiation, as we did here for our AT2 model) and showed that SARS-CoV-2 induces iAT2-intrinsic cytotoxicity and inflammatory response, but failed to induce type 1 interferon pathways (IFN $\alpha / \beta$ ). It is possible that prolonged culture of iAT2 pneumocytes gives rise to some DATPs but cannot robustly do so in the presence of inhibitors of AT1 differentiation. This (spatially segregated viral and host immune response) is a common theme across many lung infections (including bacterial pneumonia and other viral pandemics (Hou et al., 2020; Taubenberger and Morens, 2008; Weinheimer et al., 2012; Chan et al., 2013) and hence, this mixed cellularity model is appropriate for use in modeling diverse lung infections and respiratory pandemics to come.

Second, among all the established lung models so far, ours features four key properties that are desirable whenever disease models are being considered for their use in HTP modes for rapid screening of candidate therapeutics and vaccines: (i) reproducibility, propagability, and scalability; (ii) cost-effectiveness; (iii) personalization; and (iv) modularity, with the potential to add other immune and nonimmune cell types to our multicellular complex lung model. We showed that the protocol we have optimized supports isolation, expansion, and propagability at least up to 12-15 passages (at the time of submission of this work), with documented retention of proximal and distal airway components up to P8 (by RNA seq). We noted some variability of cell types between patient to patient, and between early and late passages of ALOs, which is probably because of the heterogeneity of organoids isolated from patient's lung specimens. Feasibility has also been established for scaling up and optimizing the conditions for them to be used in miniaturized 384-well infectivity assays. We also showed that the protocols for generating lung organoids could be reproduced in both genders, and regardless of the donor's smoking status, consistency in outcome and growth characteristics was observed across all isolation attempts. The ALOs are also cost-effective; the need for exclusive reliance on recombinant growth factors was replaced at least in part with conditioned media from a commonly used cell line (L-WRN/ ATCC CRL-2647 cells). Such media has a batch-to-batch stable cocktail of Wnt, R-Spondin, and Noggin, and has been shown to improve reproducibility in the context of Gl organoids in independent laboratories (VanDussen et al., 2019). By that token, our culture conditions may have also improved reproducibility. The major disadvantage, however, remains 
Table 5. Downregulated genes and pathways: healthy vs COVID-19 lung (GSE151764).

Genes

\begin{tabular}{|c|c|c|c|c|}
\hline CX3CR1 & JAML & KLRB1 & GRAP2 & CD226 \\
\hline ARG1 & CX3CR1 & LY9 & MMP9 & CD160 \\
\hline MPO & HLA-DQB2 & CCL17 & $\mathrm{RORC}$ & FOXP3 \\
\hline IL2 & TNFRSF9 & CCL22 & CCR4 & CRTAM \\
\hline BCL2 & CXCR5 & TCF7 & IRS1 & CCR6 \\
\hline CA4 & CD1C & CXCR4 & ITK & CEACAM8 \\
\hline IGF1R & CD69 & CD83 & KLRG1 & PTGS2 \\
\hline \multicolumn{5}{|c|}{ Pathways } \\
\hline \multicolumn{3}{|l|}{ Name } & p-value & FDR \\
\hline \multicolumn{3}{|c|}{ Chemokine receptors bind chemokines } & $2.85 E-11$ & 4.98E-09 \\
\hline \multicolumn{3}{|c|}{ Immune system } & $1.25 \mathrm{E}-10$ & 1.09E-08 \\
\hline \multicolumn{3}{|c|}{ Interleukin-4 and interleukin-13 signaling } & $2.82 \mathrm{E}-09$ & $1.64 \mathrm{E}-07$ \\
\hline \multicolumn{3}{|c|}{$\begin{array}{l}\text { RUNX1 and FOXP3 control the development of regulatory T } \\
\text { lymphocytes (Tregs) }\end{array}$} & 4.31E-07 & 0.00001853717999 \\
\hline \multicolumn{3}{|c|}{ Peptide ligand-binding receptors } & $6.71 \mathrm{E}-07$ & 0.00002348305743 \\
\hline \multicolumn{3}{|c|}{ Signaling by Interleukins } & 0.000001503658493 & 0.0000436060963 \\
\hline \multicolumn{3}{|c|}{ Cytokine signaling in Immune system } & 0.00002606505855 & 0.0006516264636 \\
\hline \multicolumn{3}{|c|}{ Dectin-1-mediated noncanonical NF-kB signaling } & 0.00008640543215 & 0.001814514075 \\
\hline \multicolumn{3}{|c|}{$\begin{array}{l}\text { Immunoregulatory interactions between a lymphoid and a non- } \\
\text { lymphoid cell }\end{array}$} & 0.0001083388675 & 0.002058438482 \\
\hline \multicolumn{3}{|c|}{ Class A/1 (rhodopsin-like receptors) } & 0.0001833048828 & 0.003116183008 \\
\hline \multicolumn{3}{|c|}{ Interleukin-10 signaling } & 0.0002366961934 & 0.0035504429 \\
\hline \multicolumn{3}{|c|}{ RUNX3 regulates immune response and cell migration } & 0.0005791814113 & 0.007747184934 \\
\hline \multicolumn{3}{|c|}{ Extra-nuclear estrogen signaling } & 0.0005959373026 & 0.007747184934 \\
\hline \multicolumn{3}{|c|}{$\begin{array}{l}\text { BH3-only proteins associate with and inactivate anti-apoptotic } \\
\text { BCL-2 members }\end{array}$} & 0.0006992547523 & 0.008391057028 \\
\hline \multicolumn{3}{|c|}{ CLEC7A (Dectin-1) signaling } & 0.0008228035145 & 0.00905083866 \\
\hline \multicolumn{3}{|c|}{ Generation of second messenger molecules } & 0.001171991908 & 0.01171991908 \\
\hline \multicolumn{3}{|c|}{ Innate immune system } & 0.001676404092 & 0.01572360367 \\
\hline \multicolumn{3}{|c|}{ GPCR ligand binding } & 0.001747067074 & 0.01572360367 \\
\hline \multicolumn{3}{|c|}{ Adaptive immune system } & 0.002059835991 & 0.01853852391 \\
\hline \multicolumn{3}{|c|}{$\begin{array}{l}\text { Estrogen-dependent nuclear events downstream of ESR- } \\
\text { membrane signaling }\end{array}$} & 0.00467005583 & 0.03736044664 \\
\hline \multicolumn{3}{|c|}{ C-type lectin receptors (CLRs) } & 0.00545804495 & 0.0436643596 \\
\hline \multicolumn{3}{|c|}{ Transcriptional regulation by RUNX3 } & 0.008124332599 & 0.05687032819 \\
\hline \multicolumn{3}{|c|}{ BMAL1:CLOCK, NPAS2 activates circadian gene expression } & 0.009518272709 & 0.06662790896 \\
\hline \multicolumn{3}{|c|}{ ESR-mediated signaling } & 0.01207376237 & 0.08451633662 \\
\hline \multicolumn{3}{|c|}{ Transcriptional regulation by RUNX1 } & 0.01288156371 & 0.08786708747 \\
\hline \multicolumn{3}{|c|}{ TCR signaling } & 0.01464451458 & 0.08786708747 \\
\hline
\end{tabular}


Table 6. The list of GSE numbers used in the figures.

\begin{tabular}{|c|c|c|c|}
\hline GSE\# & Cell type/tissue & References & Figure \\
\hline GSE132914 & Tissue from idiopathic pulmonary fibrosis subjects and donor controls & PMID:32991815 & Figure 1A \\
\hline GSE151764 & COVID-19 and normal lung tissue post-mortem & PMID:33033248 & $\begin{array}{l}\text { Figure } 4 A-E, \\
\text { Figure } 5 E-G\end{array}$ \\
\hline GSE155241 & hPSC lung organoids and colon organoids infected with SARS-CoV-2 & PMID:33116299 & $\begin{array}{l}\text { Figure } 4 E, F, \\
\text { Figure } 6 D\end{array}$ \\
\hline GSE156063 & Upper airway of COVID-19 patients and other acute respiratory illnesses & PMID:33203890 & $\begin{array}{l}\text { Figure } 4 E, \\
\text { Figure } 5 F, H\end{array}$ \\
\hline GSE147507 & A549 cells and bulk lung & PMID:32416070; PMID:33782412 & $\begin{array}{l}\text { Figure } 4 E, F \text {, } \\
\text { Figure } 5 F\end{array}$ \\
\hline GSE145926 & $\begin{array}{l}\text { Bronchoalveolar lavage fluid (BALF) immune cells from COVID-19 and healthy } \\
\text { subjects }\end{array}$ & PMID:32398875 & $\begin{array}{l}\text { Figure } 4 E_{,} \\
\text {Figure } 5 F_{,},\end{array}$ \\
\hline GSE150819 & Human bronchial organoids & $\begin{array}{l}\text { From commercially available } \\
\text { HBEpC }\end{array}$ & $\begin{array}{l}\text { Figure } 4 F \\
\text { Figure } 6 C\end{array}$ \\
\hline GSE149312 & Intestinal organoids infected with SARS-CoV or SARS-CoV-2 & PMID:32358202 & Figure 4F \\
\hline GSE151803 & hPSC-derived pancreatic and lung organoids infected with SARS-CoV-2 & No publication yet & Figure 4F \\
\hline GSE153940 & Vero E6 control or SARS-CoV-2-infected cells & PMID:32707573 & Figure 6B \\
\hline GSE153218 & $\begin{array}{l}\text { SARS-CoV-2-infected bronchoalveolar cells derived from organoids grown } \\
\text { using progenitor cells from human fetal lung but tip (LBT). }\end{array}$ & PMID:33283287 & Figure $6 \mathrm{H}$ \\
\hline
\end{tabular}

that the composition of the media is undefined. Because the model is propagable, repeated iPSCreprogramming (another expensive step) is also eliminated, further cutting costs compared to many other models. As for personalization, our model is derived from adult lung stem cells from deep lung biopsies; each organoid line was established from one patient. By avoiding iPSCs or expanded potential stem cells (EPSCs), this model not only captures genetics but also retains organ-specific epigenetic programming in the lung, and hence, potentially additional programming that may occur in disease (such as in the setting of chronic infection, injury, inflammation, somatic mutations, etc.). The ability to replicate donor phenotype and genotype in vitro allows for potential use as preclinical human models for phase ' 0 ' clinical trials. As for modularity, by showing that the $3 \mathrm{D}$ lung organoids could be used as polarized monolayers on transwells to allow infectious agents to access the apical surface (in this case, SARS-CoV-2), we demonstrate that the organoids have the potential to be reverse-engineered with additional components in a physiologically relevant spatially segregated manner: for example, immune and stromal cells can be placed in the lower chamber to model complex lung diseases that are yet to be modeled and have no cure (e.g., idiopathic pulmonary fibrosis, etc.).

Third, the value of the ALO models is further enhanced due to the availability of companion readouts/biomarkers (e.g., ViP signatures in the case of respiratory viral pandemics, or monitoring the $\mathrm{E}$ gene, or viral shedding, etc.) that can rapidly and objectively vet treatment efficacy based on set therapeutic goals. Of these readouts, the host response, as assessed by ViP signatures, is a key vantage point because an overzealous host response is what is known to cause fatality. Recently, a systematic review of the existing preclinical animal models revealed that most of the animal models of COVID-19 recapitulated mild patterns of human COVID-19; no severe illness associated with mortality was observed, suggesting a wide gap between COVID-19 in humans (Spagnolo et al., 2020) and animal models (Ehaideb et al., 2020). It is noteworthy that alternative models that effectively support viral replication, such as the proximal airway epithelium or iPSC-derived AT2 cells (analyzed in this work) or a fetal lung bud tip-derived organoid model recently described by others (Lamers et al., 2021), do not recapitulate the host response in COVID-19. The lung model we present here is distinct from all currently available other models (see Table 1) because of the confirmed presence of both proximal and distal airway cell types over successive passages, which is yet to be accomplished for adult lung organoid models. Another distinguishing feature of our model is the way we rigorously validated its usefulness in modeling COVID-19 via computational approaches. We confirmed, based on the gene expression changes upon SARS-CoV-2-challenge, that our model most closely recapitulates the 
Table 7. Upregulated genes and pathways: uninfected vs infected (48 hpi) lung organoid monolayers.

\begin{tabular}{|c|c|c|c|c|}
\hline \multicolumn{5}{|l|}{ Genes } \\
\hline IFI35 & EPSTI1 & AMIGO2 & \multicolumn{2}{|l|}{ IFITM2 } \\
\hline SLC4A11 & CMPK2 & WARS1 & \multicolumn{2}{|l|}{ FAAP100 } \\
\hline APOL1 & OASL & IFI27 & \multicolumn{2}{|l|}{ ISG15 } \\
\hline OAS3 & IFI44L & CD14 & \multicolumn{2}{|l|}{ SLC35F6 } \\
\hline IFIT3 & IFI44 & \multicolumn{3}{|l|}{ SAMD9L } \\
\hline IFIT2 & PARP9 & \multicolumn{3}{|l|}{ SRP9P1 } \\
\hline \multicolumn{5}{|l|}{ Pathways } \\
\hline \multicolumn{3}{|l|}{ Name } & p-value & FDR \\
\hline \multicolumn{3}{|c|}{ Interferon signaling } & $1.11 \mathrm{E}-16$ & $4.22 \mathrm{E}-15$ \\
\hline \multicolumn{3}{|c|}{ Interferon alpha/beta signaling } & $1.11 \mathrm{E}-16$ & $4.22 \mathrm{E}-15$ \\
\hline \multicolumn{3}{|c|}{ Cytokine signaling in Immune system } & 1.15E-10 & 2.89E-09 \\
\hline \multicolumn{3}{|c|}{ Immune system } & 0.000002540114879 & 0.00004826218271 \\
\hline \multicolumn{3}{|c|}{ OAS antiviral response } & 0.0004764545663 & 0.007146818495 \\
\hline \multicolumn{3}{|c|}{ Antiviral mechanism by IFN-stimulated genes } & 0.001033347261 & 0.01240016713 \\
\hline \multicolumn{3}{|c|}{ Interferon gamma signaling } & 0.001889694619 & 0.02078664081 \\
\hline \multicolumn{3}{|c|}{ Transfer of LPS from LBP carrier to CD14 } & 0.006318772245 & 0.05686895021 \\
\hline \multicolumn{3}{|c|}{ TRIF-mediated programmed cell death } & 0.02091267586 & 0.1656073329 \\
\hline \multicolumn{3}{|c|}{ MyD88 deficiency (TLR2/4) } & 0.03733748271 & 0.1656073329 \\
\hline \multicolumn{4}{|c|}{ IRAK2-mediated activation of TAK1 complex upon TLR7/8 or 9 stimulation 0.03733748271} & 0.1656073329 \\
\hline \multicolumn{3}{|c|}{ TRAF6-mediated induction of TAK1 complex within TLR4 complex } & 0.03937173812 & 0.1656073329 \\
\hline \multicolumn{3}{|c|}{ IRAK4 deficiency (TLR2/4) } & 0.03937173812 & 0.1656073329 \\
\hline \multicolumn{3}{|c|}{ Activation of IRF3/IRF7 mediated by TBK1/IKK epsilon } & 0.04140183322 & 0.1656073329 \\
\hline \multicolumn{3}{|c|}{ Caspase activation via death receptors in the presence of ligand } & 0.04140183322 & 0.1656073329 \\
\hline \multicolumn{3}{|c|}{ IKK complex recruitment mediated by RIP1 } & 0.04948077476 & 0.1855013265 \\
\hline
\end{tabular}

human disease, that is, COVID-19. Analyses also pinpointed the importance of two factors that were

Table 8. Downregulated genes and pathways: uninfected vs. infected (48 hpi) lung organoid monolayers.

\begin{tabular}{|c|c|c|c|}
\hline AC093392.1 & ARHGAP19 & HLA-V & RN7SL718P \\
\hline MT-TV & AC138969.3 & AC016766.1 & \\
\hline \multicolumn{4}{|l|}{ Pathways } \\
\hline Name & p-value & FDR & \\
\hline rRNA processing in the mitochondrion & 0.01892731246 & 0.08366120773 & \\
\hline tRNA processing in the mitochondrion & 0.02127149105 & 0.08366120773 & \\
\hline Mitochondrial translation termination & 0.04399155446 & 0.08366120773 & \\
\hline Mitochondrial translation elongation & 0.04399155446 & 0.08366120773 & \\
\hline Mitochondrial translation initiation & 0.04490921762 & 0.08366120773 & \\
\hline Mitochondrial translation & 0.04765767844 & 0.08366120773 & \\
\hline
\end{tabular}




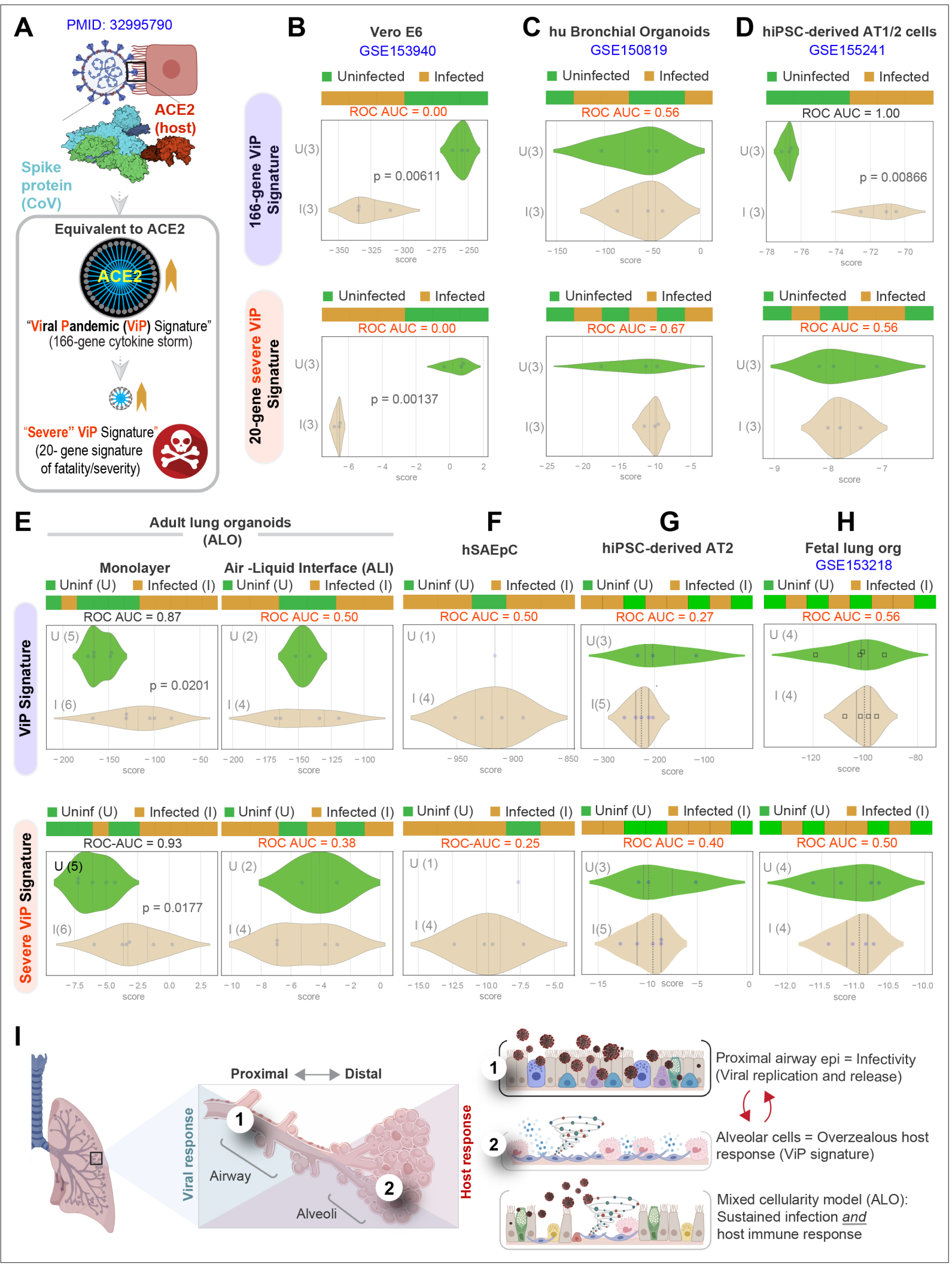

Figure 6. Both proximal and distal airway components are required to model the overzealous host response in COVID-19. (A) Schematic summarizing the immune signatures identified based on ACE2-equivalent gene induction observed invariably in any respiratory viral pandemic. The 166-gene ViP signature captures the cytokine storm in COVID-19, whereas the 20-gene subset severe ViP signature is indicative of disease severity/fatality. (B-D) Publicly available RNA seq datasets from commonly used lung models, Vero E6 (B), human bronchial organoids (C), and hPSC-derived AT1/2 cellFigure 6 continued on next page 
Figure 6 continued

predominant lung organoids are classified using the 166-gene ViP signature (top row) and 20-gene severity signature (bottom row). (E-G) RNA seq datasets generated in this work using either human small airway epithelial cells (E), adult lung organoids as submerged or air-liquid interphase (ALI) models (left and right, respectively, in F) and hiPSC-derived AT2 cells (G) were analyzed and visualized as in (B-D). (H) Publicly available RNA seq datasets from fetal lung organoid monolayers (Lamers et al., 2021) infected or not with SARS-CoV-2 were analyzed as in (B-D) for the ability of ViP signatures to classify infected (I) from uninfected (U) samples. Receiver operating characteristics area under the curve (ROC AUC) in all figure panels indicate the performance of a classification model using the ViP signatures. (I) Summary of findings in this work, its relationship to the observed clinical phases in COVID-19, and key aspects of modeling the same. Table 6 lists details regarding the patient cohorts/tissue or cell types represented in each transcriptomic dataset.

Key resources table

critical in modeling COVID-19: (i) adult source and (ii) model completeness, with both proximal and distal airway cells. We conclude that the model revealed here, in conjunction with the ViP signatures described earlier (Sahoo et al., 2021), could serve as a preclinical model with companion diagnostics to identify drugs that target both the viral and host response in pandemics.

\section{Limitations of the study}

Our adult stem-cell-derived lung organoids, complete with all epithelial cell types, can model COVID19 , but remains a simplified/rudimentary version compared to the adult human organ. While we successfully demonstrated the proximo-distal mixed cellular composition of the ALOs using four different approaches (flow cytometry, RNA seq, confocal immunofluorescence, and targeted qPCR) and showed that such mixed cellularity is preserved during prolonged culture, the exact cellular proportion was not assessed here. Single-cell sequencing and multiplexed profiling by flow cytometry are some of the approaches that can provide such in-depth characterization to assess cellular composition at baseline and track how such composition changes upon infection and injury. For instance, although the epithelial contributions to the host response are important, they alone cannot account for the response of the immune cells and the nonimmune stromal cells, and their crosstalk with the epithelium. Given that epithelial inflammation and damage is propagated by vicious forward-feedback loops of multicellular crosstalk, it is entirely possible that the epithelial signatures induced in infected ALO-derived monolayers are also only a fraction of the actual epithelial response mounted in vivo. Regardless of the missing components, what appears to be the case is that we already have a model that recapitulates approximately a quarter to half of the genes that are induced across diverse COVID-19-infected patient samples. This model can be further improved by the simultaneous addition of endothelial cells and immune cells to better understand the pathophysiological basis for DAD, microangiopathy, and even organizing fibrosis with loss of lung capacity that has been observed in many patients (Spagnolo et al., 2020); these insights should be valuable to fight some of the long-term sequelae of COVID-19. Future work with flow cytometry and cell sorting of our lung organoids would help us understand each cell type's role in viral pathogenesis. Larger living biobanks of genotyped and phenotyped ALOs, representing donors of different age, ethnicity, predisposing conditions, and coexisting comorbidities, will advance our understanding of why SARS-CoV-2 and possibly other infectious agents may trigger different disease course in different hosts. Although we provide proof-of-concept studies in low-throughput mode demonstrating the usefulness of the ALOs as human preclinical models for screening therapeutics in phase ' 0 ' trials, optimization for the same to be adapted in HTP mode was not attempted here.

\section{Materials and methods}

\begin{tabular}{lllll}
$\begin{array}{l}\text { Reagent type } \\
\text { (species) or resource }\end{array}$ & Designation & Source or reference & Identifiers & Additional information \\
\hline \multirow{2}{*}{ Antibody } & $\begin{array}{l}\text { Anti-ACE2 (mouse } \\
\text { monoclonal) }\end{array}$ & Santa Cruz & $\begin{array}{l}\text { Cat\# sc390851 } \\
\text { RRID::AB_2861379 }\end{array}$ & IF (1:100) \\
\hline Antibody & $\begin{array}{l}\text { Anti-human ACE2 (rat } \\
\text { monoclonal) }\end{array}$ & BioLegend & $\begin{array}{l}\text { Cat\# 375802 } \\
\text { RRID::AB_2860959 }\end{array}$ & IF (1:50) \\
\hline
\end{tabular}

Continued on next page 
Continued

\begin{tabular}{|c|c|c|c|c|}
\hline $\begin{array}{l}\text { Reagent type } \\
\text { (species) or resource }\end{array}$ & Designation & Source or reference & Identifiers & Additional information \\
\hline Antibody & $\begin{array}{l}\text { Anti-acetylated a tubulin } \\
\text { (mouse monoclonal) }\end{array}$ & Santa Cruz & $\begin{array}{l}\text { Cat\# sc23950 } \\
\text { RRID::AB_628409 }\end{array}$ & $\begin{array}{l}\text { IF }(1: 500) \\
\text { FC }(1: 8000)\end{array}$ \\
\hline Antibody & $\begin{array}{l}\text { Anti-AQP5 (mouse } \\
\text { monoclonal) }\end{array}$ & Santa Cruz & $\begin{array}{l}\text { Cat\# sc514022 } \\
\text { RRID::AB_2891066 }\end{array}$ & $\begin{array}{l}\text { IF }(1: 100) \\
\text { FC }(1: 800)\end{array}$ \\
\hline Antibody & $\begin{array}{l}\text { Anti-CC10 (mouse } \\
\text { monoclonal) }\end{array}$ & Santa Cruz & $\begin{array}{l}\text { Cat\# sc365992 } \\
\text { RRID::AB_10915481 }\end{array}$ & IF $(1: 100)$ \\
\hline Other & DAPI & Invitrogen & $\begin{array}{l}\text { Cat\# D1306 } \\
\text { RRID::AB_2629482 }\end{array}$ & IF $(1: 500)$ \\
\hline Antibody & $\begin{array}{l}\text { Recombinant anti- } \\
\text { cytokeratin } 5 \text { (rabbit } \\
\text { monoclonal) }\end{array}$ & Abcam & $\begin{array}{l}\text { Cat\# ab52635 } \\
\text { RRID::AB_869890 }\end{array}$ & $\begin{array}{l}\text { IF }(1: 100) \\
\text { FC }(1: 8000)\end{array}$ \\
\hline Antibody & $\begin{array}{l}\text { Recombinant anti-mucin } \\
5 \mathrm{AC} \text { (rabbit monoclonal) }\end{array}$ & Abcam & $\begin{array}{l}\text { Cat\# ab229451 } \\
\text { RRID::AB_2891067 }\end{array}$ & $\begin{array}{l}\text { IF }(1: 150) \\
\text { FC }(1: 800)\end{array}$ \\
\hline Antibody & $\begin{array}{l}\text { Anti-sodium potassium } \\
\text { ATPase (rabbit monoclonal) }\end{array}$ & Abcam & $\begin{array}{l}\text { Cat\# ab76020 } \\
\text { RRID::AB_1310695 }\end{array}$ & IF $(1: 400)$ \\
\hline Antibody & $\begin{array}{l}\text { Anti-occludin (mouse } \\
\text { monoclonal) }\end{array}$ & Thermo Fisher & $\begin{array}{l}\text { Cat\# OC-3F10 } \\
\text { RRID::AB_2533101 }\end{array}$ & IF $(1: 500)$ \\
\hline Other & Phalloidin, Alexa Fluor 594 & Invitrogen & $\begin{array}{l}\text { Cat\# } \\
\text { A12381RRID:AB_2315633 }\end{array}$ & IF $(1: 500)$ \\
\hline Other & Propidium iodide & Invitrogen & V13241 & FC $(1: 100)$ \\
\hline Antibody & $\begin{array}{l}\text { SARS-CoV/SARS-CoV-2 } \\
\text { nucleocapsid antibody } \\
\text { (mouse monoclonal) }\end{array}$ & Sino Biological & $\begin{array}{l}\text { Cat\# 40143-MM05 } \\
\text { RRID::AB_2827977 }\end{array}$ & $\begin{array}{l}\text { IF }(1: 250) \\
\text { IHC }(1: 500)\end{array}$ \\
\hline Antibody & $\begin{array}{l}\text { Anti-SARS spike } \\
\text { glycoprotein (mouse } \\
\text { monoclonal) }\end{array}$ & Abcam & $\begin{array}{l}\text { Cat\# ab273433 } \\
\text { RRID::AB_2891068 }\end{array}$ & IHC (1:250) \\
\hline Antibody & $\begin{array}{l}\text { anti-SP-B (mouse } \\
\text { monoclonal) }\end{array}$ & Santa Cruz & $\begin{array}{l}\text { Cat\# sc133143 } \\
\text { RRID::AB_2285686 }\end{array}$ & $\begin{array}{l}\text { IF }(1: 100) \\
\text { FC }(1: 8000)\end{array}$ \\
\hline Antibody & $\begin{array}{l}\text { Anti-prosurfactant protein } \\
\text { C (rabbit polyclonal) }\end{array}$ & Abcam & $\begin{array}{l}\text { Cat\# ab90716 } \\
\text { RRID::AB_10674024 }\end{array}$ & IF $(1: 150)$ \\
\hline Antibody & $\begin{array}{l}\text { Goat anti-rat lgG H\&L } \\
\text { secondary antibody, Alexa } \\
\text { Flour } 594\end{array}$ & Invitrogen & $\begin{array}{l}\text { Cat\# A-11007 } \\
\text { RRID:AB_10561522 }\end{array}$ & IF (1:500) \\
\hline Antibody & $\begin{array}{l}\text { Goat anti-rabbit lgG H\&L } \\
\text { secondary antibody, Alexa } \\
\text { Fluor } 594\end{array}$ & Invitrogen & $\begin{array}{l}\text { Cat\# A-11012 } \\
\text { RRID:AB_2534079 }\end{array}$ & IF $(1: 500)$ \\
\hline Antibody & $\begin{array}{l}\text { Goat anti-mouse IgG H\&L } \\
\text { secondary antibody, Alexa } \\
\text { Fluor } 488\end{array}$ & Invitrogen & $\begin{array}{l}\text { Cat\# A-11011 } \\
\text { RRID:AB_143157 }\end{array}$ & $\begin{array}{l}\text { IF }(1: 500) \\
\text { FC }(1: 1000)\end{array}$ \\
\hline Antibody & $\begin{array}{l}\text { Goat anti-rabbit lgG H\&L } \\
\text { secondary antibody, Alexa } \\
\text { Fluor } 488\end{array}$ & Abcam & $\begin{array}{l}\text { Cat\# ab150077 } \\
\text { RRID:AB_2630356 }\end{array}$ & FC $(1: 1000)$ \\
\hline Other & $\begin{array}{l}\text { Countess II Automated Cell } \\
\text { Counter }\end{array}$ & $\begin{array}{l}\text { Thermo Fisher } \\
\text { Scientific }\end{array}$ & AMQAX1000 & $\begin{array}{l}\text { Section'The preparation of lung organoid- } \\
\text { derived monolayers' }\end{array}$ \\
\hline Other & $\begin{array}{l}\text { Epithelial Volt-Ohm (TEER) } \\
\text { Meter }\end{array}$ & Millipore & MERS00002 & $\begin{array}{l}\text { Section 'Permeability of lung monolayer using } \\
\text { FITC-dextran' }\end{array}$ \\
\hline Other & Leica TCS SPE Confocal & Leica Microsystems & TCS SPE & Section'Immunofluorescence' \\
\hline Other & Power Pressure Cooker XL & Tristar Products & & Section'Immunohistochemistry' \\
\hline Other & Canon Rebel XS DLSR & Canon & & Figure 2-figure supplement 1 \\
\hline
\end{tabular}

Continued on next page 
Continued

\begin{tabular}{|c|c|c|c|c|}
\hline $\begin{array}{l}\text { Reagent type } \\
\text { (species) or resource }\end{array}$ & Designation & Source or reference & Identifiers & Additional information \\
\hline Other & $\begin{array}{l}\text { MiniAmp Plus Thermal } \\
\text { Cycler }\end{array}$ & Applied Biosystems & Cat\# A37835 & Section'Quantitative (q)RT-PCR' \\
\hline Other & QuantStudio5 & Applied Biosystems & $\begin{array}{l}\text { Cat\# A28140 } \\
\text { RRID:SCR_020240 }\end{array}$ & Section'Quantitative (q)RT-PCR' \\
\hline Other & $\begin{array}{l}\text { Light Microscope } \\
\text { (brightfield images) }\end{array}$ & Carl Zeiss LLC & $\begin{array}{l}\text { Axio Observer, Inverted; } \\
491917-0001-000\end{array}$ & Figure 2-figure supplement 1 \\
\hline Other & $\begin{array}{l}\text { Spark } 20 \text { M Multimode } \\
\text { Microplate Reader }\end{array}$ & Tecan & & $\begin{array}{l}\text { Section'Permeability of lung monolayer using } \\
\text { FITC-dextran' }\end{array}$ \\
\hline Other & $\begin{array}{l}\text { Guava easyCyte Benchtop } \\
\text { Flow Cytometer }\end{array}$ & Millipore & Guava easyCyte 62L & $\begin{array}{l}\text { Section'The characterization of lung cell types } \\
\text { using flow cytometry' }\end{array}$ \\
\hline Software, algorithm & ImageJ & ImageJ & RRID:SCR_003070 & \\
\hline Software, algorithm & GraphPad Prism & GraphPad Prism & RRID:SCR_002798 & \\
\hline Software, algorithm & LAS AF Software & LAS AF Software & & \\
\hline Software, algorithm & $\begin{array}{l}\text { QuantStudio Design \& } \\
\text { Analysis Software }\end{array}$ & $\begin{array}{l}\text { QuantStudio Design } \\
\text { \& Analysis Software }\end{array}$ & & \\
\hline Software, algorithm & CIBERSORTx & CIBERSORTx & & \\
\hline Software, algorithm & FlowJo & $\begin{array}{l}\text { FlowJo V10, BD } \\
\text { BioSciences }\end{array}$ & RRID:SCR_008520 & \\
\hline $\begin{array}{l}\text { Chemical compound, } \\
\text { drug }\end{array}$ & Zinc formalin & Fisher Scientific & Cat\# 23-313096 & \\
\hline $\begin{array}{l}\text { Chemical compound, } \\
\text { drug }\end{array}$ & Xylene & WWR & Cat\# XX0060-4 & \\
\hline $\begin{array}{l}\text { Chemical compound, } \\
\text { drug }\end{array}$ & Hematoxylin & Sigma-Aldrich Inc & Cat\# MHS1 & \\
\hline $\begin{array}{l}\text { Chemical compound, } \\
\text { drug }\end{array}$ & Ethanol & Koptec & Cat\# UN1170 & \\
\hline $\begin{array}{l}\text { Chemical compound, } \\
\text { drug }\end{array}$ & Sodium citrate & Sigma-Aldrich & Cat\# W302600 & \\
\hline $\begin{array}{l}\text { Chemical compound, } \\
\text { drug }\end{array}$ & $\operatorname{DAB}(10 \times)$ & Thermo Fisher & Cat\# 1855920 & $(1: 10)$ \\
\hline $\begin{array}{l}\text { Chemical compound, } \\
\text { drug }\end{array}$ & $\begin{array}{l}\text { Stable peroxidase substrate } \\
\text { buffer }(10 \times)\end{array}$ & Thermo Fisher & Cat\# 34062 & $(1: 10)$ \\
\hline $\begin{array}{l}\text { Chemical compound, } \\
\text { drug }\end{array}$ & $3 \%$ hydrogen peroxide & Target & Cat\# 245-07-3628 & \\
\hline $\begin{array}{l}\text { Chemical compound, } \\
\text { drug }\end{array}$ & Horse serum & Vector Labs & Cat\# 30022 & \\
\hline $\begin{array}{l}\text { Commercial assay } \\
\text { or kit }\end{array}$ & $\begin{array}{l}\text { HRP Horse Anti-Rabbit lgG } \\
\text { Polymer Detection Kit }\end{array}$ & Vector Laboratories & Cat\# MP-7401 & \\
\hline $\begin{array}{l}\text { Chemical compound, } \\
\text { drug }\end{array}$ & $\begin{array}{l}\text { Paraformaldehyde 16\% } \\
\text { Solution, EM Grade }\end{array}$ & $\begin{array}{l}\text { Electron Microscopy } \\
\text { Sciences }\end{array}$ & Cat\# 15710 & \\
\hline $\begin{array}{l}\text { Chemical compound, } \\
\text { drug }\end{array}$ & $100 \%$ methanol & Supelco & Cat\# MX0485 & \\
\hline $\begin{array}{l}\text { Chemical compound, } \\
\text { drug }\end{array}$ & Glycine & Fisher Scientific & Cat\# BP381-5 & \\
\hline $\begin{array}{l}\text { Chemical compound, } \\
\text { drug }\end{array}$ & Bovine serum albumin & Sigma-Aldrich & Cat\# A9647-100G & \\
\hline
\end{tabular}

Continued on next page 
Continued

Reagent type

(species) or resource Designation

Source or reference Identifiers

Additional information

Chemical compound,

drug

drug

drug

Triton-X 100

Sigma-Aldrich

Cat\# X100-500ML

Chemical compound, Gill Modified Hematoxylin

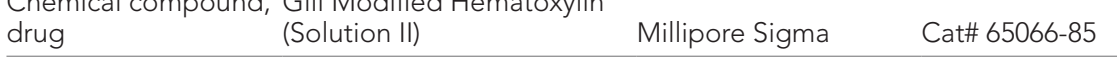

Chemical compound,

drug HistoGel Thermo Scientific Cat\# HG4000012

Chemical compound,

drug TrypLE Select Thermo Scientific Cat\# 12563-011

Chemical compound

drug Advanced DMEM/F-12 Thermo Scientific Cat\# 12634-010

Chemical compound

drug HEPES buffer Life Technologies Cat\# 15630080

Chemical compound,

drug Glutamax Thermo Scientific Cat\# 35050-061

Chemical compound,
drug Penicillin-streptomycin Thermo Scientific Cat\# 15140-122

Chemical compound,

drug Collagenase type I Thermo Scientific Cat\# 17100-017

Chemical compound,

$\begin{array}{lll}\text { drug } & \text { Corning } & \text { Cat\# } 354234\end{array}$

Chemical compound,

drug Chemical compound,

Chemical compound,

drug Nigma-Aldrich Cact\# A9165

Chemical compound,

drug Nicotinamide Sigma-Aldrich $\quad$ Cat\# N0636

Chemical compound,

drug

Chemical compound,

drug

Chemical compound,

drug

Chemical compound,

drug SB202190 Sigma-Aldrich Cat\# S7067-25MG

Chemical compound,

drug R\&D Systems Cat\# 1254/50

Chemical compound,

drug DPBS Thermo Scientific Cat\# 14190-144

Chemical compound,

drug Ultrapure Water Invitrogen Cat\# 10977-015

Chemical compound,

drug

Chemical compound,

drug

GF-7 (KGF)

PeproTech

Cat\# 100-19-50ug

FF10 PeproTech Cat\# 100-26-50ug

Bio-Techne Sales
Corp.

Continued on next page 
Continued

Reagent type

(species) or resource Designation

Source or reference Identifiers

Additional information

Chemical compound,

\begin{tabular}{llll} 
drug & Heparin & Sigma-Aldrich & Cat\# H3149 \\
Other & $\begin{array}{l}\text { PneumaCult Ex-Plus } \\
\text { Medium }\end{array}$ & $\begin{array}{l}\text { STEMCELL } \\
\text { Technologies }\end{array}$ & Cat\# 5040 \\
\hline & PneumaCult ALI Medium & $\begin{array}{l}\text { STEMCELL } \\
\text { Other }\end{array}$ & Technologies
\end{tabular}

Chemical compound,

drug Goat serum Vector Laboratories Cat\# MP-7401

Chemical compound,

drug Fetal bovine serum

Chemical compound, Animal Component-Free

drug Cell Dissociation Kit $\quad$ Technologies Cat\# 5426

Chemical compound,

drug Red Blood Cell Lysis Buffer Invitrogen

Cat\# 00-4333-57

Chemical compound,

drug Cell Recovery Solution Corning Cat\# 354253

Chemical compound,

drug Sodium azide Fisher Scientific Cat\# S227l-100

Chemical compound, Cyto-Fast Fix/Perm Buffer

$\begin{array}{llll}\text { drug } & \text { Set } & \text { BioLegend } & 26803\end{array}$

Chemical compound,

drug FITC-dextran Sigma-Aldrich Cat\# FD10S

Commercial assay

or kit

Quick-RNA MicroPrep Kit Zymo Research Cat\# R1051

Commercial assay

or kit Quick-RNA MiniPrep Kit Zymo Research Cat\#R1054

Chemical compound,

drug Ethyl alcohol, pure Sigma-Aldrich Cat\# E7023

Chemical compound,

\begin{tabular}{|c|c|c|c|c|}
\hline drug & TRI Reagent & Zymo Research & Cat\# R2050-1-200 & \\
\hline $\begin{array}{l}\text { Sequence-based } \\
\text { reagent }\end{array}$ & $\begin{array}{l}\text { 2x SYBR Green qPCR } \\
\text { Master Mix }\end{array}$ & Bimake & Cat\# B21203 & \\
\hline $\begin{array}{l}\text { Sequence-based } \\
\text { reagent }\end{array}$ & qScript cDNA SuperMix & Quanta Biosciences & Cat\# 95048 & \\
\hline $\begin{array}{l}\text { Sequence-based } \\
\text { reagent }\end{array}$ & $\begin{array}{l}\text { Applied Biosystems } \\
\text { TaqMan Fast Advanced } \\
\text { Master Mix }\end{array}$ & Thermo Scientific & Cat\# 4444557 & \\
\hline $\begin{array}{l}\text { Sequence-based } \\
\text { reagent }\end{array}$ & 18S , Hs99999901_s1 & Thermo Scientific & Cat\# 4331182 & \\
\hline $\begin{array}{l}\text { Sequence-based } \\
\text { reagent }\end{array}$ & $\begin{array}{l}\text { E_Sarbeco_F1 Forward } \\
\text { Primer }\end{array}$ & IDT & Cat\# 10006888 & \\
\hline $\begin{array}{l}\text { Sequence-based } \\
\text { reagent }\end{array}$ & $\begin{array}{l}\text { E_Sarbeco_R2 Reverse } \\
\text { Primer }\end{array}$ & IDT & Cat\# 10006890 & \\
\hline $\begin{array}{l}\text { Sequence-based } \\
\text { reagent }\end{array}$ & E_Sarbeco_P1 Probe & IDT & Cat\# 10006892 & \\
\hline Other & 12-well Tissue Culture Plate & CytoOne & Cat\# CC7682-7512 & $\begin{array}{l}\text { Section'Isolation and culture of human whole } \\
\text { lung-derived organoids' }\end{array}$ \\
\hline Other & $\begin{array}{l}\text { Transwell Inserts ( } 6.5 \mathrm{~mm} \text {, } \\
0.4 \mu \mathrm{m} \text { pore size) }\end{array}$ & Corning & Cat\# 3470 & $\begin{array}{l}\text { Section'The preparation of lung organoid- } \\
\text { derived monolayers' }\end{array}$ \\
\hline
\end{tabular}

Continued on next page 
Continued

Reagent type

(species) or resource Designation

Source or reference Identifiers

Additional information

\begin{tabular}{|c|c|c|c|c|}
\hline Other & $\begin{array}{l}\text { Microscope Cover Glass (\#1 } \\
\text { Thickness) } 24 \times 50 \mathrm{~mm}\end{array}$ & WWR & Cat\# 16004-098 & Section'Immunofluorescence' \\
\hline Other & $\begin{array}{l}\text { Microscope Cover Glass (\#1 } \\
\text { Thickness) } 25 \text { mm diameter }\end{array}$ & $\begin{array}{l}\text { Chemglass Life } \\
\text { Sciences }\end{array}$ & Cat\# CLS-1760-025 & Section'Immunofluorescence' \\
\hline Other & $\begin{array}{l}\text { Millicell EZ Slide 8-Well } \\
\text { Chamber }\end{array}$ & Millipore Sigma & Cat\# PEZGS0816 & Section'Immunofluorescence' \\
\hline Other & Trypan Blue Stain & Invitrogen & Cat\# T10282 & $(1: 2)$ \\
\hline Other & $70 \mu \mathrm{m}$ Cell Strainer & $\begin{array}{l}\text { Thermo Fisher } \\
\text { Scientific }\end{array}$ & Cat\# 22-363-548 & $\begin{array}{l}\text { Section'The preparation of lung organoid- } \\
\text { derived monolayers' }\end{array}$ \\
\hline Other & $100 \mu \mathrm{m}$ Cell Strainer & Corning & Cat\# 352360 & $\begin{array}{l}\text { Section'Isolation and culture of human whole } \\
\text { lung-derived organoids' }\end{array}$ \\
\hline Other & $\begin{array}{l}\text { Noyes Spring Scissors - } \\
\text { Angled }\end{array}$ & Fine Science Tools & Cat\# 15013-12 & $\begin{array}{l}\text { Section'Isolation and culture of human whole } \\
\text { lung-derived organoids' }\end{array}$ \\
\hline
\end{tabular}

\section{Detailed methods}

\section{Collection of human lung specimens for organoid isolation}

To generate adult healthy lung organoids, fresh biopsy bites were prospectively collected after surgical resection of the lung by the cardiothoracic surgeon. Before collection of the lung specimens, each tissue was sent to a gross anatomy room where a pathologist cataloged the area of focus, and the extra specimens were routed to the research lab in Human Transport Media (HTM, Advanced DMEM/F-12, 10 mM HEPES, 1× Glutamax, 1× penicillin-streptomycin, $5 \mu \mathrm{M}$ Y-27632) for cell isolation. Deidentified lung tissues obtained during surgical resection, which were deemed excess by clinical pathologists, were collected using an approved human research protocol (IRB\# 101590; PI: Thistlethwaite). Isolation and biobanking of organoids from these lung tissues were carried out using an approved human research protocol (IRB\# 190105: PI Ghosh and Das) that covers human subject research at the UC San Diego HUMANOID Center of Research Excellence (CoRE). For all the deidentified human subjects, information, including age, gender, and previous history of the disease, was collected from the chart following the rules of HIPAA and described in Table 3.

A portion of the same lung tissue specimen was fixed in 10\% zinc-formalin for at least $24 \mathrm{hr}$ followed by submersion in $70 \% \mathrm{EtOH}$ until embedding in FFPE blocks.

\section{Autopsy procedures for lung tissue collection from COVID-19-positive human subjects}

The lung specimens from COVID-19-positive human subjects were collected through autopsy (the study was IRB exempt). All donations to this trial were obtained after telephone consent followed by written email confirmation by the next of kin/power of attorney per California state law (no in-person visitation could be allowed into our COVID-19 ICU during the pandemic). The team member followed the CDC guidelines for COVID19 and the autopsy procedures (CAP, 2020; CDC, 2020). Lung specimens were collected in $10 \%$ zinc-formalin and stored for $72 \mathrm{hr}$ before processing for histology. Patient characteristics are listed in Table 3.

Autopsy \#2 was a standard autopsy performed by anatomical pathology in the BSL3 autopsy suite. The patient expired and his family consented for autopsy. After $48 \mathrm{hr}$, the lungs were removed and immersion fixed whole in $10 \%$ formalin for $48 \mathrm{hr}$ and then processed further. Lungs were only partially fixed at this time (about 50\% fixed in thicker segments) and were sectioned into small $2-4 \mathrm{~cm}$ chunks and immersed in $10 \%$ formalin for further investigation.

Autopsy \#4 and \#5 were collected from rapid postmortem lung biopsies. The procedure was performed in the Jacobs Medical Center ICU (all of the ICU rooms have a pressure-negative environment, with air exhausted through HEPA filters [Biosafety Level 3 (BSL3)] for isolation of SARS-CoV-2 virus). Biopsies were performed 2-4 hr after patient expiration. The ventilator was shut off to reduce the aerosolization of viral particles at least $1 \mathrm{hr}$ after the loss of pulse and before sample collection. Every team member had personal protective equipment in accordance with the university policies for 
procedures on patients with COVID-19 (N95 mask+ surgical mask, hairnet, full face shield, surgical gowns, double surgical gloves, booties). Lung biopsies were obtained after L-thoracotomy in the fifth intercostal space by the cardiothoracic surgery team. Samples were taken from the left upper lobe (LUL) and left lower lobe (LLL) and then sectioned further.

Isolation and culture of human whole lung-derived organoids

A previously published protocol was modified to isolate lung organoids from three human subjects (Sachs et al., 2019; Zhou et al., 2018). Briefly, normal human lung specimens were washed with PBS/4× penicillin-streptomycin and minced with surgical scissors. Tissue fragments were resuspended in $10 \mathrm{ml}$ of wash buffer (Advanced DMEM/F-12, $10 \mathrm{mM}$ HEPES, 1× Glutamax, 1× penicillinstreptomycin) containing $2 \mathrm{mg} / \mathrm{ml}$ Collagenase Type I (Thermo Fisher, USA) and incubated at $37{ }^{\circ} \mathrm{C}$ for approximately $1 \mathrm{hr}$. During incubation, tissue pieces were sheared every $10 \mathrm{~min}$ with a $10 \mathrm{ml}$ serological pipette and examined under a light microscope to monitor the progress of digestion. When 80-100\% of single cells were released from connective tissue, the digestion buffer was neutralized with $10 \mathrm{ml}$ wash buffer with added $2 \%$ fetal bovine serum; the suspension was passed through a $100 \mu \mathrm{m}$ cell strainer and centrifuged at $200 \mathrm{rcf}$. Remaining erythrocytes were lysed in $2 \mathrm{ml}$ red blood cell lysis buffer (Invitrogen) at room temperature for $5 \mathrm{~min}$, followed by the addition of $10 \mathrm{ml}$ of wash buffer and centrifugation at 200 rcf. Cell pellets were resuspended in cold Matrigel (Corning, USA) and seeded in $25 \mu \mathrm{l}$ droplets on a 12-well tissue culture plate. The plate was inverted and incubated at $37^{\circ} \mathrm{C}$ for $10 \mathrm{~min}$ to allow complete polymerization of the Matrigel before the addition of $1 \mathrm{ml}$ Lung Expansion Medium per well. Lung expansion media was prepared by modifying a media that was optimized previously for growing Gl-organoids ( $50 \%$ conditioned media, prepared from L-WRN cells with Wnt3a, R-spondin, and Noggin, ATCC-CRL-3276) (Sayed et al., 2020c; Ghosh et al., 2020; Sayed et al., 2020a; Sayed et al., 2020b) with a proprietary cocktail from the HUMANOID CoRE containing B27, TGF- $\beta$ receptor inhibitor, antioxidants, p38 MAPK inhibitor, FGF 7, FGF 10, and ROCK inhibitor. The lung expansion media was compared to alveolosphere media I (IMDM and F12 as the basal medium with B27, low concentration of KGF, monothioglycerol, GSK3 inhibitor, ascorbic acid, dexamethasone, IBMX, CAMP, and ROCK inhibitor) and II (F12 as the basal medium with added $\mathrm{CaCl}_{2}, \mathrm{~B}^{27}$, low concentration of KGF, GSK3 inhibitor, TGF- $\beta$ receptor inhibitor dexamethasone, IBMX, cAMP, and ROCK inhibitor) modified from previously published literature (Jacob et al., 2019; Yamamoto et al., 2017). Neither alvelosphere media contain any added Wnt3a, R-spondin, and Noggin. The composition of these media was developed either by fundamentals of adult stem cell-derived mixed epithelial cellularity in other organs (like the GI tract [Miyoshi and Stappenbeck, 2013; Sato et al., 2009; Sayed et al., 2020c]) or rationalized based on published growth conditions for proximal and distal airway components (Gotoh et al., 2014; Sachs et al., 2019; van der Vaart and Clevers, 2021). Organoids were maintained in a humidified incubator at $37{ }^{\circ} \mathrm{C} / 5 \% \mathrm{CO}_{2}$, with a complete media change performed every 3 days. After the organoids reached confluency between 7 and 10 days, organoids were collected in PBS/0.5 mM EDTA and centrifuged at $200 \mathrm{rcf}$ for $5 \mathrm{~min}$. Organoids were dissociated in $1 \mathrm{ml}$ trypLE Select (Gibco, USA) per well at $37^{\circ} \mathrm{C}$ for $4-5 \mathrm{~min}$ and mechanically sheared. Wash buffer was added at a 1:5, trypLE to wash buffer ratio. The cell suspension was subsequently centrifuged, resuspended in Matrigel, and seeded at a 1:5 ratio. Lung organoids were biobanked and passage 3-8 cells were used for experiments. Subculture was performed every 7-10 days.

The preparation of lung organoid-derived monolayers

Lung organoid-derived monolayers were prepared using a modified protocol of Gl organoid-derived monolayers (Sayed et al., 2020c; Ghosh et al., 2020; Sayed et al., 2020a; Sayed et al., 2020b). Briefly, transwell inserts ( $6.5 \mathrm{~mm}$ diameter, $0.4 \mu \mathrm{m}$ pore size, Corning) were coated in Matrigel diluted in cold PBS at a 1:40 ratio and incubated for $1 \mathrm{hr}$ at room temperature. Confluent organoids were collected in PBS/EDTA on day 7 and dissociated into single cells in trypLE for 6-7 min at $37{ }^{\circ} \mathrm{C}$. Following enzymatic digestion, the cell suspension was mechanically sheared through vigorous pipetting with a $1000 \mu \mathrm{l}$ pipette and neutralized with wash buffer. The suspension was centrifuged, resuspended in PneumaCult Ex-Plus Medium (StemCell, Canada), and passed through a $70 \mu \mathrm{m}$ cell strainer. The coating solution was aspirated, and cells were seeded onto the apical membrane at $1.8 \mathrm{E} 5$ cells per transwell with $200 \mu \mathrm{l}$ PneumaCult Ex-Plus media. $700 \mu \mathrm{l}$ of PneumaCult Ex-Plus was added to the 
basal chamber. Cells were cultured over the course of 2-4 days. A media change of both the apical and basal chambers was performed every $24 \mathrm{hr}$.

\section{ALI model of lung organoids}

Organoids were dissociated into single cells and expanded in T-75 flasks in PneumaCult Ex-Plus Medium until confluency was reached. Cells were dissociated in ACF Enzymatic Dissociation Solution (StemCell) for 6-7 min at $37^{\circ} \mathrm{C}$ and neutralized in equal volume ACF Enzyme Inhibition Solution (StemCell). Cells were seeded in the apical chamber of transwells at 3.3E4 cells per transwell in $200 \mu \mathrm{l}$ of PneumaCult Ex-Plus Medium. $500 \mu \mathrm{l}$ of PneumaCult Ex-Plus was added to the basal chamber. Media in both chambers was changed every other day until confluency was reached ( $\sim 4$ days). The media was completely removed from the apical chamber, and media in the basal chamber was replaced with ALI Maintenance Medium (StemCell). The media in the basal chamber was changed every 2 days. The apical chamber was washed with warm PBS every 5-7 days to remove accumulated mucus. Cells were cultured under ALI conditions for 21+ days until they completed differentiation into a pseudostratified mucociliary epithelium. To assess the integrity of the epithelial barrier, TEER was measured with an Epithelial Volt-Ohm Meter (Millicell, USA). The media was removed from the basal chamber, and wash media was added to both chambers. Cultures were equilibrated to $37^{\circ} \mathrm{C}$ before TEER values were measured. Final values were expressed as $\Omega \cdot \mathrm{cm}^{2}$ units and were calculated by multiplying the growth area of the membrane by the raw TEER value.

The culture of primary airway epithelial cells and iPSC-derived alveolar epithelial cells

Primary NHBE cells were obtained from Lonza and grown according to instructions. NHBE cells were cultured in T25 cell culture tissue flasks with PneumaCult-Ex Plus media (StemCell). Cells were seeded at $~ 100,000$ cells $/ \mathrm{T} 25$ flask and incubated at $37{ }^{\circ} \mathrm{C}, 5 \% \mathrm{CO}_{2}$. Once cells reached $70-80 \%$ confluency, they were dissociated using $0.25 \%$ Trypsin in dissociation media and plated in 24-well transwells (Corning). Primary human bronchial epithelial cells (HBEpC) and small airway epithelial cells (HSAEpC) were obtained from Cell Applications Inc The HBEpC and HSAEpC were cultured in human bronchial/ tracheal epithelial cell media and small airway epithelial cell media, respectively, following the instructions of Cell Application.

Human iPSC-derived alveolar epithelial type 2 cells (iHAEpC2) were obtained from Cell Applications Inc and cultured in growth media (i536K-05, Cell Applications Inc) according to the manufacturer's instructions. All the primary cells were used within early passages (5-6) to avoid any gradual disintegration of the airway epithelium with columnar epithelial structure and epithelial integrity.

The infection with SARS-Cov2

Lung organoid-derived monolayers or primary airway epithelial cells either in 384-well plates or in transwells were washed twice with antibiotic-free lung wash media. 1E5 PFU of SARS-CoV-2 strain USA-WA1/2020 (BEI Resources NR-52281) in complete DMEM was added to the apical side of the transwell and allowed to incubate for $24,48,72$, and $96 \mathrm{hr}$ at $34{ }^{\circ} \mathrm{C}$ and $5 \% \mathrm{CO}_{2}$. After incubation, the media was removed from the basal side of the transwell. The apical side of the transwells was then washed twice with (antibiotic-free lung wash media) and then twice with PBS. TRIzol Reagent (Thermo Fisher 15596026) was added to the well and incubated at $34{ }^{\circ} \mathrm{C}$ and $5 \% \mathrm{CO}_{2}$ for $10 \mathrm{~min}$. The TRIzol Reagent was removed and stored at $-80^{\circ} \mathrm{C}$ for RNA analysis.

\section{RNA isolation}

Organoids and monolayers used for lung cell-type studies were lysed using RNA lysis buffer followed by RNA extraction per Zymo Research Quick-RNA MicroPrep Kit instructions. Tissue samples and monolayers in SARS-CoV2 studies were lysed in TRI-Reagent and RNA was extracted using Zymo Research Direct-zol RNA Miniprep.

\section{Quantitative (q)RT-PCR}

Organoid and monolayer cell-type gene expression was measured by qRT-PCR using 2x SYBR Green qPCR Master Mix. cDNA was amplified with gene-specific primer/probe set for the lung cell type markers and qScript cDNA SuperMix $(5 \times)$. qRT-PCR was performed with the Applied Biosystems 
QuantStudio 5 Real-Time PCR System. Cycling parameters were as follows: $95{ }^{\circ} \mathrm{C}$ for $20 \mathrm{~s}$, followed by 40 cycles of $1 \mathrm{~s}$ at $95^{\circ} \mathrm{C}$ and $20 \mathrm{~s}$ at $60^{\circ} \mathrm{C}$. All samples were assayed in triplicate and eukaryotic $18 \mathrm{~S}$ ribosomal RNA was used as a reference.

\begin{tabular}{|c|c|c|}
\hline Cell types & Marker & Primer sequence \\
\hline Basal cells & ITGA6, NGFR, TP63 & $\begin{array}{l}\text { ITGA6 F 'CGAAACCAAGGTTCTGAGCCC' } \\
\text { ITGA6 R 'CTTGGATCTCCACTGAGGCAGT' } \\
\text { NGFR F' CCTCATCCCTGTCTATTGCTCC } \\
\text { NGFR R' GTTGGCTCCTTGCTTGTTCTGC } \\
\text { TP63 F' CAGGAAGACAGAGTGTGCTGGT } \\
\text { TP63 R' AATTGGACGGCGGTTCATCCCT }\end{array}$ \\
\hline Goblet & Muc5AC & $\begin{array}{l}\text { Muc5AC F 'GGAACTGTGGGGACAGCTCTT' } \\
\text { Muc5AC R 'GTCACATTCCTCAGCGAGGTC' }\end{array}$ \\
\hline Cilia & FoxJ1 & $\begin{array}{l}\text { FoxJ1 F 'ACTCGTATGCCACGCTCATCTG' } \\
\text { FoxJ1 R 'GAGACAGGTTGTGGCGGATTGA' }\end{array}$ \\
\hline Club cell & SCGB1A1 & $\begin{array}{l}\text { SCGB1A1 F 'CAAAAGCCCAGAGAAAGCATC' } \\
\text { SCGB1A1 R 'CAGTTGGGGATCTTCAGCTTC' }\end{array}$ \\
\hline Alveolar type 1 & AQP5, PDPN & $\begin{array}{l}\text { AQP5 F 'TACGGTGTGGCACCGCTCAATG' } \\
\text { AQP5 R 'AGTCAGTGGAGGCGAAGATGCA' } \\
\text { PDPN F 'GTGCCGAAGATGATGTGGTGAC' } \\
\text { PDPN R 'GGACTGTGCTTTCTGAAGTTGGC' }\end{array}$ \\
\hline Alveolar type 2 & SFTPA1, SFTPC & $\begin{array}{l}\text { SFTPA1 F 'CACCTGGAGAAATGCCATGTCC' } \\
\text { SFTPA1 R 'AAGTCGTGGAGTGTGGCTTGGA' } \\
\text { SFTPC F 'GTCCTCATCGTCGTGGTGATTG' } \\
\text { SFTPC R 'AGAAGGTGGCAGTGGTAACCAG' }\end{array}$ \\
\hline
\end{tabular}

Assessment of SARS-CoV-2 infectivity test

Assessment of SARS-CoV-2 infectivity test was determined by qPCR using TaqMan assays and TaqMan Universal PCR Master Mix as done before (Corman et al., 2020; Lamers et al., 2020). cDNA was amplified with gene-specific primer/probe set for the E gene and QPCR was performed with the Applied Biosystems QuantStudio 3 Real-Time PCR System. The specific TaqMan primer/probe set for E gene are as follows: forward 5'-ACAGGTACGTTAATAGTTAATAGCGT-3' (IDT, Cat\# 10006888); reverse 5'-ATATTGCAGCAGTACGCACACA-3'; probe 5'-FAM-ACACTAGCCATCCTTACTGCGCTTCG-BBQ-3' and 18S rRNA. Cycling parameters were as follows: $95^{\circ} \mathrm{C}$ for $20 \mathrm{~s}$, followed by 40 cycles of $1 \mathrm{~s}$ at $95^{\circ} \mathrm{C}$ and $20 \mathrm{~s}$ at $60^{\circ} \mathrm{C}$. All samples were assayed in triplicate, and gene eukaryotic $18 \mathrm{~S}$ ribosomal RNA was used as a reference.

\section{Immunofluorescence}

Organoids and lung organoid-derived monolayers in plates or in 8-well chamber slides were fixed by either (i) 4\% PFA at room temperature for $30 \mathrm{~min}$ and quenched with $30 \mathrm{mM}$ glycine for $5 \mathrm{~min}$, (ii) icecold $100 \%$ methanol at $-20{ }^{\circ} \mathrm{C}$ for $20 \mathrm{~min}$, and (iii) ice-cold $100 \%$ methanol on ice for $20 \mathrm{~min}$. Subsequently, samples were permeabilized and blocked for $2 \mathrm{hr}$ using an in-house blocking buffer (2 mg/ ml BSA and $0.1 \%$ Triton X-100 in PBS); as described previously (Lopez-Sanchez et al., 2014). Primary antibodies were diluted in blocking buffer and allowed to incubate overnight at $4{ }^{\circ} \mathrm{C}$; secondary antibodies were diluted in blocking buffer and allowed to incubate for $2 \mathrm{hr}$ in the dark. Antibody dilutions are listed in the key resources table. ProLong Glass was used as a mounting medium. \#1 Thick Coverslips were applied to slides and sealed. Samples were stored at $4{ }^{\circ} \mathrm{C}$ until imaged. FFPE-embedded organoid and lung tissue sections underwent antigen retrieval as previously described in Materials and methods for immunohistochemistry staining. After antigen retrieval and cooling in DI water, samples were permeabilized and blocked in blocking buffer and treated as mentioned above for immunofluorescence. Images were acquired at room temperature with Leica TCS SPE confocal and with DMI4000 $B$ microscope using the Leica LAS-AF Software. Images were taken with a $40 \times$ oil-immersion objective using 405-, 488-, $561 \mathrm{~nm}$ laser lines for excitation. z-stack images were acquired by successive z-slices of $1 \mu \mathrm{m}$ in the desired confocal channels. Fields of view that were representative and/or of interest were determined by randomly imaging three different fields. z-slices of a z-stack were overlaid to create maximum intensity projection images; all images were processed using FIJI (ImageJ) software. 


\section{Embedding of organoids in HistoGel}

Organoids were seeded on a layer of Matrigel in 6-well plates and grown for 7-8 days. Once mature, organoids were fixed in 4\% PFA at room temperature for $30 \mathrm{~min}$ and quenched with $30 \mathrm{mM}$ glycine for 5 min. Organoids were gently washed with PBS and harvested using a cell scraper. Organoids were resuspended in PBS using wide-bore $1000 \mu \mathrm{l}$ pipette tips. Organoids were stained using Gill's hematoxylin for 5 min for easier FFPE embedding and sectioning visualization. Hematoxylin-stained organoids were gently washed in PBS and centrifuged and excess hematoxylin was aspirated. Organoids were resuspended in $65^{\circ} \mathrm{C}$ HistoGel and centrifuged at $65{ }^{\circ} \mathrm{C}$ for $5 \mathrm{~min}$. HistoGel-embedded organoid pellets were allowed to cool to room temperature and stored in $70 \%$ ethanol at $4{ }^{\circ} \mathrm{C}$ until ready for FFPE embedding by LJI Histology Core. Successive FFPE-embedded organoid sections were cut at a $4 \mu \mathrm{m}$ thickness and fixed on to microscope slides.

\section{Immunohistochemistry}

For SARS CoV-nucleoprotein (np) antigen retrieval, slides were immersed in Tris-EDTA buffer (pH 9.0) and boiled for $10 \mathrm{~min}$ at $100{ }^{\circ} \mathrm{C}$ inside a pressure cooker. Endogenous peroxidase activity was blocked by incubation with $3 \% \quad \mathrm{H}_{2} \mathrm{O}_{2}$ for 10 min. To block nonspecific protein binding, $2.5 \%$ goat serum was added. Tissues were then incubated with a rabbit SARS CoV-NP antibody (Sino Biological, see key resource table) for $1.5 \mathrm{hr}$ at room temperature in a humidified chamber and then rinsed with TBS or PBS three times, for $5 \mathrm{~min}$ each. Sections were incubated with horse anti-rabbit IgG secondary antibodies for $30 \mathrm{~min}$ at room temperature and then washed with TBS or PBS three times for 5 min each. Sections were incubated with DAB and counterstained with hematoxylin for $30 \mathrm{~s}$.

\section{Permeability of lung monolayer using FITC-dextran}

Adult lung monolayers were grown for 2 days in PneumaCult Ex-Plus media on transwell inserts (6.5 mm diameter, $0.4 \mu \mathrm{m}$ pore size, Corning). TEER was monitored with an Epithelial Volt-Ohm Meter (Millicell). On the second day of growth, FITC-dextran (10 kD) was added at a 1:50 dilution in lung wash media. The basolateral side of the insert was changed to lung wash media only. After 30 min of incubation with FITC-dextran, $50 \mu \mathrm{l}$ of the basolateral supernatant was transferred to an opaque welled 96-well plate. Fluorescence was measured using a TECAN plate reader.

\section{The characterization of lung cell types using flow cytometry}

Lung organoids were dissociated into single cells via trypLE digestion and strained with a $30 \mu \mathrm{m}$ filter (Miltenyi Biotec, Germany). Approximately 2.5E5 cells for each sample were fixed and permeabilized at room temperature in Cyto-Fast Fix Perm buffer (BioLegend, USA) for 20 min. The samples were subsequently washed with Cyto-Fast Perm Wash solution (BioLegend) and incubated with lung epithelial cell-type markers for $30 \mathrm{~min}$. Following primary antibody incubation, the samples were washed and incubated with propidium iodide (Invitrogen) and Alexa Flour 488 secondary antibodies (Invitrogen) for $30 \mathrm{~min}$. Samples were resuspended in FACS buffer (PBS, 5 \% FBS, 2 mM sodium azide). Flow cytometry was performed using Guava easyCyte Benchtop Flow Cytometer (Millipore) and data was analyzed using InCyte (version 3.3) and FlowJo X v10 software.

\section{RNA sequencing}

RNA sequencing libraries were generated using the Illumina TruSeq Stranded Total RNA Library Prep Gold with TruSeq Unique Dual Indexes (Illumina, San Diego, CA). Samples were processed following the manufacturer's instructions, except modifying RNA shear time to $5 \mathrm{~min}$. The resulting libraries were multiplexed and sequenced with 100 basepair (bp) paired-end (PE100) to a depth of approximately 25-40 million reads per sample on an Illumina NovaSeq 6000 by the Institute of Genomic Medicine (IGM) at the University of California San Diego. Samples were demultiplexed using bcl2fasta v2.20 Conversion Software (Illumina). RNAseq data was processed using kallisto (version 0.45.0) and human genome GRCh38 Ensembl version 94 annotation (Homo_sapiens GRCh38.94 chr_patch_hapl_ scaff.gtf). Gene-level transcripts per million (TPM) values and gene annotations were computed using tximport and biomaRt $\mathrm{R}$ package. A custom Python script was used to organize the data and log reduced using log2(TPM +1). The raw data and processed data are deposited in Gene Expression Omnibus under accession nos. GSE157055 and GSE157057. 


\section{Data collection and annotation}

Publicly available COVID-19 gene expression databases were downloaded from the National Center for Biotechnology Information (NCBI) Gene Expression Omnibus website (GEO) (Edgar et al., 2002; Barrett et al., 2005; Barrett et al., 2013). If the dataset is not normalized, RMA (Robust Multichip Average) (Irizarry et al., 2003a; Irizarry et al., 2003b) is used for microarrays and TPM (Li and Dewey, 2011; Pachter, 2011) is used for RNA seq data for normalization. We used log2(TPM +1) to compute the final log-reduced expression values for RNA seq data. Accession numbers for these crowdsourced datasets are provided in the figures and article. All of the above datasets were processed using the Hegemon data analysis framework (Dalerba et al., 2011; Dalerba et al., 2016; Volkmer et al., 2012).

\section{Analysis of RNA seq datasets}

DESeq2 (Love et al., 2014) was applied to uninfected and infected samples to identify up- and downregulated genes. A gene signature score is computed using both the up- and downregulated genes that are used to order the sample. To compute the gene signature score, first, the genes present in this list were normalized according to a modified Z-score approach centered around StepMiner threshold (formula $=($ expr $-S T h r) / 3^{*}$ stddev). The normalized expression values for every probeset for all the genes were added or subtracted (depending on up and downregulated genes) together to create the final score. The samples were ordered based on the final gene signature score. The gene signature score is used to classify sample categories, and the performance of the multiclass classification is measured by ROC-AUC values. A color-coded bar plot is combined with a violin plot to visualize the gene signature-based classification. All statistical tests were performed using $\mathrm{R}$ version 3.2.3 (2015-12-10). Standard t-tests were performed using Python scipy.stats.ttest_ind package (version 0.19.0) with Welch's two-sample t-test (unpaired, unequal variance (equal_var = False), and unequal sample size) parameters. Multiple hypothesis correction was performed by adjusting p-values with statsmodels.stats.multitest.multipletests (fdr_bh: Benjamini/Hochberg principles). The results were independently validated with $R$ statistical software ( $R$ version 3.6.1; 2019-07-05). Pathway analysis of gene lists was carried out via the Reactome database and algorithm (Fabregat et al., 2018). Reactome identifies signaling and metabolic molecules and organizes their relations into biological pathways and processes. Violin, swarm, and bubble plots were created using Python seaborn package version 0.10 .1 .

\section{Single-Cell RNA seq data analysis}

Single-Cell RNA seq data from GSE145926 was downloaded from GEO in the HDF5 Feature Barcode Matrix Format. The filtered barcode data matrix was processed using Seurat v3 R package (Stuart et al., 2019) and Scanpy Python package (Wolf et al., 2018). Pseudo bulk analysis of GSE145926 data was performed by adding counts from the different cell subtypes and normalized using log2(CPM + 1). Epithelial cells were identified using SFTPA1, SFTPB, AGER, AQP4, SFTPC, SCGB3A2, KRT5, CYP2F1, CCDC153, and TPPP3 genes using SCINA algorithm (Zhang et al., 2019). Pseudo bulk datasets were prepared by adding counts from the selected cells and normalized using $\log (C P M+1)$.

\section{Assessment of cell-type proportions}

CIBERSORTx (https://cibersortx.stanford.edu/runcibersortx.php) was used for cell-type deconvolution of our dataset (which was normalized by CPM). As reference samples, we first used the singlecell RNA seq dataset (GSE132914) from Gene Expression Omnibus (GEO). Next, we analyzed the bulk RNA seq datasets for the identification of cell types of interest using relevant gene markers (see Table 2): AT1 cells (PDPN, AQP5, P2RX4, TIMP3, SERPINE1), AT2 cells (SFTPA1, SFTPB, SFTPC, SFTPD, SCGB1A1, ABCA3, LAMP3), BASAL cells (CD44, KRT5, KRT13, KRT14, CKAP4, NGFR, ITGA6), CLUB cells (SCGB1A1, SCGB3A2, SFTPA1, SFTPB, SFTPD, ITGA6, CYP2F1), GOBLET cells (CDX2, MUC5AC, MUC5B, TFF3), ciliated cells (ACTG2, TUBB4A, FOXA3, FOXJ1, SNTN), and generic lung lineage cells (GJA1, TTF1, EPCAM) were identified using SCINA algorithm. Then, normalized pseudo counts were obtained with the CPM normalization method. The cell-type signature matrix was derived from the single-cell RNA seq dataset, cell types, and gene markers of interest. It was constructed by taking an average from gene expression levels for each of the markers across each cell type. 


\section{Statistical analysis}

All experiments were repeated at least three times, and results were presented either as one representative experiment or as average \pm SEM. Statistical significance between datasets with three or more experimental groups was determined using one-way ANOVA including a Tukey's test for multiple comparisons. For all tests, a $p$-value of 0.05 was used as the cutoff to determine significance $\left({ }^{*} p<0.05\right.$, ${ }^{* \star} p<0.01,{ }^{* * *} p<0.001$, and $\left.{ }^{* \star * *} p<0.0001\right)$. All experiments were repeated a least three times, and $\mathrm{p}$-values are indicated in each figure. All statistical analyses were performed using GraphPad Prism 6.1. A part of the statistical tests was performed using R version 3.2 .3 (2015-12-10). Standard t-tests were performed using Python scipy.stats.ttest_ind package (version 0.19.0).

\section{Acknowledgements}

The authors thank Victor Pretorius, Rachel White, and Jen Bigbee (Department of Cardiothoracic Surgery, UC San Diego) who assisted with thoracotomies during rapid autopsies.

\section{Additional information}

Funding

\begin{tabular}{|c|c|c|}
\hline Funder & Grant reference number & Author \\
\hline $\begin{array}{l}\text { National Institute of } \\
\text { Diabetes and Digestive } \\
\text { and Kidney Diseases }\end{array}$ & 3R01DK107585-05S1 & Soumita Das \\
\hline $\begin{array}{l}\text { National Institute of } \\
\text { Diabetes and Digestive } \\
\text { and Kidney Diseases }\end{array}$ & 1R01DK107585-01A1 & Soumita Das \\
\hline $\begin{array}{l}\text { National Institute of Allergy } \\
\text { and Infectious Diseases }\end{array}$ & R01-Al 155696 & $\begin{array}{l}\text { Debashis Sahoo } \\
\text { Pradipta Ghosh } \\
\text { Soumita Das }\end{array}$ \\
\hline $\begin{array}{l}\text { National Institute of Allergy } \\
\text { and Infectious Diseases }\end{array}$ & R01-Al141630 & Pradipta Ghosh \\
\hline National Cancer Institute & CA100768 & Pradipta Ghosh \\
\hline National Cancer Institute & CA160911 & Pradipta Ghosh \\
\hline $\begin{array}{l}\text { National Institute of } \\
\text { General Medical Sciences }\end{array}$ & R01-GM138385 & Debashis Sahoo \\
\hline $\begin{array}{l}\text { National Heart, Lung, and } \\
\text { Blood Institute }\end{array}$ & R01- HL32225 & Patricia A Thistlethwaite \\
\hline $\begin{array}{l}\text { University of California, San } \\
\text { Diego }\end{array}$ & UCOP-R01RG3780 & $\begin{array}{l}\text { Debashis Sahoo } \\
\text { Pradipta Ghosh } \\
\text { Soumita Das }\end{array}$ \\
\hline $\begin{array}{l}\text { University of California, San } \\
\text { Diego }\end{array}$ & UCOP-ROORG2642 & $\begin{array}{l}\text { Pradipta Ghosh } \\
\text { Soumita Das }\end{array}$ \\
\hline $\begin{array}{l}\text { National Heart, Lung, and } \\
\text { Blood Institute }\end{array}$ & R01-HL137052 & Laura E Crotty Alexander \\
\hline $\begin{array}{l}\text { Department of Veterans } \\
\text { Affairs Merit Award }\end{array}$ & $1101 \mathrm{~B} \times 004767$ & Laura E Crotty Alexander \\
\hline
\end{tabular}

Author contributions

Courtney Tindle, Conceptualization, Conducted experiments on adult lung-derived 3D-organoids and 2D-monolayers, Data curation, Formal analysis, Investigation, Methodology, Writing - original draft; MacKenzie Fuller, Ayden Fonseca, Conceptualization, Data curation, Formal analysis, Investigation, Methodology, Writing - review and editing; Sahar Taheri, Data curation, Formal analysis, 
Methodology, Project administration; Stella-Rita Ibeawuchi, Nathan Beutler, Gajanan Dattatray Katkar, Amanraj Claire, Vanessa Castillo, Data curation, Formal analysis, Investigation, Methodology; Moises Hernandez, Data curation, Methodology, Resources; Hana Russo, Jason Duran, Ann Tipps, Grace Lin, Thomas F Rogers, Methodology, Resources; Laura E Crotty Alexander, Patricia A Thistlethwaite, Ranajoy Chattopadhyay, Methodology, Resources, Writing - review and editing; Debashis Sahoo, Conceptualization, Funding acquisition, Investigation, Methodology, Project administration, Resources, Software, Supervision, Writing - original draft, Writing - review and editing; Pradipta Ghosh, Soumita Das, Conceptualization, Data curation, Formal analysis, Funding acquisition, Investigation, Methodology, Project administration, Resources, Supervision, Validation, Writing - original draft, Writing - review and editing

Author ORCIDs

MacKenzie Fuller (iD http://orcid.org/0000-0001-6781-8710

Vanessa Castillo (iD http://orcid.org/0000-0002-4182-8846

Moises Hernandez (iD http://orcid.org/0000-0002-7651-2673

Laura E Crotty Alexander (iD http://orcid.org/0000-0002-5091-2660

Debashis Sahoo (iD http://orcid.org/0000-0003-2329-8228

Pradipta Ghosh (iD http://orcid.org/0000-0002-8917-3201

Soumita Das (iD http://orcid.org/0000-0003-3895-3643

Ethics

Ethics Statement:The human subject research was performed following the approved protocol at University of California San Diego. Deidentified lung tissues obtained during surgical resection, that were deemed excess by clinical pathologists, were collected using an approved human research protocol (IRB\# 101590; PI: Thistlethwaite). Isolation and biobanking of organoids from these lung tissues were carried out using an approved human research protocol (IRB\# 190105: PI Ghosh and Das) that covers human subject research at the UC San Diego HUMANOID Center of Research Excellence (CoRE). For all the deidentified human subjects, information including age, gender, and previous history of the disease, was collected from the chart following the rules of HIPAA.

Decision letter and Author response

Decision letter https://doi.org/10.7554/eLife.66417.sa1

Author response https://doi.org/10.7554/eLife.66417.sa2

\section{Additional files}

Supplementary files

- Transparent reporting form

Data availability

Sequencing data have been deposited in GEO under accession codes GSE157055, and GSE157057.

The following dataset was generated:

\begin{tabular}{lllll}
\hline Author(s) & Year & Dataset title & Dataset URL & Database and Identifier \\
\hline $\begin{array}{llll}\text { Sahoo D, Das S, } \\
\text { Ghosh P }\end{array}$ & 2020 & $\begin{array}{l}\text { Human lung organoid for } \\
\text { modeling infection and } \\
\text { disease conditions }\end{array}$ & $\begin{array}{l}\text { https://www.ncbi. } \\
\text { nlm.nih.gov/geo/ }\end{array}$ & $\begin{array}{l}\text { NCBI Gene Expression } \\
\text { query/acc.cgi?acc } \\
\text { GSE157057 }\end{array}$ \\
& & & Gmibus, GSE157057 \\
& & &
\end{tabular}

\section{References}

Abdelwahab EMM, Rapp J, Feller D, Csongei V, Pal S, Bartis D, Thickett DR, Pongracz JE. 2019. WNT signaling regulates trans-differentiation of stem cell like type 2 alveolar epithelial cells to type 1 epithelial cells. Respiratory Research 20: 204. DOI: https://doi.org/10.1186/s12931-019-1176-x, PMID: 31492143

Andrea Valeria Arrossi AV, Farver C. 2020. The pulmonary pathology of covid-19. Cleveland Clinic Journal of Medicine 478: 137-150. DOl: https://doi.org/10.3949/ccjm.87a.ccc063 
Barrett T, Suzek TO, Troup DB, Wilhite SE, Ngau WC, Ledoux P, Rudnev D, Lash AE, Fujibuchi W, Edgar R. 2005. NCBI GEO: Mining millions of expression profiles--database and tools. Nucleic Acids Research 33: D562-D566. DOI: https://doi.org/10.1093/nar/gki022, PMID: 15608262

Barrett T, Wilhite SE, Ledoux P, Evangelista C, Kim IF, Tomashevsky M, Marshall KA, Phillippy KH, Sherman PM, Holko M, Yefanov A, Lee H, Zhang N, Robertson CL, Serova N, Davis S, Soboleva A. 2013. NCBI GEO: Archive for functional Genomics data sets--update. Nucleic Acids Research 41: D991-D995. DOI: https://doi.org/10. 1093/nar/gks1193, PMID: 23193258

Bonser LR, Koh KD, Johansson K, Choksi SP, Cheng D, Liu L, Sun DI, Zlock LT, Eckalbar WL, Finkbeiner WE, Erle DJ. 2021. Flow-cytometric analysis and purification of airway epithelial-cell subsets. American Journal of Respiratory Cell and Molecular Biology 64: 308-317. DOI: https://doi.org/10.1165/rcmb.2020-0149MA, PMID: 33196316

Borczuk AC, Salvatore SP, Seshan SV, Patel SS, Bussel JB, Mostyka M, Elsoukkary S, He B, Del Vecchio C, Fortarezza F, Pezzuto F, Navalesi P, Crisanti A, Fowkes ME, Bryce CH, Calabrese F, Beasley MB. 2020. COVID-19 pulmonary pathology: a multi-institutional autopsy cohort from Italy and New York City. Modern Pathology 33 : 2156-2168. DOI: https://doi.org/10.1038/s41379-020-00661-1, PMID: 32879413

Bratic A, Larsson NG. 2013. The role of mitochondria in aging. The Journal of Clinical Investigation 123: 951-957. DOI: https://doi.org/10.1172/JCl64125, PMID: 23454757

Bukys MA, Mihas A, Finney K, Sears K, Trivedi D, Wang Y, Oberholzer J, Jensen J. 2020. High-dimensional design-of-experiments extracts small-molecule-only induction conditions for dorsal pancreatic endoderm from pluripotency. IScience 23: 101346. DOI: https://doi.org/10.1016/j.isci.2020.101346, PMID: 32745983

CAP. 2020. Amended COVID-19 Autopsy guideline statement from the CAP autopsy committee. https:// documents.cap.org/documents/COVID-Autopsy-Statement.pdf [Accessed November 09, 2020].

Carsana L, Sonzogni A, Nasr A, Rossi RS, Pellegrinelli A, Zerbi P, Rech R, Colombo R, Antinori S, Corbellino M, Galli M, Catena E, Tosoni A, Gianatti A, Nebuloni M. 2020. Pulmonary post-mortem findings in a series of covid-19 cases from northern Italy: A two-centre descriptive study. The Lancet. Infectious Diseases 20: 1135-1140. DOI: https://doi.org/10.1016/S1473-3099(20)30434-5, PMID: 32526193

CDC. 2020. Collection and submission of post-mortem specimens from deceased persons with known or suspected covid-19 (interim guidance). https://www.cdc.gov/coronavirus/2019-ncov/hcp/guidancepostmortem-specimens.html [Accessed February 12, 2020].

Chan RWY, Chan MCW, Agnihothram S, Chan LLY, Kuok DIT, Fong JHM, Guan Y, Poon LLM, Baric RS, Nicholls JM, Peiris JSM. 2013. Tropism of and innate immune responses to the novel human Betacoronavirus lineage $C$ virus in human ex vivo respiratory organ cultures. Journal of Virology 87: 6604-6614. DOI: https:// doi.org/10.1128/JVI.00009-13, PMID: 23552422

Chen YW, Huang SX, de Carvalho A, Ho SH, Islam MN, Volpi S, Notarangelo LD, Ciancanelli M, Casanova JL, Bhattacharya J, Liang AF, Palermo LM, Porotto M, Moscona A, Snoeck HW. 2017. A three-dimensional model of human lung development and disease from pluripotent stem cells. Nature Cell Biology 19: 542-549. DOI: https://doi.org/10.1038/ncb3510, PMID: 28436965

Chen Y, Li L. 2020. SARS-CoV-2: virus dynamics and host response. The Lancet. Infectious Diseases 20: 515-516. DOI: https://doi.org/10.1016/S1473-3099(20)30235-8, PMID: 32213336

Choi J, Park JE, Tsagkogeorga G, Yanagita M, Koo BK, Han N, Lee JH. 2020. Inflammatory signals induce at2 cell-derived damage-associated transient progenitors that mediate alveolar regeneration. Cell Stem Cell 27: 366-382.. DOI: https://doi.org/10.1016/j.stem.2020.06.020, PMID: 32750316

Corman VM, Landt O, Kaiser M, Molenkamp R, Meijer A, Chu DK, Bleicker T, Brünink S, Schneider J, Schmidt ML, Mulders DG, Haagmans BL, van der Veer B, van den Brink S, Wijsman L, Goderski G, Romette JL, Ellis J, Zambon M, Peiris M, et al. 2020. Detection of 2019 novel coronavirus (2019-NCOV) by real-time RT-PCR. Euro Surveillance 25: 2000045. DOI: https://doi.org/10.2807/1560-7917.ES.2020.25.3.2000045, PMID: 31992387

Cox RM, Wolf JD, Plemper RK. 2021. Therapeutically administered ribonucleoside analogue MK-4482/ EIDD-2801 blocks SARS-CoV-2 transmission in ferrets. Nature Microbiology 6: 11-18. DOI: https://doi.org/10. 1038/s41564-020-00835-2, PMID: 33273742

Dalerba P, Kalisky T, Sahoo D, Rajendran PS, Rothenberg ME, Leyrat AA, Sim S, Okamoto J, Johnston DM, Qian D, Zabala M, Bueno J, Neff NF, Wang J, Shelton AA, Visser B, Hisamori S, Shimono Y, van de Wetering M, Clevers $\mathrm{H}$, et al. 2011. Single-cell dissection of transcriptional heterogeneity in human colon tumors. Nature Biotechnology 29: 1120-1127. DOI: https://doi.org/10.1038/nbt.2038, PMID: 22081019

Dalerba P, Sahoo D, Paik S, Guo X, Yothers G, Song N, Wilcox-Fogel N, Forgó E, Rajendran PS, Miranda SP, Hisamori S, Hutchison J, Kalisky T, Qian D, Wolmark N, Fisher GA, van de Rijn M, Clarke MF. 2016. CDX2 as a prognostic biomarker in stage II and stage III colon cancer. The New England Journal of Medicine 374: 211-222. DOI: https://doi.org/10.1056/NEJMoa1506597, PMID: 26789870

Damiani S, Fiorentino M, De Palma A, Foschini MP, Lazzarotto T, Gabrielli L, Viale PL, Attard L, Riefolo M, D'Errico A. 2021. Pathological post-mortem findings in lungs infected with SARS-COV-2. The Journal of Pathology 253: 31-40. DOI: https://doi.org/10.1002/path.5549, PMID: 32930394

Duan F, Guo L, Yang L, Han Y, Thakur A, Nilsson-Payant BE, Wang P, Zhang Z, Ma CY, Zhou X, Han T, Zhang T, Wang X, Xu D, Duan X, Xiang J, Tse HF, Liao C, Luo W, Huang FP, et al. 2020. Modeling COVID-19 with human pluripotent stem cell-derived cells reveals synergistic effects of anti-inflammatory macrophages with ace 2 inhibition against sars-cov-2. Research Square. DOI: https://doi.org/10.21203/rs.3.rs-62758/v1, PMID: 32839764 
Dvorak A, Tilley AE, Shaykhiev R, Wang R, Crystal RG. 2011. Do airway epithelium air-liquid cultures represent the in vivo airway epithelium transcriptome? American Journal of Respiratory Cell and Molecular Biology 44: 465-473. DOI: https://doi.org/10.1165/rcmb.2009-0453OC, PMID: 20525805

Dye BR, Hill DR, Ferguson MAH, Tsai YH, Nagy MS, Dyal R, Wells JM, Mayhew CN, Nattiv R, Klein OD, White ES, Deutsch GH, Spence JR. 2015. In vitro generation of human pluripotent stem cell derived lung organoids. eLife 4: e05098. DOI: https://doi.org/10.7554/eLife.05098, PMID: 25803487

Edgar R, Domrachev M, Lash AE. 2002. Gene Expression Omnibus: NCBI gene expression and hybridization array data repository. Nucleic Acids Research 30: 207-210. DOI: https://doi.org/10.1093/nar/30.1.207, PMID: 11752295

Ehaideb SN, Abdullah ML, Abuyassin B, Bouchama A. 2020. A Systematic Review Uncovers a Wide-Gap between COVID-19 in Humans and Animal Models. [medRxiv]. DOI: https://doi.org/10.1101/2020.07.15. 20147041

Engevik MA, Engevik KA, Yacyshyn MB, Wang J, Hassett DJ, Darien B, Yacyshyn BR, Worrell RT. 2015. Human clostridium difficile infection: Inhibition of nhe3 and microbiota profile. American Journal of Physiology. Gastrointestinal and Liver Physiology 308: G497-G509. DOI: https://doi.org/10.1152/ajpgi.00090.2014, PMID: 25552580

Fabregat A, Jupe S, Matthews L, Sidiropoulos K, Gillespie M, Garapati P, Haw R, Jassal B, Korninger F, May B, Milacic M, Roca CD, Rothfels K, Sevilla C, Shamovsky V, Shorser S, Varusai T, Viteri G, Weiser J, Wu G, et al. 2018. The Reactome pathway knowledgeBase. Nucleic Acids Research 46: D649-D655. DOI: https://doi.org/ 10.1093/nar/gkx1132, PMID: 29145629

Forbester JL, Goulding D, Vallier L, Hannan N, Hale C, Pickard D, Mukhopadhyay S, Dougan G. 2015. Interaction of Salmonella enterica SEROVAR typhimurium with intestinal organoids derived from human induced pluripotent stem cells. Infection and Immunity 83: 2926-2934. DOI: https://doi.org/10.1128/IAI. 00161-15, PMID: 25964470

Ghaedi M, Calle EA, Mendez JJ, Gard AL, Balestrini J, Booth A, Bove PF, Gui L, White ES, Niklason LE. 2013. Human IPS cell-derived alveolar epithelium repopulates lung extracellular matrix. The Journal of Clinical Investigation 123: 4950-4962. DOI: https://doi.org/10.1172/JCl68793, PMID: 24135142

Ghosh P, Swanson L, Sayed IM, Mittal Y, Lim BB, Ibeawuchi SR, Foretz M, Viollet B, Sahoo D, Das S. 2020. The stress polarity signaling (SPS) pathway serves as a marker and a target in the leaky gut barrier: Implications in aging and cancer. Life Science Alliance 3: e201900481. DOI: https://doi.org/10.26508/lsa.201900481, PMID: 32041849

Gotoh S, Ito I, Nagasaki T, Yamamoto Y, Konishi S, Korogi Y, Matsumoto H, Muro S, Hirai T, Funato M, Mae SI, Toyoda T, Sato-Otsubo A, Ogawa S, Osafune K, Mishima M. 2014. Generation of alveolar epithelial spheroids via isolated progenitor cells from human pluripotent stem cells. Stem Cell Reports 3: 394-403. DOI: https://doi. org/10.1016/j.stemcr.2014.07.005, PMID: 25241738

Gras D, Petit A, Charriot J, Knabe L, Alagha K, Gamez AS, Garulli C, Bourdin A, Chanez P, Molinari N, Vachier I. 2017. Epithelial ciliated beating cells essential for ex vivo ALI culture growth. BMC Pulmonary Medicine 17: 80. DOI: https://doi.org/10.1186/s12890-017-0423-5, PMID: 28468615

Han Y, Yang L, Duan X, Duan F, Nilsson-Payant BE, Yaron TM, Wang P, Tang X, Zhang T, Zhao Z, Bram Y, Redmond D, Houghton S, Nguyen D, Xu D, Wang X, Uhl S, Huang Y, Johnson JL, Xiang J, et al. 2020a. Identification of Candidate COVID-19 Therapeutics Using Hpsc-Derived Lung Organoids. [bioRxiv]. DOI: https://doi.org/10.1101/2020.05.05.079095, PMID: 32511403

Han Y, Duan X, Yang L, Nilsson-Payant BE, Wang P, Duan F, Tang X, Yaron TM, Zhang T, Uhl S, Bram Y, Richardson C, Zhu J, Zhao Z, Redmond D, Houghton S, Nguyen D-HT, Xu D, Wang X, Jessurun J, et al. 2020 b. Identification of SARS-COV-2 inhibitors using lung and colonic organoids. Nature 589: 270-275. DOI: https:// doi.org/10.1038/s41586-020-2901-9, PMID: 33116299

Hild M, Jaffe AB. 2016. Production of 3-d airway organoids from primary human airway basal cells and their use in high-throughput screening. Curr Protoc Stem Cell Biol 37: IE.. DOI: https://doi.org/10.1002/cpsc.1

Hoffmann M, Kleine-Weber H, Schroeder S, Krüger N, Herrler T, Erichsen S, Schiergens TS, Herrler G, Wu NH, Nitsche A, Müller MA, Drosten C, Pöhlmann S. 2020. SARS-COV-2 cell entry depends on ace2 and tmprss2 and is blocked by a clinically proven protease inhibitor. Cell 181: 271-280.. DOI: https://doi.org/10.1016/j.cell.2020. 02.052, PMID: 32142651

Hou YJ, Okuda K, Edwards CE, Martinez DR, Asakura T, Kato T, Lee RE, Yount BL, Mascenik TM, Chen G, Olivier KN, Ghio A, Tse LV, Leist SR, Gralinski LE, Schäfer A, Dang H, Gilmore R, Nakano S, Sun L, et al. 2020. SARS-COV-2 reverse genetics reveals a variable infection gradient in the respiratory tract. Cell 182: 429-446. DOI: https://doi.org/10.1016/j.cell.2020.05.042, PMID: 32526206

Huang SXL, Islam MN, O’Neill J, Hu Z, Yang Y-G, Chen Y-W, Mumau M, Green MD, Vunjak-Novakovic G, Bhattacharya J, Snoeck H-W. 2014. Efficient generation of lung and airway epithelial cells from human pluripotent stem cells. Nature Biotechnology 32: 84-91. DOI: https://doi.org/10.1038/nbt.2754, PMID: 24291815

Huang J, Hume AJ, Abo KM, Werder RB, Villacorta-Martin C, Alysandratos KD, Beermann ML, Simone-Roach C, Lindstrom-Vautrin J, Olejnik J, Suder EL, Bullitt E, Hinds A, Sharma A, Bosmann M, Wang R, Hawkins F, Burks EJ, Saeed M, Wilson AA, et al. 2020. SARS-CoV-2 Infection of Pluripotent Stem Cell-Derived Human Lung Alveolar Type 2 Cells Elicits a Rapid Epithelial-Intrinsic Inflammatory Response. Cell Stem Cell 27: 962-973.. DOl: https://doi.org/10.1016/j.stem.2020.09.013, PMID: 32979316

Hui KPY, Cheung MC, Perera R, Ng KC, Bui CHT, Ho JCW, Ng MMT, Kuok DIT, Shih KC, Tsao SW, Poon LLM, Peiris M, Nicholls JM, Chan MCW. 2020. Tropism, replication competence, and innate immune responses of the 
coronavirus SARS-COV-2 in human respiratory tract and conjunctiva: An analysis in ex-vivo and in-vitro cultures. The Lancet. Respiratory Medicine 8: 687-695. DOI: https://doi.org/10.1016/S2213-2600(20)30193-4, PMID: 32386571

Hussman JP. 2020. Cellular and Molecular Pathways of COVID-19 and Potential Points of Therapeutic Intervention. Frontiers in Pharmacology 11: 1169. DOl: https://doi.org/10.3389/fphar.2020.01169, PMID: 32848776

Irizarry RA, Bolstad BM, Collin F, Cope LM, Hobbs B, Speed TP. 2003a. Summaries of Affymetrix GENECHIP probe level data. Nucleic Acids Research 31: e15. DOI: https://doi.org/10.1093/nar/gng015, PMID: 12582260

Irizarry RA, Hobbs B, Collin F, Beazer-Barclay YD, Antonellis KJ, Scherf U, Speed TP. 2003b. Exploration, normalization, and summaries of high density oligonucleotide array probe level data. Biostatistics 4: 249-264. DOI: https://doi.org/10.1093/biostatistics/4.2.249, PMID: 12925520

Jacob A, Morley M, Hawkins F, McCauley KB, Jean JC, Heins H, Na CL, Weaver TE, Vedaie M, Hurley K, Hinds A, Russo SJ, Kook S, Zacharias W, Ochs M, Traber K, Quinton LJ, Crane A, Davis BR, White FV, et al. 2017. Differentiation of human pluripotent stem cells into functional lung alveolar epithelial cells. Cell Stem Cell 21: 472-488.. DOI: https://doi.org/10.1016/j.stem.2017.08.014, PMID: 28965766

Jacob A, Vedaie M, Roberts DA, Thomas DC, Villacorta-Martin C, Alysandratos KD, Hawkins F, Kotton DN. 2019. Derivation of self-renewing lung alveolar epithelial type II cells from human pluripotent stem cells. Nature Protocols 14: 3303-3332. DOI: https://doi.org/10.1038/s41596-019-0220-0, PMID: 31732721

Jia HP, Look DC, Shi L, Hickey M, Pewe L, Netland J, Farzan M, Wohlford-Lenane C, Perlman S, McCray PB. 2005. Ace2 receptor expression and severe acute Respiratory syndrome coronavirus infection depend on differentiation of human airway epithelia. Journal of Virology 79: 14614-14621. DOI: https://doi.org/10.1128/ JVI.79.23.14614-14621.2005, PMID: 16282461

Kalsi KK, Sonya Jackson S, Baines DL. 2020. Zonulin antagonist protects against tight junction disruption by Pseudomonas aeruginosa in airway epithelial cells. Faseb Journal (Experimental Biology Abstract) 1: 05094. DOI: https://doi.org/10.1096/fasebj.2020.34.s1.05094

Kawakita N, Toba H, Miyoshi K, Sakamoto S, Matsumoto D, Takashima M, Aoyama M, Inoue S, Morimoto M, Nishino T, Takizawa H, Tangoku A. 2020. Bronchioalveolar stem cells derived from mouse-induced pluripotent stem cells promote airway epithelium regeneration. Stem Cell Research \& Therapy 11: 430. DOI: https://doi. org/10.1186/s13287-020-01946-7, PMID: 33008488

Kaye M. 2006. Sars-associated coronavirus replication in cell lines. Emerging Infectious Diseases 12: 128-133. DOI: https://doi.org/10.3201/eid1201.050496, PMID: 16494729

Khelloufi MK, Loiseau E, Jaeger M, Molinari N, Chanez P, Gras D, Viallat A. 2018. Spatiotemporal organization of Cilia drives multiscale mucus swirls in model human bronchial epithelium. Scientific Reports 8: 2447. DOI: https://doi.org/10.1038/s41598-018-20882-4, PMID: 29402960

Knoops K, Kikkert M, van den Worm S, Zevenhoven-Dobbe JC, van der MY, Koster AJ, Mommaas AM, Snijder EJ. 2008. Sars-coronavirus replication is supported by a reticulovesicular network of modified endoplasmic reticulum. PLOS Biology 6: e226. DOI: https://doi.org/10.1371/journal.pbio.0060226, PMID: 18798692

Konishi S, Gotoh S, Tateishi K, Yamamoto Y, Korogi Y, Nagasaki T, Matsumoto H, Muro S, Hirai T, Ito I, Tsukita S, Mishima M. 2016. Directed induction of functional multi-ciliated cells in proximal airway epithelial spheroids from human pluripotent stem cells. Stem Cell Reports 6: 18-25. DOI: https://doi.org/10.1016/j.stemcr.2015.11. 010, PMID: 26724905

Lakdawala SS, Menachery VD. 2020. The search for a COVID-19 animal model. Science 368: 942-943. DOI: https://doi.org/10.1126/science.abc6141, PMID: 32467379

Lamers MM, Beumer J, van der Vaart J, Knoops K, Puschhof J, Breugem TI, Ravelli RBG, Paul van Schayck J, Mykytyn AZ, Duimel HQ, van Donselaar E, Riesebosch S, Kuijpers HJH, Schipper D, van de Wetering WJ, de Graaf M, Koopmans M, Cuppen E, Peters PJ, Haagmans BL, et al. 2020. SARS-COV-2 productively infects human gut enterocytes. Science 369: 50-54. DOI: https://doi.org/10.1126/science.abc1669, PMID: 32358202

Lamers MM, van der Vaart J, Knoops K, Riesebosch S, Breugem TI, Mykytyn AZ, Beumer J, Schipper D, Bezstarosti K, Koopman CD, Groen N, Ravelli RBG, Duimel HQ, Demmers JAA, Verjans G, Koopmans MPG, Muraro MJ, Peters PJ, Clevers H, Haagmans BL. 2021. An organoid-derived bronchioalveolar model for sars-cov-2 infection of human alveolar type ii-like cells. The EMBO Journal 40: e105912. DOI: https://doi.org/ 10.15252/embj.2020105912, PMID: 33283287

Leslie JL, Huang S, Opp JS, Nagy MS, Kobayashi M, Young VB, Spence JR. 2015. Persistence and toxin production by clostridium difficile within human intestinal organoids result in disruption of epithelial paracellular barrier function. Infection and Immunity 83: 138-145. DOI: https://doi.org/10.1128/IAI.02561-14, PMID: 25312952

Li B, Dewey CN. 2011. RSEM: accurate transcript quantification from RNA-Seq data with or without a reference genome. BMC Bioinformatics 12: 323. DOI: https://doi.org/10.1186/1471-2105-12-323, PMID: 21816040

Li Y, Wu J, Wang S, Li X, Zhou J, Huang B, Luo D, Cao Q, Chen Y, Chen S, Ma L, Peng L, Pan H, Travis WD, Nie X. 2021. Progression to fibrosing diffuse alveolar damage in a series of 30 minimally invasive autopsies with covid-19 pneumonia in Wuhan, China. Histopathology 78: 542-555. DOI: https://doi.org/10.1111/his.14249, PMID: 32926596

Liao M, Liu Y, Yuan J, Wen Y, Xu G, Zhao J, Cheng L, Li J, Wang X, Wang F, Liu L, Amit I, Zhang S, Zhang Z. 2020. Single-cell landscape of bronchoalveolar immune cells in patients with covid-19. Nature Medicine 26: 842-844. DOI: https://doi.org/10.1038/s41591-020-0901-9, PMID: 32398875 
Liu M, Gu C, Wang Y. 2014. Upregulation of the tight junction protein occludin: effects on ventilation-induced lung injury and mechanisms of action. BMC Pulmonary Medicine 14: 94. DOI: https://doi.org/10.1186/14712466-14-94, PMID: 24884662

Lopez-Sanchez I, Dunkel Y, Roh YS, Mittal Y, De Minicis S, Muranyi A, Singh S, Shanmugam K, Aroonsakool N, Murray F, Ho SB, Seki E, Brenner DA, Ghosh P. 2014. Giv/girdin is a central hub for profibrogenic signalling networks during liver fibrosis. Nature Communications 5: 4451. DOI: https://doi.org/10.1038/ncomms5451, PMID: 25043713

Love MI, Huber W, Anders S. 2014. Moderated estimation of fold change and dispersion for RNA-seq data with DESeq2. Genome Biology 15: 550. DOI: https://doi.org/10.1186/s13059-014-0550-8, PMID: 25516281

Lowery SA, Sariol A, Perlman S. 2021. Innate immune and inflammatory responses to SARS-CoV-2: Implications for COVID-19. Cell Host \& Microbe 29: 1052-1062. DOI: https://doi.org/10.1016/j.chom.2021.05.004, PMID: 34022154

Lucas C, Wong P, Klein J, Castro TBR, Silva J, Sundaram M, Ellingson MK, Mao T, Oh JE, Israelow B, Takahashi T, Tokuyama M, Lu P, Venkataraman A, Park A, Mohanty S, Wang H, Wyllie AL, Vogels CBF, Earnest R, et al. 2020. Longitudinal analyses reveal immunological misfiring in severe covid-19. Nature 584: 463-469. DOI: https:// doi.org/10.1038/s41586-020-2588-y, PMID: 32717743

McCauley KB, Hawkins F, Serra M, Thomas DC, Jacob A, Kotton DN. 2017. Efficient derivation of functional human airway epithelium from pluripotent stem cells via temporal regulation of WNT signaling. Cell Stem Cell 20: 844-857.. DOI: https://doi.org/10.1016/j.stem.2017.03.001, PMID: 28366587

McGowan SE. 2014. chapter 4 - the formation of pulmonary alveoli. Pinkerton KE (Ed). Lung: Development, Aging and the Environment. 2nd edition. Academic Press. p. 65-84.

Milewska A, Kula-Pacurar A, Wadas J, Suder A, Szczepanski A, Dabrowska A, Owczarek K, Marcello A, Ochman M, Stacel T, Rajfur Z, Sanak M, Labaj P, Branicki W, Pyrc K. 2020. Replication of severe Acute Respiratory syndrome Coronavirus 2 in human respiratory epithelium. Journal of Virology 94: e00957. DOI: https://doi.org/10.1128/JVI.00957-20, PMID: 32434888

Miller AJ, Dye BR, Ferrer-Torres D, Hill DR, Overeem AW, Shea LD, Spence JR. 2019. Generation of lung organoids from human pluripotent stem cells in vitro. Nature Protocols 14: 518-540. DOI: https://doi.org/10. 1038/s41596-018-0104-8, PMID: 30664680

Miyoshi H, Stappenbeck TS. 2013. In vitro expansion and genetic modification of gastrointestinal stem cells in spheroid culture. Nature Protocols 8: 2471-2482. DOI: https://doi.org/10.1038/nprot.2013.153, PMID: 24232249

Mou H, Vinarsky V, Tata PR, Brazauskas K, Choi SH, Crooke AK, Zhang B, Solomon GM, Turner B, Bihler H, Harrington J, Lapey A, Channick C, Keyes C, Freund A, Artandi S, Mense M, Rowe S, Engelhardt JF, Hsu YC et al. 2016. Dual smad signaling inhibition enables long-term expansion of diverse epithelial basal cells. Cell Stem Cell 19: 217-231. DOI: https://doi.org/10.1016/j.stem.2016.05.012, PMID: 27320041

Mulay A, Konda B, Garcia G, Yao C, Beil S, Sen C, Purkayastha A, Kolls JK, Pociask DA, Pessina P, Sainz de Aja J, Garcia-de-Alba C, Kim CF, Gomperts B, Arumugaswami V, Stripp BR. 2020. SARS-COV-2 Infection of Primary Human Lung Epithelium for COVID-19 Modeling and Drug Discovery. [bioRxiv]. DOI: https://doi.org/10.1101/ 2020.06.29.174623, PMID: 32637946

Nienhold R, Ciani Y, Koelzer VH, Tzankov A, Haslbauer JD, Menter T, Schwab N, Henkel M, Frank A, Zsikla V, Willi N, Kempf W, Hoyler T, Barbareschi M, Moch H, Tolnay M, Cathomas G, Demichelis F, Junt T, Mertz KD. 2020. Two Distinct Immunopathological Profiles in Autopsy Lungs of Covid-19. [medRxiv]. DOI: https://doi.org/ 10.1101/2020.06.17.20133637

Nikolić MZ, Rawlins EL. 2017. Lung Organoids and Their Use To Study Cell-Cell Interaction. Current Pathobiology Reports 5: 223-231. DOl: https://doi.org/10.1007/s40139-017-0137-7, PMID: 28596933

Pachter L. 2011. Models for Transcript Quantification from RNA-Seq. [arXiv]. https://arxiv.org/abs/1104.3889

Padela S, Yi M, Cabacungan J, Shek S, Belcastro R, Masood A, Jankov RP, Tanswell AK. 2008. A critical role for fibroblast growth factor-7 during early alveolar formation in the neonatal rat. Pediatric Research 63: 232-238. DOI: https://doi.org/10.1203/PDR.0b013e31815f6e3a, PMID: 18091341

Porotto M, Ferren M, Chen YW, Siu Y, Makhsous N, Rima B, Briese T, Greninger AL, Snoeck HW, Moscona A. 2019. Authentic modeling of human respiratory virus infection in human pluripotent stem cell-derived lung organoids. MBio 10: 147706017. DOI: https://doi.org/10.1128/mBio.00723-19, PMID: 31064833

Prytherch Z, Job C, Marshall H, Oreffo V, Foster M, BéruBé K. 2011. Tissue-specific stem cell differentiation in an in vitro airway model. Macromolecular Bioscience 11: 1467-1477. DOI: https://doi.org/10.1002/mabi. 201100181, PMID: 21994115

Rabata A, Fedr R, Soucek K, Hampl A, Koledova Z. 2020. 3D Cell Culture Models Demonstrate a Role for FGF and WNT Signaling in Regulation of Lung Epithelial Cell Fate and Morphogenesis. Frontiers in Cell and Developmental Biology 8: 574. DOI: https://doi.org/10.3389/fcell.2020.00574, PMID: 32850782

Randell SH, Fulcher ML, O'Neal W, Olsen JC. 2011. Primary epithelial cell models for cystic fibrosis research. Methods in Molecular Biology 742: 285-310. DOI: https://doi.org/10.1007/978-1-61779-120-8_18, PMID: 21547740

Rayner RE, Makena P, Prasad GL, Cormet-Boyaka E. 2019. Optimization of Normal Human Bronchial Epithelial (NHBE) Cell 3D Cultures for in vitro Lung Model Studies. Scientific Reports 9: 500. DOI: https://doi.org/10. 1038/s41598-018-36735-z, PMID: 30679531

Rock JR, Onaitis MW, Rawlins EL, Lu Y, Clark CP, Xue Y, Randell SH, Hogan BLM. 2009. Basal cells as stem cells of the mouse trachea and human airway epithelium. PNAS 106: 12771-12775. DOI: https://doi.org/10.1073/pnas. 0906850106, PMID: 19625615 
Roden AC. 2020. The spectrum of histopathologic findings in lungs of patients with fatal covid-19 infection. Archives of Pathology \& Laboratory Medicine 145: 11-21. DOI: https://doi.org/10.5858/arpa.2020-0491-SA Rogers TF, Zhao F, Huang D, Beutler N, Burns A, He WT, Limbo O, Smith C, Song G, Woehl J, Yang L, Abbott RK, Callaghan S, Garcia E, Hurtado J, Parren M, Peng L, Ramirez S, Ricketts J, Ricciardi MJ, et al. 2020. Isolation of potent SARS-COV-2 neutralizing antibodies and protection from disease in a small animal model. Science 369: 956-963. DOI: https://doi.org/10.1126/science.abc7520, PMID: 32540903

Sachs N, Papaspyropoulos A, Zomer-van Ommen DD, Heo I, Böttinger L, Klay D, Weeber F, Huelsz-Prince G, lakobachvili N, Amatngalim GD, de Ligt J, van Hoeck A, Proost N, Viveen MC, Lyubimova A, Teeven L, Derakhshan S, Korving J, Begthel H, Dekkers JF, et al. 2019. Long-term expanding human airway organoids for disease modeling. The EMBO Journal 38: e100300. DOI: https://doi.org/10.15252/embj.2018100300, PMID: 30643021

Sahoo D, Katkar GD, Khandelwal S, Behroozikhah M, Claire A, Castillo V, Tindle C, Fuller M, Taheri S, Rogers TF, Beutler N, Ramirez SI, Rawlings SA, Pretorius V, Smith DM, Burton DR, Alexander LEC, Duran J, Crotty S, Dan JM, et al. 2021. Ai-Guided Discovery of the Invariant Host Response to Viral Pandemics. [bioRxiv]. DOI: https://doi.org/10.1101/2020.09.21.305698, PMID: 32995790

Salahudeen AA, Choi SS, Rustagi A, Zhu J, van Unen V, de la O SM, Flynn RA, Margalef-Català M, Santos AJM, Ju J, Batish A, Usui T, Zheng GXY, Edwards CE, Wagar LE, Luca V, Anchang B, Nagendran M, Nguyen K, Hart DJ, et al. 2020. Progenitor identification and SARS-CoV-2 infection in human distal lung organoids. Nature 588: 670-675. DOI: https://doi.org/10.1038/s41586-020-3014-1, PMID: 33238290

Sato T, Vries RG, Snippert HJ, van de Wetering M, Barker N, Stange DE, van Es JH, Abo A, Kujala P, Peters PJ, Clevers H. 2009. Single LGR5 stem cells build crypt-villus structures in vitro without a mesenchymal niche. Nature 459: 262-265. DOI: https://doi.org/10.1038/nature07935, PMID: 19329995

Sato T, Clevers H. 2015. Snapshot: Growing organoids from stem cells. Cell 161: e1701. DOI: https://doi.org/10. 1016/j.cell.2015.06.028, PMID: 26091044

Sayed IM, Chakraborty A, Abd El-Hafeez AA, Sharma A, Sahan AZ, Huang WJM, Sahoo D, Ghosh P, Hazra TK Das S. 2020a. The DNA glycosylase NEIL2 suppresses fusobacterium-infection-induced inflammation and DNA damage in colonic epithelial cells. Cells 9: 1980. DOI: https://doi.org/10.3390/cells9091980, PMID: 32872214

Sayed IM, Sahan AZ, Venkova T, Chakraborty A, Mukhopadhyay D, Bimczok D, Beswick EJ, Reyes VE, Pinchuk I, Sahoo D, Ghosh P, Hazra TK, Das S. 2020b. Helicobacter pylori infection downregulates the dna glycosylase neil2, resulting in increased genome damage and inflammation in gastric epithelial cells. The Journal of Biological Chemistry 295: 11082-11098. DOI: https://doi.org/10.1074/jbc.RA119.009981, PMID: 32518160

Sayed IM, Suarez K, Lim E, Singh S, Pereira M, Ibeawuchi SR, Katkar G, Dunkel Y, Mittal Y, Chattopadhyay R, Guma M, Boland BS, Dulai PS, Sandborn WJ, Ghosh P, Das S. 2020c. Host engulfment pathway controls inflammation in inflammatory bowel disease. The FEBS Journal 287: 3967-3988. DOI: https://doi.org/10.1111/ febs.15236, PMID: 32003126

Schlingmann B, Molina SA, Koval M. 2015. Claudins: Gatekeepers of lung epithelial function. Seminars in Cell \& Developmental Biology 42: 47-57. DOI: https://doi.org/10.1016/j.semcdb.2015.04.009, PMID: 25951797

Schultze JL, Aschenbrenner AC. 2021. COVID-19 and the human innate immune system. Cell 184: 1671-1692. DOI: https://doi.org/10.1016/j.cell.2021.02.029, PMID: 33743212

Shami SG, Evans MJ. 2015. Kinetics of pulmonary cells. Parent RA (Ed). (EM ID= Biology of the Normal Lung"c1fd9724-9ce9-40eb-8620-4combiolofve34dthe. Academic Press. p. 1-164. DOI: https://doi.org/10. 1016/B978-0-12-404577-4.15002-7

Sheahan TP, Sims AC, Zhou S, Graham RL, Pruijssers AJ, Agostini ML, Leist SR, Schäfer A, Dinnon KH, Stevens LJ, Chappell JD, Lu X, Hughes TM, George AS, Hill CS, Montgomery SA, Brown AJ, Bluemling GR, Natchus MG, Saindane M, et al. 2020. An orally bioavailable broad-spectrum antiviral inhibits SARS-COV-2 in human airway epithelial cell cultures and multiple coronaviruses in mice. Science Translational Medicine 12: eabb5883. DOI: https://doi.org/10.1126/scitranslmed.abb5883, PMID: 32253226

Spagnolo P, Balestro E, Aliberti S, Cocconcelli E, Biondini D, Casa GD, Sverzellati N, Maher TM. 2020. Pulmonary fibrosis secondary to covid-19: A call to arms? The Lancet. Respiratory Medicine 8: 750-752. DOI: https://doi.org/10.1016/S2213-2600(20)30222-8, PMID: 32422177

Stuart T, Butler A, Hoffman P, Hafemeister C, Papalexi E, Mauck WM, Hao Y, Stoeckius M, Smibert P, Satija R. 2019. Comprehensive integration of single-cell data. Cell 177: 1888-1902.. DOI: https://doi.org/10.1016/j.cell. 2019.05.031, PMID: 31178118

Suzuki T. 2020. Generation of Human Bronchial Organoids for SARS-COV-2 Research. [bioRxiv]. DOI: https://doi. org/10.1101/2020.05.25.115600

Tadokoro T, Gao X, Hong CC, Hotten D, Hogan BLM. 2016. BMP signaling and cellular dynamics during regeneration of airway epithelium from basal progenitors. Development 143: 764-773. DOI: https://doi.org/ 10.1242/dev.126656, PMID: 26811382

Taubenberger JK, Morens DM. 2008. The pathology of influenza virus infections. Annual Review of Pathology 3 : 499-522. DOI: https://doi.org/10.1146/annurev.pathmechdis.3.121806.154316, PMID: 18039138

van der Vaart J, Clevers H. 2021. Airway organoids as models of human disease. Journal of Internal Medicine 289: 604-613. DOI: https://doi.org/10.1111/joim.13075, PMID: 32350962

VanDussen KL, Sonnek NM, Stappenbeck TS. 2019. L-WRN conditioned medium for gastrointestinal epithelial stem cell culture shows replicable batch-to-batch activity levels across multiple research teams. Stem Cell Research 37: 101430. DOI: https://doi.org/10.1016/j.scr.2019.101430, PMID: 30933720

Volkmer JP, Sahoo D, Chin RK, Ho PL, Tang C, Kurtova AV, Willingham SB, Pazhanisamy SK, Contreras-Trujillo H, Storm TA, Lotan Y, Beck AH, Chung Bl, Alizadeh AA, Godoy G, Lerner SP, van de Rijn M, Shortliffe LD, 
Weissman IL, Chan KS. 2012. Three differentiation states risk-stratify bladder cancer into distinct subtypes. PNAS 109: 2078-2083. DOI: https://doi.org/10.1073/pnas.1120605109, PMID: 22308455

Weinheimer VK, Becher A, Tönnies M, Holland G, Knepper J, Bauer TT, Schneider P, Neudecker J, Rückert JC, Szymanski K, Temmesfeld-Wollbrueck B, Gruber AD, Bannert N, Suttorp N, Hippenstiel S, Wolff T, Hocke AC. 2012. Influenza A viruses target type ii pneumocytes in the human lung. The Journal of Infectious Diseases 206: 1685-1694. DOI: https://doi.org/10.1093/infdis/jis455, PMID: 22829640

Williamson IA, Arnold JW, Samsa LA, Gaynor L, DiSalvo M, Cocchiaro JL, Carroll I, Azcarate-Peril MA, Rawls JF, Allbritton NL, Magness ST. 2018. A high-throughput organoid microinjection platform to study gastrointestinal microbiota and luminal physiology. Cellular and Molecular Gastroenterology and Hepatology 6: 301-319. DOI: https://doi.org/10.1016/j.jcmgh.2018.05.004, PMID: 30123820

Wolf FA, Angerer P, Theis FJ. 2018. SCANPY: large-scale single-cell gene expression data analysis. Genome Biology 19: 15. DOI: https://doi.org/10.1186/s13059-017-1382-0, PMID: 29409532

Wong AP, Bear CE, Chin S, Pasceri P, Thompson TO, Huan LJ, Ratjen F, Ellis J, Rossant J. 2012. Directed differentiation of human pluripotent stem cells into mature airway epithelia expressing functional CFTR protein. Nature Biotechnology 30: 876-882. DOI: https://doi.org/10.1038/nbt.2328, PMID: 22922672

Wong MH, Johnson MD. 2013. Differential response of primary alveolar type I and type II cells to LPS stimulation. PLOS ONE 8: e55545. DOI: https://doi.org/10.1371/journal.pone.0055545, PMID: 23383221

Yamamoto K, Ferrari JD, Cao Y, Ramirez MI, Jones MR, Quinton LJ, Mizgerd JP. 2012. Type I alveolar epithelial cells mount innate immune responses during pneumococcal pneumonia. Journal of Immunology 189: 24502459. DOl: https://doi.org/10.4049/jimmunol.1200634, PMID: 22844121

Yamamoto Y, Gotoh S, Korogi Y, Seki M, Konishi S, Ikeo S, Sone N, Nagasaki T, Matsumoto H, Muro S, Ito I, Hirai T, Kohno T, Suzuki Y, Mishima M. 2017. Long-term expansion of alveolar stem cells derived from human IPS cells in organoids. Nature Methods 14: 1097-1106. DOI: https://doi.org/10.1038/nmeth.4448, PMID: 28967890

Yang J, Hernandez BJ, Martinez Alanis D, Narvaez del Pilar O, Vila-Ellis L, Akiyama H, Evans SE, Ostrin EJ, Chen J. 2016. The development and plasticity of alveolar type 1 cells. Development 143: 54-65. DOI: https:// doi.org/10.1242/dev.130005, PMID: 26586225

Yuan T, Volckaert T, Redente EF, Hopkins S, Klinkhammer K, Wasnick R, Chao CM, Yuan J, Zhang JS, Yao C, Majka S, Stripp BR, Günther A, Riches DWH, Bellusci S, Thannickal VJ, De Langhe SP. 2019. FGF10-FGFR2B Signaling Generates Basal Cells and Drives Alveolar Epithelial Regeneration by Bronchial Epithelial Stem Cells after Lung Injury. Stem Cell Reports 12: 1041-1055. DOI: https://doi.org/10.1016/j.stemcr.2019.04.003, PMID: 31056475

Zhang Z, Luo D, Zhong X, Choi JH, Ma Y, Wang S, Mahrt E, Guo W, Stawiski EW, Modrusan Z, Seshagiri S, Kapur P, Hon GC, Brugarolas J, Wang T. 2019. SCINA: A Semi-Supervised Subtyping Algorithm of Single Cells and Bulk Samples. Genes 10: 531. DOI: https://doi.org/10.3390/genes10070531, PMID: 31336988

Zhao Y, Zhao Z, Wang Y, Zhou Y, Ma Y, Zuo W. 2020. Single-cell RNA expression profiling of ACE2, the receptor of sars-cov-2. American Journal of Respiratory and Critical Care Medicine 202: 756-759. DOI: https://doi.org/ 10.1164/rccm.202001-0179LE, PMID: 32663409

Zhou J, Li C, Sachs N, Chiu MC, Wong BHY, Chu H, Poon VKM, Wang D, Zhao X, Wen L, Song W, Yuan S, Wong KKY, Chan JFW, To KKW, Chen H, Clevers H, Yuen KY. 2018. Differentiated human airway organoids to assess infectivity of emerging influenza virus. PNAS 115: 6822-6827. DOI: https://doi.org/10.1073/pnas. 1806308115, PMID: 29891677

Zhu N, Wang W, Liu Z, Liang C, Wang W, Ye F, Huang B, Zhao L, Wang H, Zhou W, Deng Y, Mao L, Su C, Qiang G, Jiang T, Zhao J, Wu G, Song J, Tan W. 2020. Morphogenesis and cytopathic effect of sars-cov-2 infection in human airway epithelial cells. Nature Communications 11: 3910. DOI: https://doi.org/10.1038/ s41467-020-17796-z, PMID: 32764693 